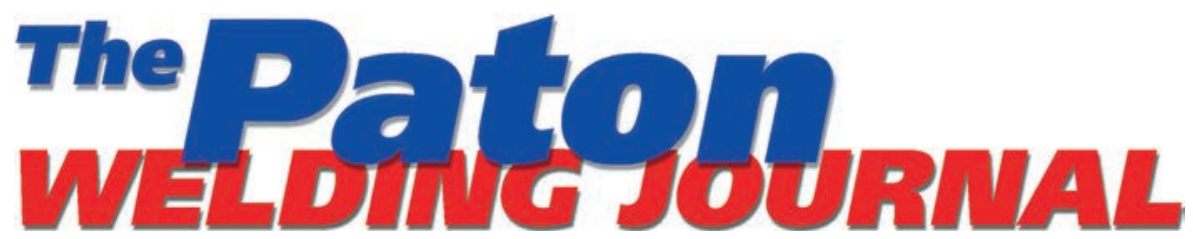

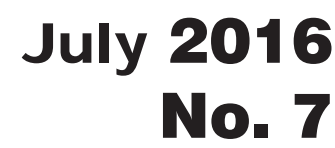

Published since 2000

English translation of the monthly «Avtomaticheskaya Svarka» (Automatic Welding) journal published in Russian since 1948

EDITORIAL BOARD

Editor-in-Chief B.E. Paton

Scientists of PWI, Kiev S.I. Kuchuk-Yatsenko (vice-chief ed.), V.N. Lipodaev (vice-chief ed.)

Yu.S. Borisov, G.M. Grigorenko A.T. Zelnichenko, V.V. Knysh,

I.V. Krivtsun, Yu.N. Lankin, L.M. Lobanov, V.D. Poznyakov, I.A. Ryabtsev, K.A. Yushchenko

Scientists of Ukrainian Universities V.V. Dmitrik, NTU «KhPl», Kharkov V.V. Kvasnitsky, NTUU «KPl», Kiev V.D. Kuznetsov, NTUU «KPI», Kiev

\section{Foreign Scientists}

N.P. Alyoshin

N.E. Bauman MSTU, Moscow, Russia Guan Qiao

Beijing Aeronautical Institute, China A.S. Zubchenko

DB «Gidropress», Podolsk, Russia M. Zinigrad

Ariel University, Israel V.I. Lysak

Volgograd STU, Russia

Ya. Pilarczyk

Welding Institute, Gliwice, Poland U. Reisgen

Welding and Joining Institute, Aachen, Germany G.A. Turichin

St. Petersburg SPU, Russia

Founders

E.O. Paton Electric Welding Institute, NASU International Association «Welding» Publisher

International Association «Welding» Translators

A.A. Fomin, O.S. Kurochko, I.N. Kutianova Editor

N.A. Dmitrieva

Electron galley

D.I. Sereda, T.Yu. Snegiryova Address

E.O. Paton Electric Welding Institute, International Association «Welding» 11 Kazimir Malevich Str. (former Bozhenko Str.), 03680, Kiev, Ukraine

Tel.: (38044) 20060 16, 2008277

Fax: (38044) 2008277,2008145

E-mail: journal@paton.kiev.ua

www.patonpublishinghouse.com

State Registration Certificate

KV 4790 of 09.01.2001

ISSN 0957-798X

Subscriptions

$\$ 348,12$ issues per year

air postage and packaging included.

Back issues available.

All rights reserved.

This publication and each of the articles contained herein are protected by copyright.

Permission to reproduce material contained in this journal must be obtained in writing from the Publisher.

\section{CONTENTS}

\section{SCIENTIFIC AND TECHNICAL}

Golovko V.V., Markashova L.I., Kushnaryova O.S. and

Zhukov V.V. Strengthening phases, structure and properties

of low-alloy steel modified welds

Lobanov L.M., Pashchin N.A., Mikhoduj O.L., Cherkashin A.V.,

Zarutsky A.V. and Kondratenko I.P. Application of

electrodynamic treatment with amplitude-frequency control

of current pulses for life extension of aircraft structures of light

alloys

Pisarev A.N., Khorunov V.F., Maksymova S.M. and

Tovmachenko V.N. Possibilities of reduction of growth of intermetallic interlayer in steel brazed using brazing filler metals of copper-phosphorus system

Som A.I. Iron-based alloy for plasma-powder surfacing of screw conveyors of extruders and injection molding machines

\section{INDUSTRIAL}

Lashchenko G.I. Technological capabilities of vibration treatment of welded structures (Review)

Fiedler M., Plozner A., Rutzinger B. and Scherleitner W.

Control of mechanical properties of high-strength steels through

optimized welding processes

Loza A.V., Chigarev V.V. and Serenko A.N. Modeling and calculation of welded stiffeners in fabrication of large-sized items for metallurgical production

Shapovalov E.V., Dolinenko V.V., Kolyada V.A., Skuba T.G.

and Klishchar F.S. Application of robotic and mechanized welding under disturbing factor conditions

Pisarev V.A. and Zhiznyakov S.N. Oxygen influence on the process of nitrogen-induced pore formation in consumable electrode arc welding 


\title{
STRENGTHENING PHASES, STRUCTURE AND PROPERTIES OF LOW-ALLOY STEEL MODIFIED WELDS
}

\author{
V.V. GOLOVKO, L.I. MARKASHOVA, O.S. KUSHNARYOVA and V.V. ZHUKOV \\ E.O. Paton Electric Welding Institute, NASU \\ 11 Kazimir Malevich Str., 03680, Kiev, Ukraine. E-mail: office@paton.kiev.ua
}

\begin{abstract}
Effect of dispersoid inoculants (phase inclusions) in form of $\mathrm{TiC}, \mathrm{SiC}$ and $\mathrm{ZrO}_{2}$ refractory compounds on kinetics of structural transformations in weld metal of high-strength low-alloy steels was investigated. Effect of the inoculants of different type on displacement of bainite transformation into area of higher temperatures is shown. Electron microscopy is used to analyze the nature of structural-phase changes in formation of bainite structure, i.e. peculiarities of fragmentation, distribution of dislocation density and morphology of carbide phase precipitation. The estimations of specific contribution of all structures and their parameters (phase composition, grain, subgrain and dislocation structures etc.) on carried change of strength characteristics and crack resistance of weld metal at inoculation of disperse phase inclusions were out. The optimum composition was determined for dispersoid inoculants used in welding of high-strength low-alloy steels. They provide for necessary mechanical properties of welded joints, including their crack resistance. 14 Ref., 7 Figures, 4 Tables.
\end{abstract}

Ke y w o r d s : structure of high-strength steels, welded joints, alloying, phase precipitates, dislocations, strengthening factors, local internal stresses

Analysis of current state of the world steel production shows a tendency to stable growth of total volumes of steel casting as well as constant rise of level of metal quality requirements [1]. At that, portion of flat products from high-strength low-alloy steels in ferrous metallurgy range is noticeably increased [2]. It is noted that development of new non-standard approaches to formation of structure of such materials [3] is necessary in order to reach higher values of strength, ductility and crack resistance of steels, used in different areas of engineering. Possibility of estimation the effect of inoculation in a metal melt of refractory non-metallic inclusions on nucleation and growth of structural constituents is considered as one of the perspective directions for this problem solving [4].

At that, it is determined that a role of non-metallic inclusions, having, as a rule, negative effect on complex of mechanical properties of steels, varies under certain conditions, i.e. reduction of their size decreases the inclusions' negative effect, and fine inclusions of certain chemical composition and morphology can be used for regulating the processes of nucleation and growth of some structural constituents. Such inclusions are called «dispersoids» $[5,6]$.

Thus, dispersoid inoculants are used in making of HSLA steels for the purpose of formation of necessary structural composition [7]. There is a series of investigations showing perspectives of the inoculants loading in a weld pool [8].
This work is also dedicated to investigation of effect of the dispersoid inoculants on conditions of structure formation and mechanical properties of weld metal of HSLA steels.

The investigations were carried out on weld specimens produced in welding of butt joints of HSLA steel using flux-cored wire in $\mathrm{M} 1\left(\mathrm{Ar}+18 \% \mathrm{CO}_{2}\right)$ shielding gas in accordance with ISO requirements. Composition of metal of examined welds is given in Table 1, size of austenite grains in the weld metal and critical points of structural transformations in it are shown in Table 2. Composition of dispersoid inoculants was selected based on the fact that, in accordance with data published in [9], formation of structural constituents depends on a value of free energy of their nucleation at metallic matrix to non-metallic inclusions interface as well as on physical-chemical characteristics of inclusions and temperature range of transformations.

Investigation procedure. Work [10] showed that weld pool loading with $\mathrm{TiC}, \mathrm{SiC}$ and $\mathrm{ZrO}_{2}$ refractory compounds in form of the dispersoid inoculants has positive effect on morphology of primary structure grains forming at weld metal crystallization. Investigation of a relationship between inoculants influence on the primary metal structure and formation of the secondary weld microstructure was also interesting. Mentioned above refractory compounds in form of disperse particles were inoculation in the weld pool by means of their introduction in a flux-cored wire 
Table 1. Composition of metal of examined welds, wt.\%

\begin{tabular}{|c|c|c|c|c|c|c|c|c|c|c|}
\hline $\begin{array}{c}\text { Designation } \\
\text { of weld }\end{array}$ & $\mathrm{C}$ & $\mathrm{Si}$ & $\mathrm{Mn}$ & $\mathrm{S}$ & $\mathrm{P}$ & $\mathrm{Cr}$ & $\mathrm{Ni}$ & $\mathrm{Mo}$ & $\mathrm{Ti}$ & $\mathrm{Zr}$ \\
\hline «0» & 0.050 & 0.290 & 1.32 & 0.024 & 0.014 & 0.16 & 2.19 & 0.27 & 0.008 & $\mathrm{~N} / \mathrm{D}$ \\
\hline «Ti» & 0.049 & 0.170 & 1.39 & 0.023 & 0.015 & 0.15 & 2.26 & 0.25 & 0.019 & $\mathrm{Same}$ \\
\hline «SiC» & 0.066 & 0.298 & 1.22 & 0.019 & 0.014 & 0.14 & 2.12 & 0.23 & 0.005 & » \\
\hline « $\mathrm{ZrO}_{2} »$ & 0.053 & 0.263 & 1.24 & 0.020 & 0.014 & 0.12 & 2.25 & 0.23 & 0.005 & 0.06 \\
\hline «TiC» & 0.054 & 0.138 & 1.28 & 0.025 & 0.011 & 0.13 & 2.22 & 0.26 & 0.012 & $\mathrm{~N} / \mathrm{D}$ \\
\hline
\end{tabular}

core. The results were compared with data obtained in welding of metals with similar technological parameters of the process, but without application of the dispersoid inoculants (weld «0»). In order to have better determination of the inoculation effect, the data received in testing of specimens of «TiC», «SiC» and « $\mathrm{ZrO}_{2}$ » weld metal, were compared with the results of examination of titanium-alloyed weld metal (weld «Ti») without inoculants.

Structural analysis of the specimens was carried out using optical microscope «Neophot-30» at from $\times 200$ to $\times 1000$ magnifications. Digital image was recorded with the help of digital camera «Olympus». Microhardness of structural constituents was measured on LECO hardness gage M-400 at $100 \mathrm{~g}$ and $1 \mathrm{~kg}$ loading, respectively, on GOST 2999-59. Peculiarities of microstructure were detected using JEOL scanning electron microscope JSM-840, equipped with image capture system MicroCapture, with its further registration on display monitor, and scanning electron microscope JSM (Holland) equipped with energy dispersive analyzer Link.

Determination of microstructure in the specimens was carried out by method of chemical etching in $4 \%$ alcoholic solution of nitric acid. The specimens for investigations were manufactured on standard procedures using diamond pastes of different dispersion. Size of structural constituents was determined in accordance with GOST 5639.

Direct transmission investigations of the fine structure were carried out on JEOL unit JEM-200 CX at accelerating voltage $200 \mathrm{kV}$ for investigation of fine (dislocation) structure of welded joint metal, substructure as well as nature of intergrain and subgrain boundaries. The foils for electron microscopy investigations were prepared by means of electroerosion cutting with further mechanical thinning on sandpaper of different grit, preliminary electrolytic thinning of prepared disks $(d=3 \mathrm{~mm})$ in PTF unit with further final thinning in developed unit for ion thinning by ionized flows of argon.

Nature of structural transformations in the weld metal was studied under conditions of simulation of welding thermal-deformation cycle using Gleeble 3800 complex equipped with fast dilatometer. The investigations were carried out using cylindrical specimens of $6 \mathrm{~mm}$ diameter and $80 \mathrm{~mm}$ length, produced from weld metal.

Investigation results. The results of dynamometric investigations showed that loading of the inoculants promotes for increase of temperature of austenite decay in weld metal cooling $\left(A_{c 3}\right)$ as well as start $\left(B_{\mathrm{s}}\right)$ and finish $\left(B_{\mathrm{f}}\right)$ of bainite transformation (see Table 2), whereas titanium alloying promotes for opposite effect. Such changes in location of structural transformation critical points were observed in size of the primary structure grain $\left(D_{\gamma}\right)$ as well as in composition of the weld metal secondary structure (Table 3).

Data of optical microscopy showed that the secondary microstructure of weld metal consists of bainite-martensite mixture with insignificant portion of ferrite constituent (Figures 1 and 2)*. Bainite is presented by morphological forms of upper, lower and

Table 2. Size of austenite grains in weld metal and critical points of structural transformations in it

\begin{tabular}{|c|c|c|c|c|}
\hline $\begin{array}{c}\text { Designation } \\
\text { of weld }\end{array}$ & $D_{\gamma}, \mu \mathrm{m}$ & $A_{c 3},{ }^{\circ} \mathrm{C}$ & $B_{s},{ }^{\circ} \mathrm{C}$ & $B_{\mathrm{f}}{ }^{\circ} \mathrm{C}$ \\
\hline$\ll 0 »$ & $70 \pm 5$ & 843 & 603 & 430 \\
\hline «Ti» & $45 \pm 5$ & 840 & 583 & 432 \\
\hline «iC» & $80 \pm 6$ & 851 & 644 & 435 \\
\hline « $\mathrm{ZrO}_{2} »$ & $90 \pm 7$ & 859 & 662 & 461 \\
\hline «TiC» & $80 \pm 6$ & 870 & 648 & 435 \\
\hline
\end{tabular}

Table 3. Composition of weld metal secondary structure

\begin{tabular}{|c|c|c|c|c|}
\hline \multirow{2}{*}{$\begin{array}{c}\text { Designation } \\
\text { of weld }\end{array}$} & \multicolumn{4}{|c|}{$\begin{array}{c}\text { Portion of constituents } \\
\text { in weld microstructure, \% }\end{array}$} \\
\cline { 2 - 5 } & $\begin{array}{c}\text { Lower } \\
\text { bainite }\end{array}$ & $\begin{array}{c}\text { Upper } \\
\text { bainite }\end{array}$ & Martensite & Ferrite \\
\hline$\ll 0 »$ & 50 & 30 & 10 & 10 \\
\hline$\ll \mathrm{Ti} »$ & 30 & 57 & 10 & 3 \\
\hline «iC» & 30 & 50 & 10 & 10 \\
\hline$\ll \mathrm{ZrO} \mathrm{Zr}_{2} »$ & 65 & 20 & 10 & 5 \\
\hline «TiC» & 25 & 60 & 10 & 5 \\
\hline
\end{tabular}

"S.N. Stepanyuk and D.Yu. Ermolenko took part in metallographic investigations. 

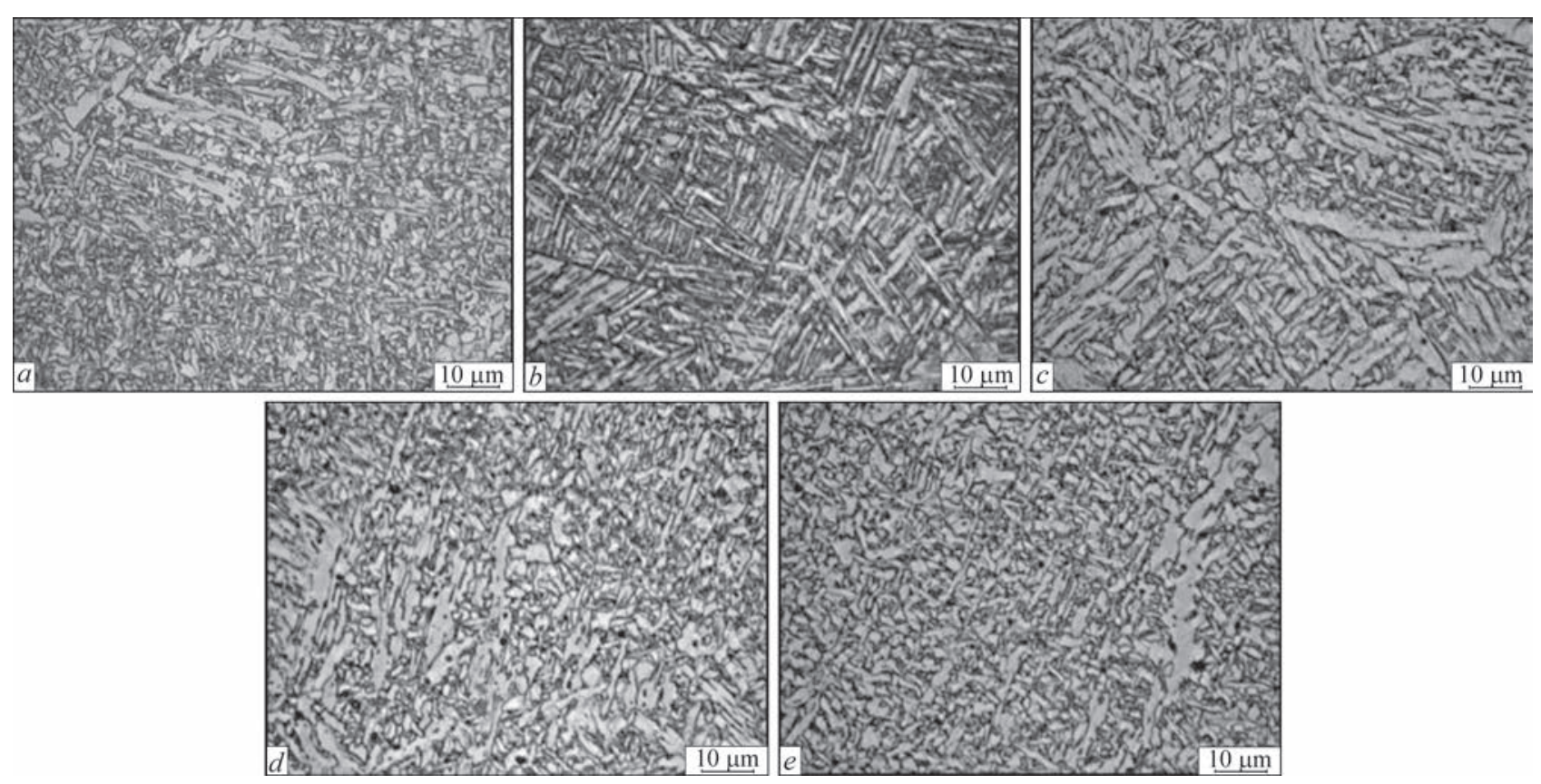

Figure 1. Microstructure of weld metals (Neophot-30) at weld pool loading with disperse refractory inclusions: $a-\ll \mathrm{Ti} » ; b-\ll \operatorname{SiC}$; $c-\ll \mathrm{ZrO}_{2} » ; d-\ll \mathrm{TiC} » ; e-\ll 0 »$

inter-grain bainite, and ferrite - by broken polygonal precipitates and Widmanstatten ferrite along grain boundaries. Martensite is formed as a traditional acicular structure. As can be seen from given data, titanium alloying of weld metal («Ti» weld) as well as $\mathrm{TiC}$ and $\mathrm{SiC}$ inoculation promoted rise of the portion of upper bainite in the microstructure and reduction of ferrite constituent content, while weld pool loading with $\mathrm{ZrO}_{2}$ dispersoids had opposite effect.

The results of determination of mechanical properties of the weld metal, given in Table 4, showed that, regardless the absence of changes in martensite content, mechanical properties of «Ti», «SiC» and «TiC» weld metal, close on content of bainite phase in composition of structural constituents, have some differences on strength indices, ductility and toughness. Besides, significant difference on level of composition of structural constituents and mechanical properties of « $\mathrm{ZrO}_{2} »$ weld metal is noted.

Methods of transmission electron microscopy were used for more detailed analysis of effect of dispersoid inoculation in the weld pool on processes of
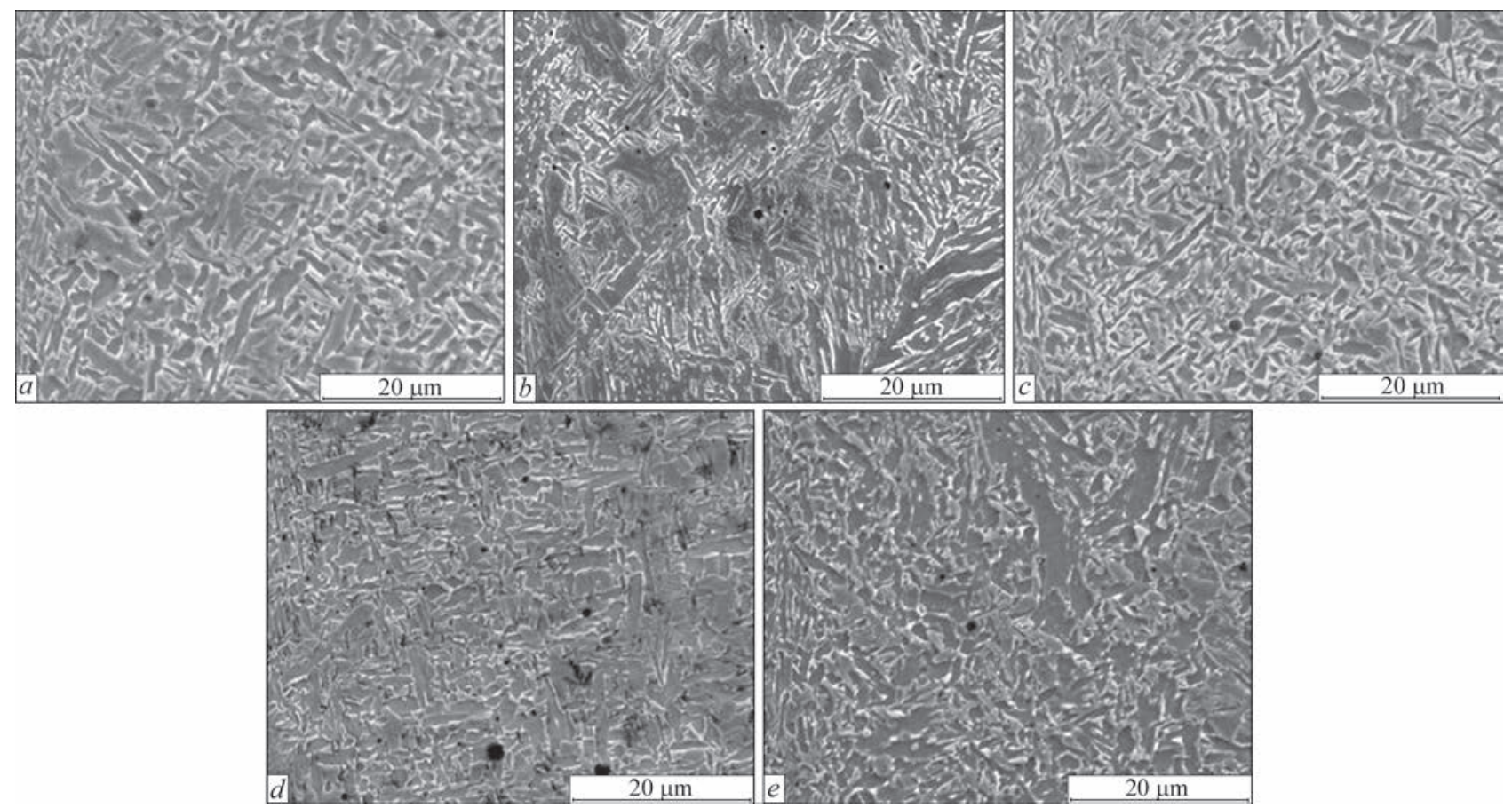

Figure 2. Microstructure of weld metals (JSM-840) at weld pool loading with disperse refractory inclusions: $a-\ll \mathrm{Ti} » ; b-\ll \mathrm{SiC}$; $c-\ll \mathrm{ZrO}_{2} » ; d-\ll \mathrm{TiC} » ; e-\ll 0 »$ 
Table 4. Weld metal mechanical properties

\begin{tabular}{|c|c|c|c|c|c|c|c|}
\hline \multirow{2}{*}{$\begin{array}{l}\text { Designation } \\
\text { of weld }\end{array}$} & \multirow{2}{*}{$\sigma_{\mathrm{t}}, \mathrm{MPa}$} & \multirow{2}{*}{$\sigma_{0.2}, \mathrm{MPa}$} & \multirow{2}{*}{$\delta, \%$} & \multirow{2}{*}{$\psi, \%$} & \multirow{2}{*}{$S_{k}, \mathrm{MPa}$} & \multicolumn{2}{|c|}{$K C V, \mathrm{~J} / \mathrm{cm}^{2}$, at $T,{ }^{\circ} \mathrm{C}$} \\
\hline & & & & & & 20 & -20 \\
\hline$\ll 0 »$ & 775 & 738 & 16 & 54 & 1384 & 61 & 43 \\
\hline «Ti» & 746 & 689 & 19 & 60 & 1865 & 60 & 57 \\
\hline «SiC» & 726 & 650 & 21 & 62 & 1910 & 85 & 65 \\
\hline « $\mathrm{ZrO}_{2} »$ & 645 & 556 & 21 & 60 & 1612 & 116 & 98 \\
\hline «TiC» & 728 & 665 & 19 & 61 & 1867 & 82 & 63 \\
\hline
\end{tabular}

weld metal structure formation. Figures 3 and 4 show typical patterns of structural constituents of metal of investigated welds, peculiarities of fragmentation, phase precipitates in them and distribution of dislocation density.

Analysis of contribution of the structural-phase parameters in change of strength characteristics of the welds showed that a lath substructure and disperse particles of phase precipitates make the largest contribution in strengthening of all considered specimens of the weld metal. The analysis were made based on developed experimental-analytical approach on evaluation of differential contribution of structure parameters in mechanical characteristics of highstrength steel welded joints [11]. Dramatic increase of strengthening, typical for upper bainite, differing by high grain boundary dislocation density ( $\rho \sim$ ( $2-$ $3) \cdot 10^{11} \mathrm{~cm}^{-2}$ ) along boundaries of the lath structure and higher saturation of this area with phase precipitates, is caused by rise of dislocation and dispersion strengthening (Figure 5).

As can be seen from given examination results, the weld pool loading with the dispersoid inoculants is accompanied by change of carbide phase morphology, that should promote for structure stabilizing and rise of metal properties [12]. Presence of the refractory dispersoids in a crystallizing weld metal promotes for partial replacement of the cementite precipitates on the grain boundaries with alloying carbides of $\mathrm{Me}_{7} \mathrm{C}_{3}, \mathrm{Me}_{23} \mathrm{C}_{6}$ and $\mathrm{Me}_{3} \mathrm{C}_{2}$ type, that allows reducing inhomogeneity of dislocation density distributions on the grain boundaries. In the cases, when increase of
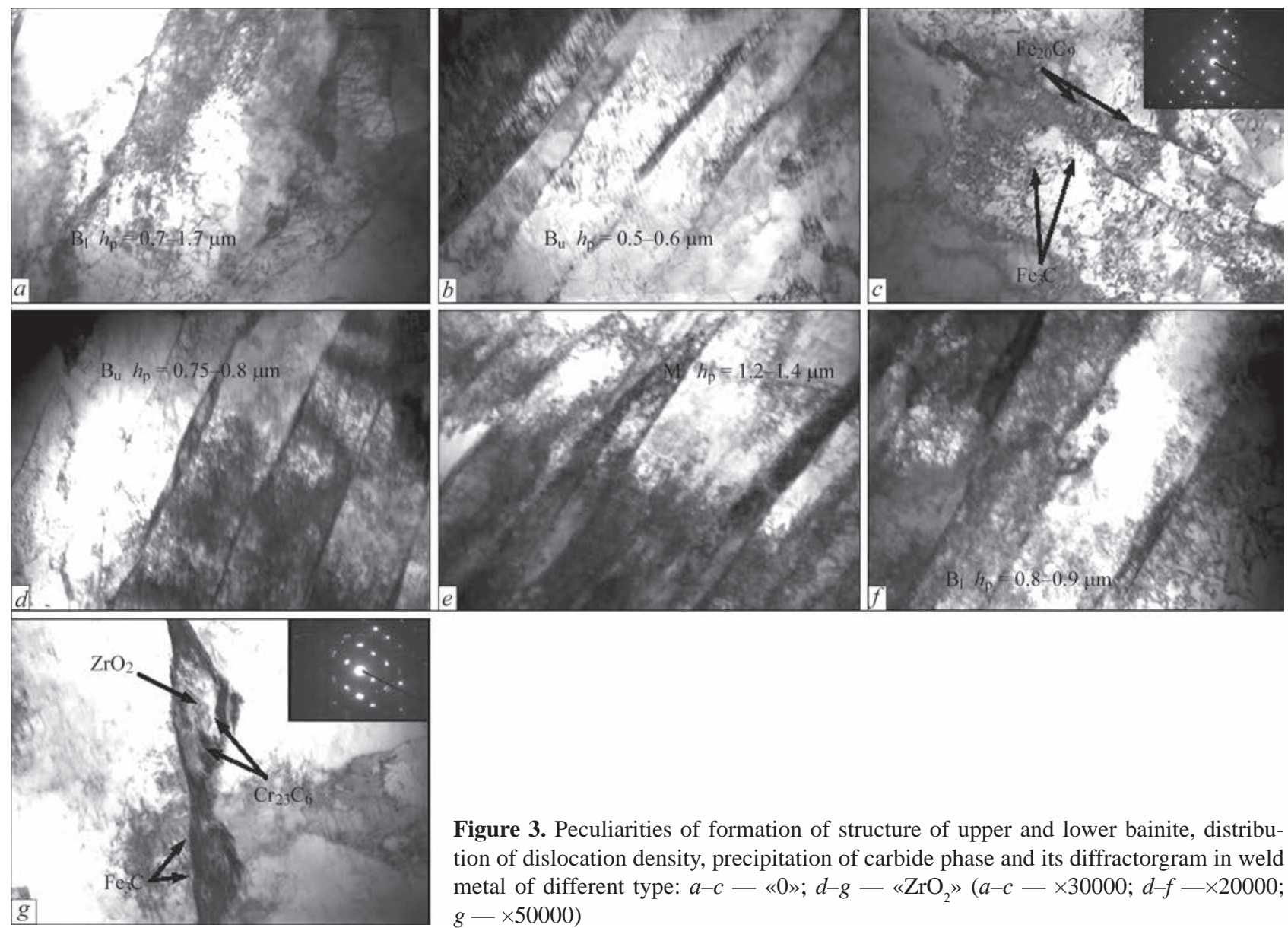

Figure 3. Peculiarities of formation of structure of upper and lower bainite, distribution of dislocation density, precipitation of carbide phase and its diffractorgram in weld metal of different type: $a-c-\ll 0 » ; d-g-\ll \mathrm{ZrO}_{2} »(a-c-\times 30000 ; d-f-\times 20000$; $g-\times 50000)$ 

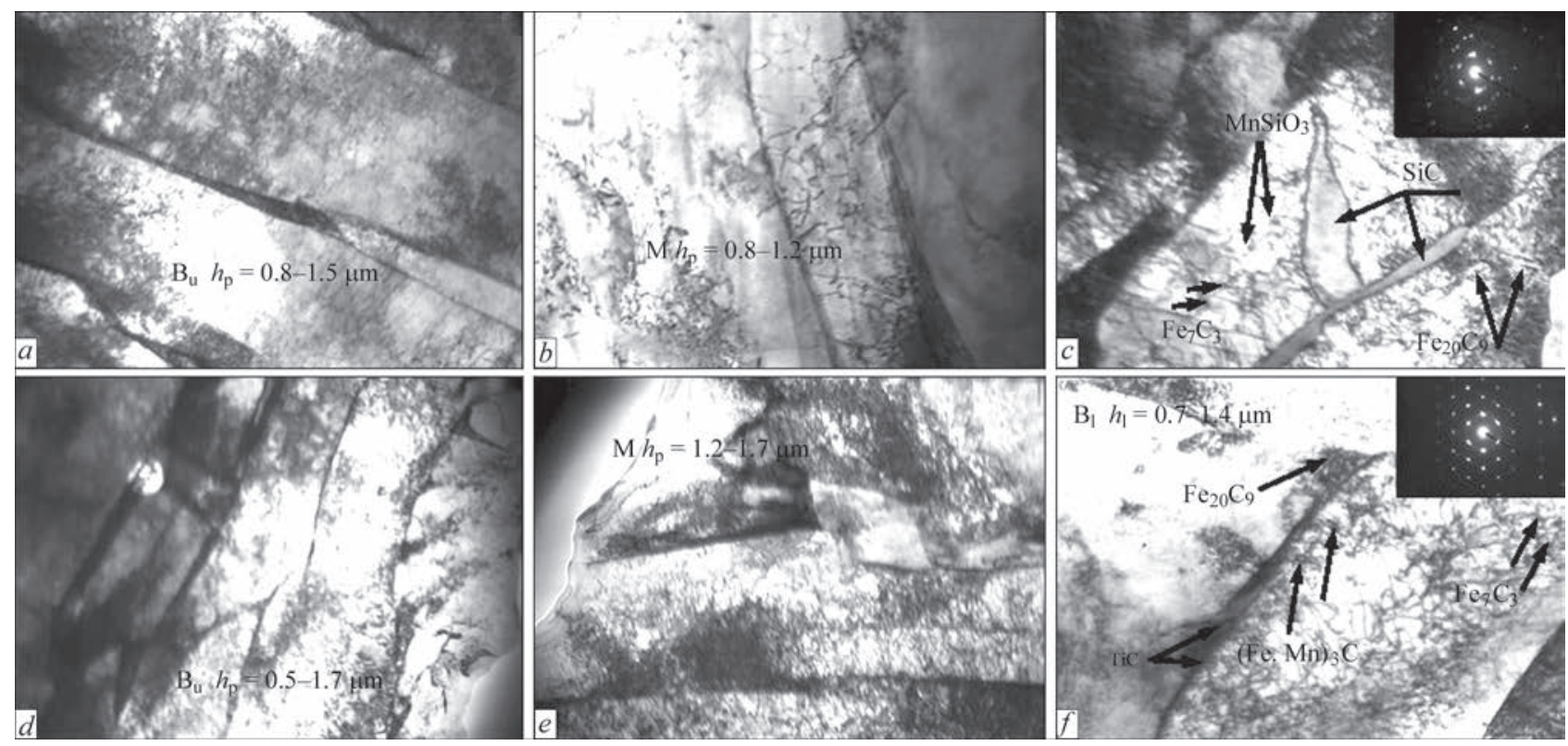

Figure 4. Peculiarities of formation of structure of upper, lower bainite and martensite, distribution of dislocation density, precipitation of carbide phase and its diffractorgram in weld metal of different type: $a-c-\ll \operatorname{SiC} » ; d-f-\ll \mathrm{TiC} »(a, b, d, e-\times 20000 ; c-\times 30000$; $f-\times 37000)$

substructure strengthening is caused by formation of a fine-grain fragmented substructure, the particles of phase precipitates have uniform distribution at uniform distribution of the dislocation density. There are no areas in form of accumulations and chains of the precipitates on the grain boundaries as well as in some volumes of the lath structure $\left(\mathrm{ZrO}_{2}\right)$.

Non-uniform distribution of the particles of phase precipitates results in increase of the dislocation density in local microvolumes close to the precipitates and on the grain boundaries, that promotes for increase of strength indices and reduction of level of weld metal ductility (welds «0» and «Ti»). Reduction of temperature of the bainite transformation start promotes for non-uniform re-distribution of the defects of crystalline lattice at their different density. It results

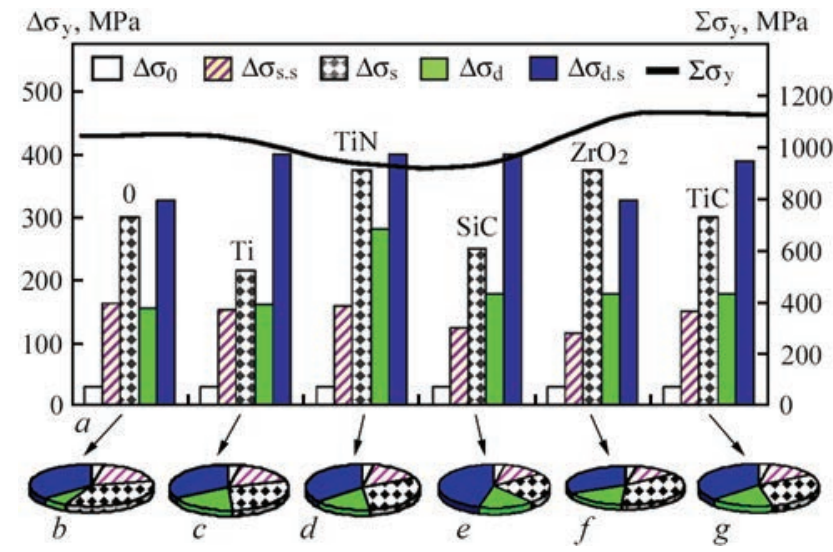

Figure 5. Change of integral values of yield point $\left(\Sigma \sigma_{y}\right)$, differential contribution of structural constituents $\left(\Delta \sigma_{\mathrm{y}}\right)$ in calculation value of yield point ( $a$ ), and percent relationship of structural contribution (grain, subgraine, dislocation, dispersion) in total change of yield point in weld metal at disperse inclusion inoculation $(b-g)$ in rise of the dislocation density from $\rho \approx(4-6) \cdot 10^{10}$ (in lath volume) to (2-3) $10^{11} \mathrm{~cm}^{-2}$ in the local microvolumes (close to phase precipitates) and formation of the zones with deformation localizing, that pro-

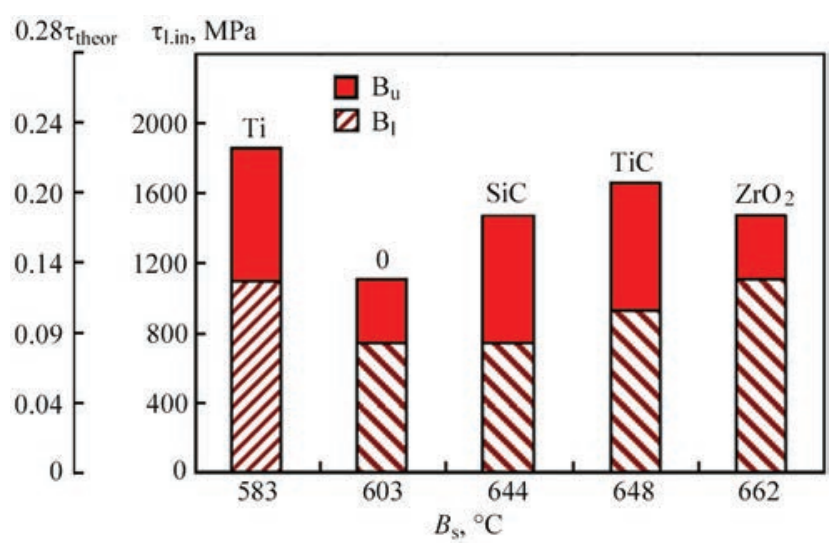

Figure 6. Results of calculation estimation of internal stresses in local structural zones

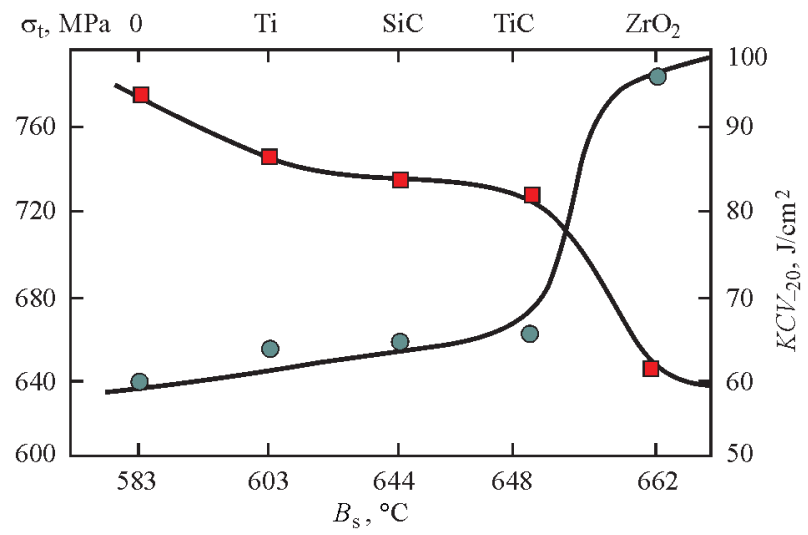

Figure 7. Effect of temperature of start of bainite transformation on mechanical properties of investigated weld metal 
motes for non-uniform level of mechanical properties and reduction of metal crack resistance (see Table 4).

The calculation methods of estimation of the internal stresses in local structural zones, based on experimental data of fine structure analysis [13, 14], allowed determining that the maximum local internal stresses are concentrated along the boundaries of upper bainite (welds «Ti», «SiC» and «TiC») and are the potential sources of nucleation and propagation of cracks, i.e. processes of crack formation (magnitudes of these values is approximately 2-3 times higher than in lower bainite structures (Figure 6)).

Increased level of the local stresses typical for upper bainite structure allows providing specific level of indices of the weld metal strength, while presence of lower bainite structure in the composition allows rising their toughness indices. Required complex of mechanical properties of the weld metal in HSLA steel welding is achieved in each case by setting a specific balance between these two morphological forms of ferrite. The results, given in Figures 6 and 7, show that the weld pool loading with the dispersoid inoculants allows rising weld metal ductility with simultaneous retain of strength level.

\section{Conclusions}

1. Weld pool loading with the dispersoid inoculants is accompanied by change of temperature of start of bainite transformation in weld metal, that makes effect on optimum transformation of structural-phase constituents, nature of dislocation distribution, change of composition and distribution of phase precipitates, i.e. carbide phases.

2. Increase of $B_{\mathrm{s}}$ rises the portion of phase precipitates of alloyed carbide type in bainite grain body as well as along their boundaries, that is accompanied by formation in intergrain boundary zone of nanosized particles of compounds, inoculated in the weld pool.

3. It is shown that rapid and gradient rise of strengthening in upper bainite structure is caused by significant increase of the dislocation density in near-boundary zones of the lath structures, which are the most saturated by phase precipitates, that promotes for rise of portion of dislocation and dispersion strengthening in grain boundary areas.
4. Use of the dispersoid inoculants in welding of HSLA steels promotes for optimization of structure-phase composition of weld metal and its service properties.

1. Flik, A. (2014) Strategic assessment of prospects in metallurgy. Chyorn. Metally, 6, 81-84.

2. Ritterbach, B. (2014) Main tendencies of research development in ferrous metallurgy. Ibid., 9, 75-78.

3. Gorynin, I.V. (2008) Sparcely-alloyed steels with nanomodified structure for service under extreme conditions. Voprosy Materialovedeniya, 2, 7-12.

4. Amondarain, Z., Aribas, M., Arana, J.L. et al. (2013) Mechanical properties and phases derived from $\mathrm{TiO}_{2}$ nanopowder inoculation in low carbon steel matrix. Materials Transact., 54(10), 1867-1876.

5. Zhang, L., Thomas, B. (2006) State of the art in the control of inclusions during steel ingot casting. Metallurg. and Mater. Transact. B, 37(10), 733-761.

6. Grong, O., Kolbeinsen, L., Eijk, C. et al. (2006) Microstructure control of steels through dispersoid metallurgy using novel grain refining alloys. ISIJ Int., 46(6), 824-831.

7. Oryshchenko, A.S., Khlusova, E.I., Golosienko, S.A. (2014) Principles of alloying and requirements to technological processes of production of high-strength hull steels of new generation. Voprosy Materialovedeniya, 78(2), 9-25.

8. Cherepanov, A.N., Afonin, Yu.V., Orishich, A.M. et al. (2010) Effect of nanodispersed powders on joint properties in $\mathrm{CO}_{2}$-laser welding of carbon steel. In: Abstr. of $6^{\text {th }}$ All-Union Conf. on Mechanics of Inhomogeneous Materials and Fracture, 109.

9. Gregg, J.M., Bhadeshia, H.K.D.H. (1997) Solid-state nucleation of acicular ferrite on minerals added to molten steel. Acta Materialia, Vol. 45, Issue 2, 739-748.

10. Golovko, V.V., Stepanyuk, S.N., Ermolenko, D.Yu. (2015) Effect of titanium-containing inoculants on structure and properties of weld metal of high-strength low-alloy steels. The Paton Welding J., 2, 14-18.

11. Markashova, L.I., Alekseenko, T.A., Berdnikova, E.N. et al. (2011) Role of structure in optimization of strength, plasticity and crack resistance properties of welded joints. In: Stroitelstvo, Materialovedenie, Mashinostroenie, Issue 58, 446-452.

12. Gorynin, V.I., Kondratiev, S.Yu., Olenin, M.I. et al. (2014) Concept of carbide designing of higher cold resistance steels. Metallovedenie i Termich. Obrab. Metallov, 712(10), 32-38.

13. Markashova, L.I., Poklyatsky, A.G., Kushnaryova, O.S. et al. (2014) Structure and service properties of welded joints of complexly-doped alloys. In: Abstr. of $7^{\text {th }}$ Int. Conf. on Mathematical Modelling and Information Technologies in Welding and Related Processes (Odessa, Ukraine, 15-19 Sept. 2014), 19-20.

14. Markashova, L.I., Shelyagin, V.D., Kushnaryova, O.S. et al. (2015) Effect of technological parameters of laser and laser-plasma alloying on properties of 38KhN3MFA steel layers. The Paton Welding J., 5/6, 124-129.

Received 02.02.2016 


\title{
APPLICATION OF ELECTRODYNAMIC TREATMENT WITH AMPLITUDE-FREQUENCY CONTROL OF CURRENT PULSES FOR LIFE EXTENSION OF AIRCRAFT STRUCTURES OF LIGHT ALLOYS*
}

\author{
L.M. LOBANOV ${ }^{1}$, N.A. PASHCHIN ${ }^{1}$, O.L. MIKHODUJ ${ }^{1}$, A.V. CHERKASHIN ${ }^{1}$, \\ A.V. ZARUTSKY ${ }^{2}$ and I.P. KONDRATENKO ${ }^{3}$ \\ ${ }^{1}$ E.O. Paton Electric Welding Institute, NASU \\ 11 Kazimir Malevich Str., 03680, Kiev, Ukraine. E-mail: office@paton.kiev.ua \\ ${ }^{2}$ N.E. Zhukovsky National Aerospace University «KhAI» \\ 17 Chkalov Str., Kharkov, Ukraine \\ ${ }^{3}$ Institute of Elecrodynamics, NASU \\ 56 Pobeda Ave., 03057, Kiev, Ukraine
}

\begin{abstract}
The pulsed electric current (PEC) generator of a new generation with the controlled amplitude-frequency characteristics of PEC for electrodynamic treatment (EDT) of thin-sheet metal structures was designed and manufactured. The use of a new class of equipment allows a significant extension of capabilities of electrodynamic effects due to the controlled synchronization of the EDT dynamic and electric pulse components. The effect of EDT on reducing the level of residual welding stresses in magnesium alloy ML10 joints was investigated. As the investigated specimens the fragments of the shell of the intermediate body of the aircraft engine D-36 containing repair welds were used. It was found that EDT allows reducing the level of residual welding stresses from 120 to -40 MPa, providing their transition from tensile to compressive ones. It is shown that the local plastic deformation applying EDT of specimens of an aircraft wing stringer of aluminum alloy D16 in the area of technological holes 1.6-2.5 times increases the resistance to a delayed fracture. 9 Ref., 2 Tables, 14 Figures.
\end{abstract}

Ke yword s : electrodynamic treatment, electric current pulse, aircraft structures, residual stresses, repair welding, body of aircraft engine, stringer, technological hole

At the repair of technological and service defects in the aircraft structures of magnesium alloys the nonconsumable electrode welding in argon (TIG) is used [1]. One of the causes for deterioration of service characteristics of products is residual stresses in repair joints reducing the life of vehicles. The presence of residual stresses causes a need in postweld heat treatment of structures in the large-sized electric furnaces, which requires significant energy costs and increases the cost of repair operations. In this case heat treatment does not completely eliminate the probability of fatigue cracks in the repair welds. This fact facilitates the search and development of alternative methods for reduction of level of residual stresses in welded joints, one of which is the electrodynamic treatment (EDT) $[2,3]$, based on the simultaneous effect of current pulse and dynamic pressure of current-conducting electrode on product or weld. The application of EDT reduces the level of residual stresses in repair welds, which in many cases may be an alternative to heat treatment. It allows reducing the cost of repair technologies at restoration of aircraft structural elements.

At the same time, in the modern technologies of aircraft industry the relevant problem is hardening of technological holes in the glider load-carrying elements of aluminum alloys in order to increase their resistance to a delayed fracture [4]. The modern mechanical methods of hardening the holes, based on the surface plastic deformation, have several disadvantages, which can be eliminated using electrodynamic effects.

The aim of the present work is the investigation of EDT effect on control of the level of residual welding and technological stresses in the elements of aircraft structures of light alloys.

The equipment for EDT of structural materials and welded joints is mainly based on the pulse current

\footnotetext{
*According to the materials of the work performed within the frames of the target integrated program of the NAS of Ukraine «Problems of Life and Safe Operation of Structures, Constructions and Machines» (2013-2015).
} 

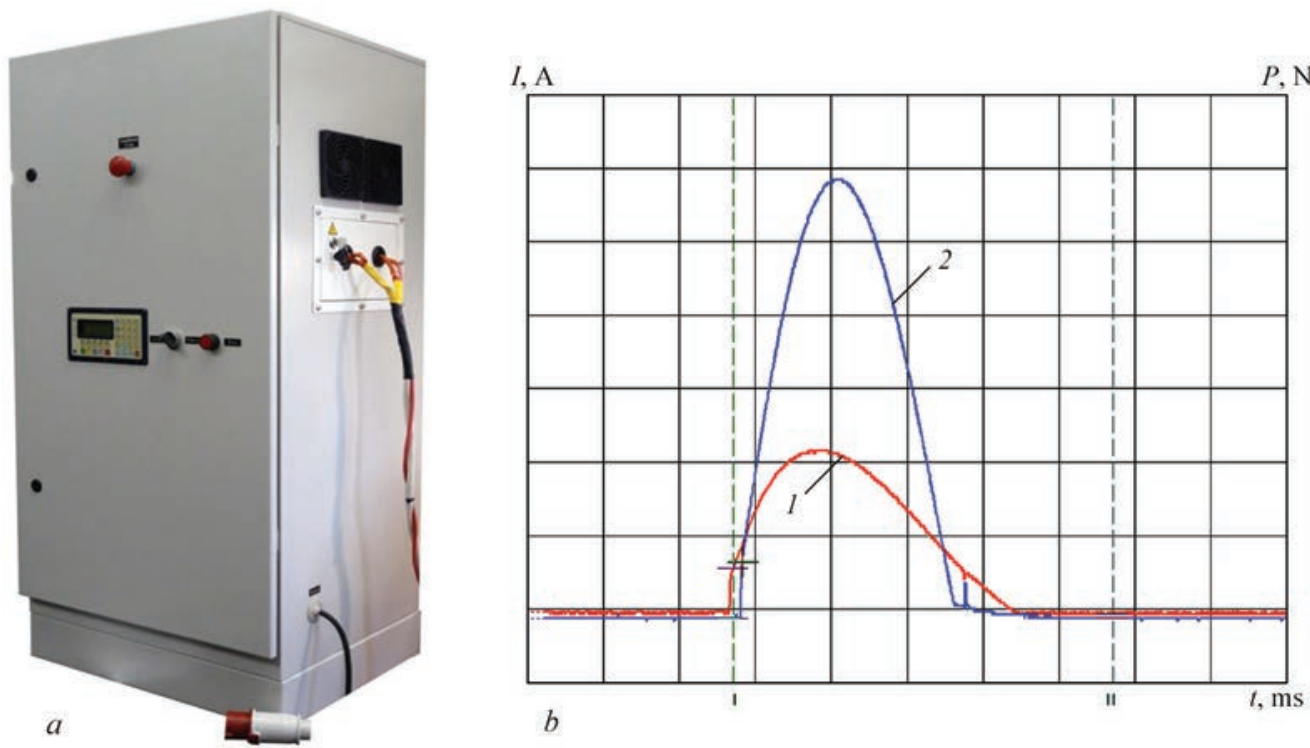

Figure 1. Pulsed current source «Iskra-4» for EDT of structural materials: $a$ - appearance; $b$ - oscillograms of current pulses of dynamic pressure 1 and direct current passing through the treated metal 2

source and electrode device providing current passing through the treatment zone and simultaneous controlled force effect on the treated surface. The treatment of welded joints of light alloys was carried out using pulsed current source of the second generation «Iskra-4» designed and manufactured at the Institute of Electrodynamics of the NAS of Ukraine.

The current pulse generator «Iskra-4», the appearance of which is shown in Figure 1, $a$, includes two independent channels, each of which includes a rectifier, charging inverter, capacitor and controlled discharge circuits.

The first channel of the pulse generator generates a current pulse 1 (Figure $1, b$ ), which is intended to create dynamic effects on the treatment zone and is supplied to the inductance coil in the electrode device
(ED), which is an operating tool for EDT (Figure 2). The second channel of the pulse generator forms a current pulse 2 correlated as to its duration with the duration of dynamic pressure (current pulse 1) to the treatment zone. The pulse current of the second channel is supplied directly to the ED electrode and transferred to the treated workpiece. The electric circuit of the second channel of the generator is closed through the contact cable, which is attached at the product.

As to its design, ED (Figure 2, $a$ ) includes electrode 1 , manufactured of refractory conductive material fixed in the yoke 3 using fixing devices 2 and 20. The yoke is connected to a disc of a non-ferromagnetic material 16, which supported against the frame 6 with the inductance coil 14 located in it with the builtin plane inducer 15 . The coil is fixed on the frame
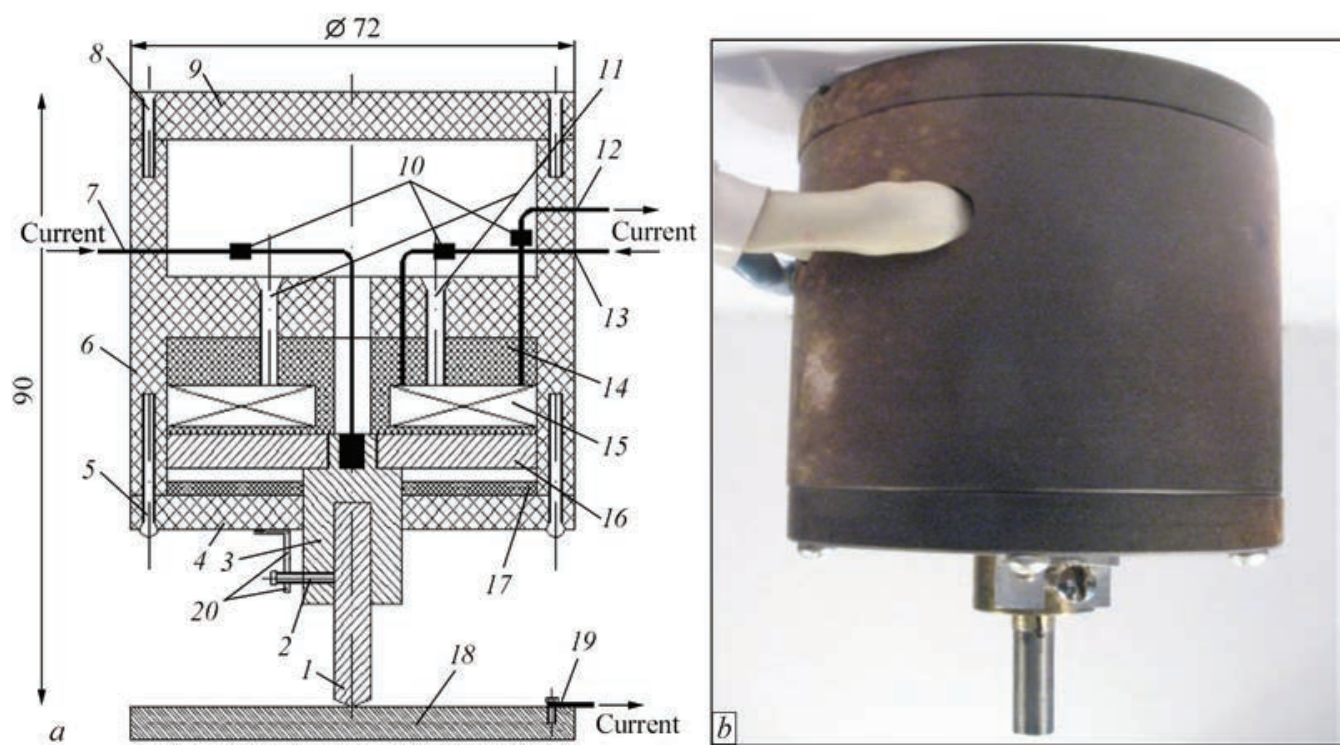

Figure 2. Electrode device for EDT with independent channels of current pulses: $a$ - design scheme (for designations see the text); $b$ - appearance 


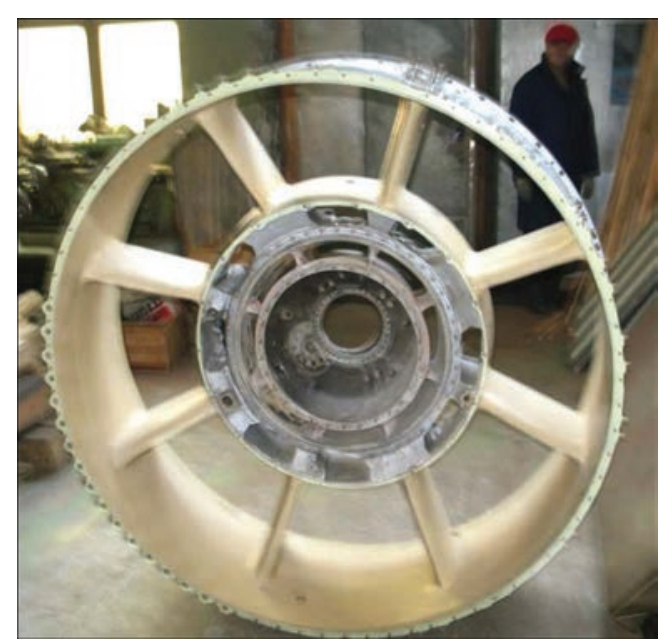

Figure 3. Appearance of intermediate body of aircraft engine of heat-resistant magnesium alloy ML10

with screws 11 . The bottom wall of the frame 4 , fixed by screws 5 , performs a role of non-magnetic backing under the disc and the damper 17. The upper (protective) cover 9 of the frame is fixed in the ED body with the screws 8 . The supply of the current pulse 2 (see Figure $1, b$ ) from the power source is carried out by the wire 7 . The short circuit of the discharge circuit providing the supply of the current pulse 2 to the treated metal 18 is carried out by the terminal 19 . The current pulse 1 (see Figure $1, b$ ) passes through the coil through the wires 12 and 13 . The supply wires 7, 12, 13 of ED are connected to the external circuits of the contact terminals 10. The appearance of ED is presented in Figure 2, $b$.

The operation of ED is carried out as follows. When a pulse current is passing through the coil the magnetic field is excited initiating eddy currents in the disc. The interaction of the induced currents with the magnetic field, which excited them, leads to generation of electrodynamic force. At the same time, in the first phase of effect, the electrodynamic force presses the electrode to the treated material, and in the second one the direction of force effect is changed to the opposite one, i.e. the electrode is repelled from the treated material. Obviously, that as to its duration the effect of the pulsed current on the treatment zone should not exceed the duration of clamping force (see Figure 1, $b$ ).

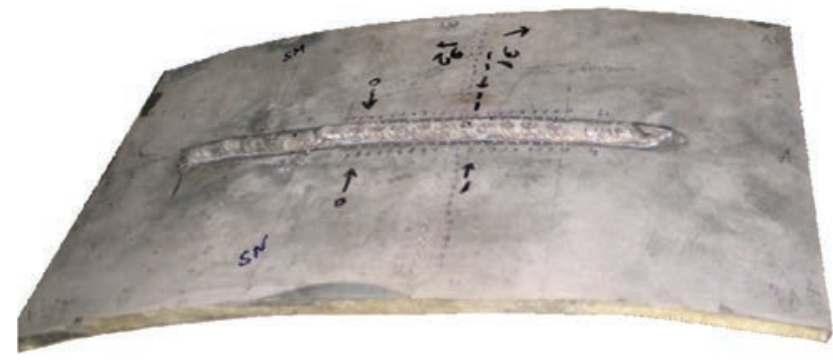

Figure 4. Specimen of repair welded joint of alloy ML10
Thus, the design of the pulsed current source is subjected to the requirements of the correlated pulse duration and exclusion of electrospark phenomena in the treatment zone. The control of channels in pulse generator «Iskra-4» is realized in three microcontrollers and programmable logics, which allow regulating current pulse parameters (amplitude), delay of one pulse with respect to the other, visualizing the pulse parameters on the light display. The pulse duration on both channels is determined by the parameters of electric circuit of discharge contours and can be changed discretely by adding/reducing the inductance contours. The additional inductances are installed on the outer side of the generator body, for which the contact groups on the side surface of the generator are provided.

In general, the basic technical characteristics of two-channel source of pulsed currents are as follows:

- power supply - three-phase mains of $380 \mathrm{~V}$ with a zero wire;

- galvanic input-output isolation — transformer of $2.5 \mathrm{kV}$;

- total installed capacity - $7 \mathrm{kVA}$;

- number of channels - 2;

- amplitude of current pulses in each channel up to $4.5 \mathrm{kA}(0-4.5 \mathrm{kA})$;

- current pulse duration in channel $1-680 \mu \mathrm{s}$;

- current pulse duration in channel $2-550 \mu \mathrm{s}$;

- phase shift of current pulses in the channels $10-100 \mu \mathrm{s}$;

- pulse repetition interval $-0.8-1.0 \mathrm{~s}$;

- operation mode - manual/automatic.

The investigations of EDT effect on regulation of residual stresses in welded joints of magnesium alloy were carried out. For this purpose, the specimens were used being the fragments of outer cylindrical shell of the intermediate body of the aircraft engine D-36 of $1.5 \mathrm{~m}$ diameter $[2,3]$ manufactured of heat-resistant magnesium alloy ML10 (Figure 3).

The geometric characteristics of the specimens (Figure 4), representing the fragments of cylindrical shell of $330 \times 200 \times 8 \mathrm{~mm}$ size and $20 \mathrm{~mm}$ longitudinal bending deflection allowed modeling the stressed state in the vicinity of the body repair welds.

On the specimens the welds were produced similar to those used in the body repair, as well as their EDT with the in-process control of values of residual stresses after welding and treatment.

On the outer surface of specimens the notches were applied having the length, width and depth of respectively 200, 2 and $4 \mathrm{~mm}$, simulating fractures of the body [3]. Over the notched area a two-pass weld was produced using manual TIG welding with Sc-containing filler metal at the mode, presented in Table 1. The 
Table 1. Mode of TIG welding of repair joints of intermediate body of ML10 alloy

\begin{tabular}{|c|c|c|c|c|}
\hline $\begin{array}{c}\text { Number } \\
\text { of passes }\end{array}$ & $U_{\mathrm{a}, \mathrm{V}}$ & $I_{\mathrm{w}}, \mathrm{A}$ & $V_{\mathrm{w}}, \mathrm{mm} / \mathrm{s}$ & $Q_{\mathrm{Ar}}, \mathrm{l} / \mathrm{s}$ \\
\hline 1 & 20 & 250 & 1.7 & 0.25 \\
\hline 2 & 20 & 350 & 1.7 & 0.35 \\
\hline
\end{tabular}

appearance of the specimen with a weld is presented in Figure 4.

The evaluation of stressed state of the outer surface of welded joint specimens was carried out using the contact-free method of electronic speckle-interferometry, based on the measurement of displacements during elastic unloading of metal volume in the investigated regions on the specimen surface caused by drilling blind holes [5]. The equipment complex was applied (Figure 5), in which the investigated area of the specimen 4 , fixed on the assembly plate 5 , was illuminated by the laser beam being a part of the optical interferometer 3 under the same angle from two directions and, thus, the components of the displacement vector in the plane were determined. The data of displacement measurements after welding and EDT were registered and processed using the specialized signal registration 1 and optical signal processing 2 units, being a part of the complex.

After welding and EDT the changes of the stressed state of welded joints were registered in the vicinity of the repair welds. According to the results of comparison of stress values before and after the treatment the efficiency of the EDT process was determined.

Using pulse generator «Iskra-4» the EDT of welded joints of specimens was carried out using the PEC series. At the same time, the amplitude values of pulsed current and dynamic pressure reached $3080 \mathrm{~A}$ and $20460 \mathrm{~N}$ respectively, and the phase shift between them amounted to $0.1 \mathrm{~ms}$, which provided synchronization of electric pulse and dynamic components of electrodynamic effect.

The sequence of EDT performance and layout scheme of the measured surface areas of the investigated specimens are presented in Figure 6.

Before EDT the initial stressed state of specimen along the lines $A-A$ and $B-B$ was registered. Along the axis $0-0$ at the surface area of the deposited weld metal of $100 \mathrm{~mm}$ length the EDT 1 was performed by the series of 20 PEC in the direction «from center to edges» (see Figure 6), after completion of which the change of the stressed state along the lines $A-A$ and $B-B$ was registered. Then EDT 2 of the base metal was performed at distance of $12 \mathrm{~mm}$ from the line $0-0$ by the series of 20 PEC in the direction «on the pass» with the subsequent control of residual stresses along the line $B-B$.

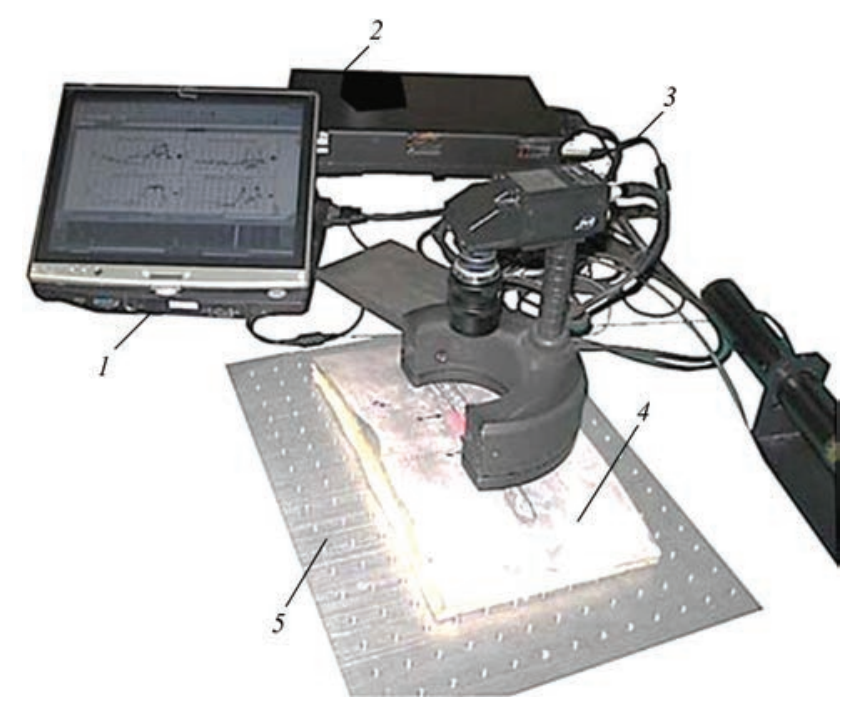

Figure 5. General appearance of equipment complex for registration of stressed state of ML10 specimens using the method of speckle-interferometry (for designations see the text)

The diagrams of the longitudinal component of plane stressed state $\sigma_{x}$ before treatment and after EDT 1 and 2 are shown in Figure 7.

Figure 7, $a$ shows distribution of $\sigma_{x}$ along the line $A-A$ (see Figure 6) after welding and EDT 1, from which it can be seen that before treatment a monotonous growth of tensile stresses $\sigma_{x}$ occurs along the weld line and their average values are $120 \mathrm{MPa}$. After EDT 1 the character of distribution of $\sigma_{x}$ along the line $A-A$ did not change significantly, but a decrease in their average values to $70 \mathrm{MPa}$ is observed.

The $\sigma_{x}$ distribution on the outer surface of the specimen after welding along the line $B-B$ perpendicular to the weld line (see Figure 6 ) is presented in Figure 7, $b$ (curve 1). The unbalance of the $\sigma_{x}$ diagram is connected with a significant bending component of the stresses on the surface of specimen caused by its initial curvature. The tensile $\sigma_{x}$ maximum value in the measured cross-section reaches the yield strength of alloy $\operatorname{ML} 10\left(\sigma_{0.2}=120 \mathrm{MPa}\right)$ at distance of $12 \mathrm{~mm}$ from the weld center.

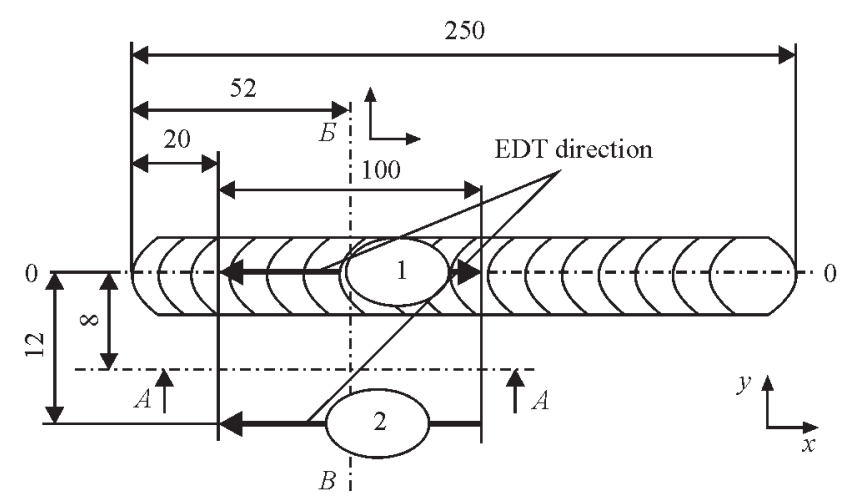

Figure 6. Sequence 1 and 2 of EDT and schemes of measured areas layout of surface of ML10 specimens along $A-A$ and $B-B$ lines 

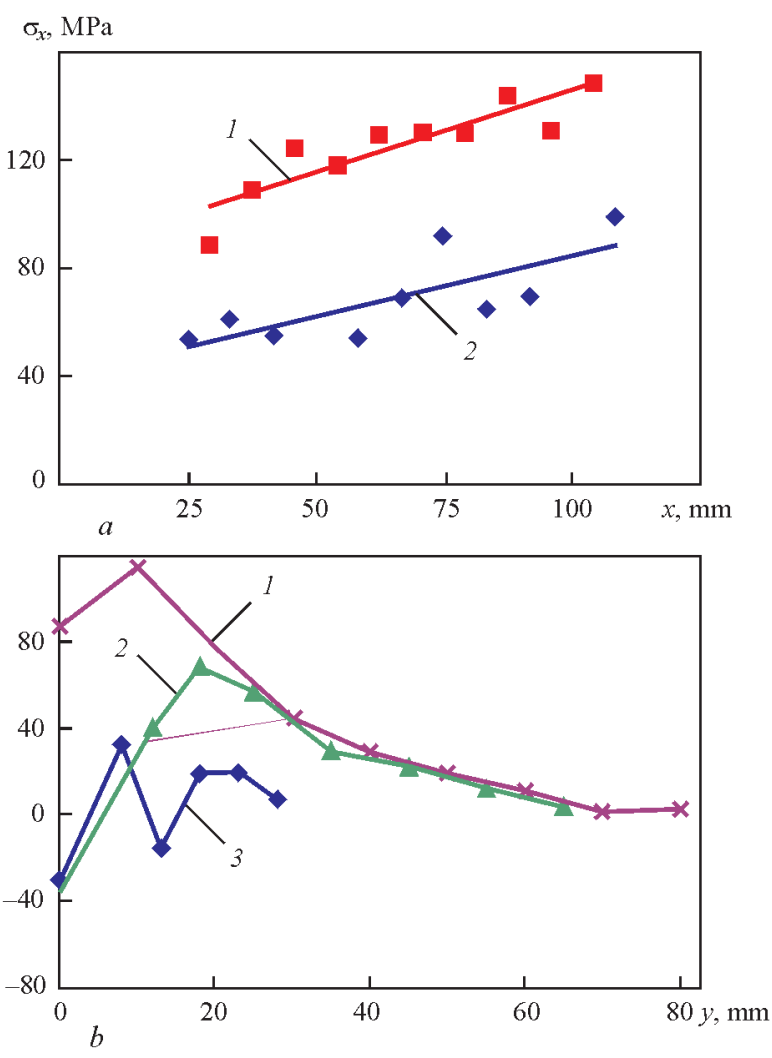

Figure 7. Stress $\sigma_{x}$ distribution in the ML10 specimen of welded joint: $a-\sigma_{x}$ before EDT (1) and after EDT 1 (2) along $A-A$ line; $b$ - the same before (1), after EDT 1 (2) and after EDT 1, 2 (3) along $B-B$ line

The influence of electrodynamic effects on the stressed state of the welded joint confirms the distribution of $\sigma_{x}$ after EDT 1 along the line $B-B$ (Figure 7, $b$; curve 2), from which it is seen that at the treated area of the weld center, $\sigma_{x}$ changed the sign from tensile to compressive stresses, whose values reached $-40 \mathrm{MPa}$. At the surface areas corresponding to the maximum values $\sigma_{x}=120 \mathrm{MPa}$, after EDT 1 stresses $\sigma_{x}$ decreased to $40 \mathrm{MPa}$, which makes $35 \%$ of their initial values. In general, it can be concluded that as a result of EDT in the treatment area a reduction of residual welding stresses and their transition from tensile to compressive ones is achieved (Figure 7, $b$; curves 1 and 2).

The $\sigma_{x}$ distribution along the line $B-B$ after EDT 2 is shown in Figure 7, $b$ (curve 3), from which it can

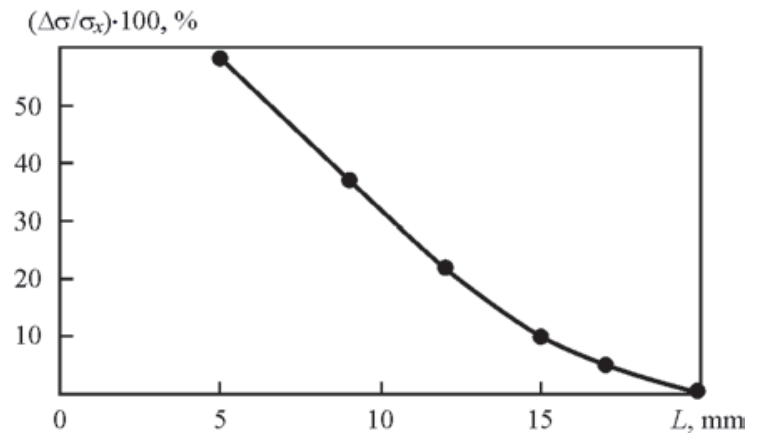

Figure 8. Effect of distance $L$ between EDT areas on efficiency of treatment $\Delta \sigma / \sigma_{x}$ be seen that after EDT 2 the formation of compressive stresses area occurs, localized at the area of electrodynamic effects, where $\sigma_{x}$ values are lowered to -20 MPa at the constant $\sigma_{x}$ values in the weld center equal to $-40 \mathrm{MPa}$. The lower efficiency of electrodynamic effect during EDT 2 of the base metal as compared to EDT 1 of weld metal can be explained by a higher plasticity of cast structure of the latter. Thus, the relative elongation of alloy ML10 $\delta=3.6 \%$, and the cast structure of the weld produced using filler containing scandium, reaches more than $6 \%$ [1]. At the same time, according to the data of work [6], the EDT efficiency increases with increase in ductility of the treated material.

The character of $\sigma_{x}$ distribution in the base metal after EDT 2 is close to that observed after EDT 1 in the weld centre. At the area of curve 3 between the areas of EDT 1 and 2, the reduction of $\sigma_{x}$ to $60 \mathrm{MPa}$ occurs, which makes only $50 \%$ of the $\sigma_{x}$ value after welding (before EDT 1 and 2), which confirms a localized character of electrodynamic effects.

Proceeding from the aforesaid, the determination of optimal distance $L$ between the areas of electrodynamic effects, providing a guaranteed overlap of the treated areas, is an important aspect in the development of EDT technology. In order to determine the optimal $L$ value at the specified electrical process parameters for the specimen of welded joint (see Figure 4) the EDT 1 of the weld metal was performed, changing the value $L$ between EDT areas. After the series of PEC the decrease in initial $\sigma_{x}$ was registered as a result of treatment $(\Delta \sigma)$ determining the EDT efficiency by the $\Delta \sigma / \sigma_{x}$ ratio.

The registration of $\Delta \sigma$ values was carried out along the weld line at the distance between the EDT areas equal to $L / 2$. The maximum value was preset to $L=20 \mathrm{~mm}$, successively reducing it to $5 \mathrm{~mm}$. The dependence $\Delta \sigma / \sigma_{x}=f(L)$ is presented in Figure 8, from which it can be seen that at $L \geq 20 \mathrm{~mm}$ the EDT efficiency is close to zero, indicating about the absence of overlapping of electrodynamic effects areas at the given EDT mode. At $L=15,12$ and $8 \mathrm{~mm}$ the $\Delta \sigma /$ $\sigma_{x}$ values reached 10,21 and $38 \%$ respectively, indicating about the partial overlap of EDT areas. At reduction to $L=5 \mathrm{~mm}$ and lower, the efficiency values were stabilized at $\Delta \sigma / \sigma_{x}=60 \%$, indicating that at distance not exceeding $5 \mathrm{~mm}$, there is a guaranteed overlapping of electrodynamic effects areas.

Thus, at the preset energy parameters of electrodynamic effects it is rational to carry out the EDT of ML10 alloy with a «step», not exceeding $5 \mathrm{~mm}$.

The presented investigation results showed that using EDT it is possible to regulate the level of residual stresses on the surface of welded joints of alloy ML10. 


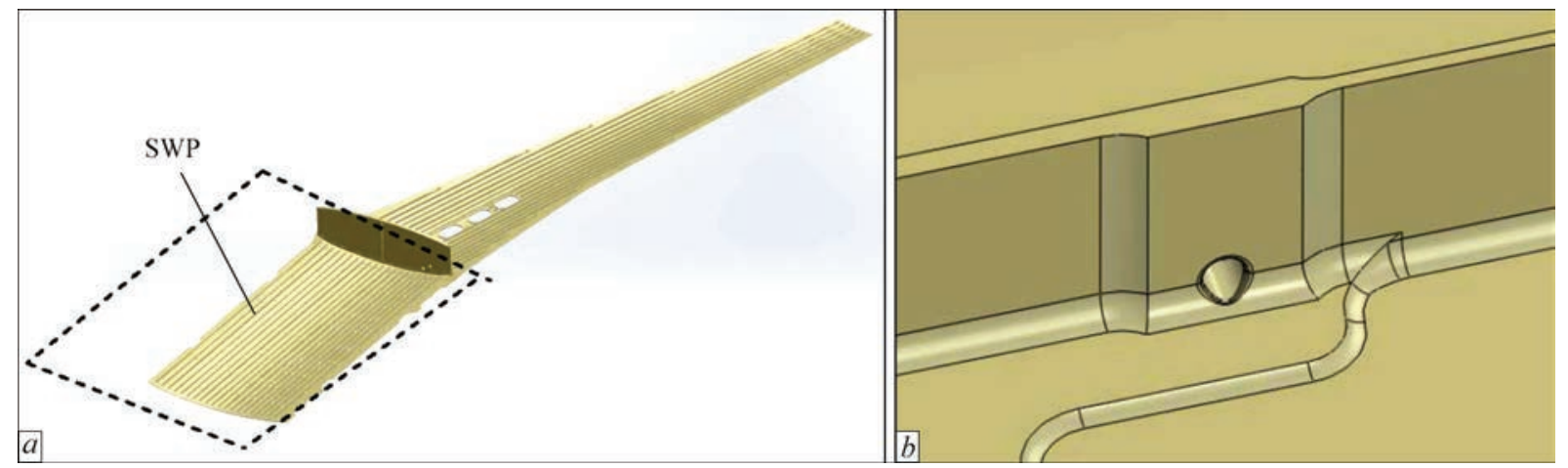

Figure 9. Appearance of bottom panel of aircraft wing: $a$ — general appearance of stringer wing panel; $b$ — hole for fuel overflow in stringer

After EDT the values of residual welding stresses are reduced significantly. The use of electrodynamic effects can positively affect the characteristics of fatigue strength of welded joints under the cyclic loads, which will provide the increasing in the service life of aircraft structures of magnesium alloys [2].

The competitiveness of aircraft products, especially passenger and transport planes, is largely determined by their optimal weight characteristics. Thus, the design weight at the specified takeoff weight and the design service life should be minimal.

The desire to achieve the life of $60,000-80,000$ flight hours under the condition of minimization of structural weight requires the application of new materials and different methods into industry to increase the fatigue life of both regular areas and the areas of structural irregularity.

To reduce the volume of aircraft fuel, which is not worked out and poured off, the holes for its overflowing are produced in the stringers of lower wing panels (Figure 9). The operation and aircraft ground tests show that such holes are the origins of fatigue cracks and may lead to premature fracture of the wing structure. This problem was encountered at the stage of service life tests of short main-line passenger aircraft SSJ-100 and multipurpose aircraft Be-200 and other [4].

To increase the endurance of aircraft wing panels in the holes area for fuel overflow the different technological methods are used, most of which are based on local deep plastic deformation (LDPD) in the hole area. These methods include barrier compression and boring used both separately and together, based on the local deformation of the material and creating residual compressive stresses in the area of increased concentration [7].

The barrier compression consists in indentation at some distance from the hole of the cylindrical punch of a specified profile, as a result of which in the holes the fields of compressive residual stresses are formed, increasing its durability (Figure 10).
The boring consists in pulling with tension through the hole of a specialized cylindrical tool-mandrel, resulting in squeezing out the part of material to the surface of the workpiece, intensive plastic deformation of the hole and, consequently, the formation of compressive stresses.

Despite the high efficiency of data of LDPD methods, increasing the fatigue life of the holes in the range from 1.5 to 10 times $[4,7]$ depending on the material and thickness of the stringer, they have certain disadvantages. For example, the equipment for realization of LDPD methods is sufficiently dimensional [4], and the technological cycle for treatment of one hole takes quite a long time.

It is challenging to use EDT for realization of LDPD, based on normal indentation of the profiled punch in the area of the hole during electrodynamic effects of PEC. The EDT advantages as compared to traditional LDPD methods are a high mobility of the positioning of the operating tool, which allows performing treatment of the holes in different spatial positions, including the operated aircraft structures. The period of treatment of one hole (excluding mounting of the tool) as compared to LDPD is many times shorter.

The different schemes of LDPD using EDT method (EDT LDPD) were investigated, aimed at creating

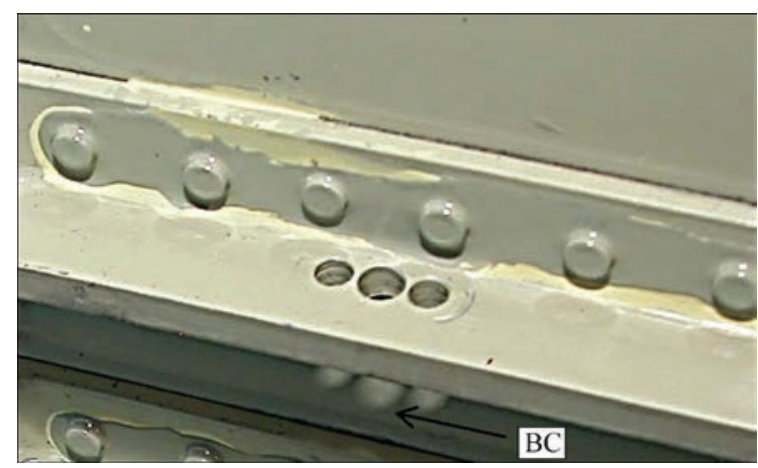

Figure 10. Stringer of the wing panel bottom part with three holes hardened using barrier compression, contour of which is marked with arrow 

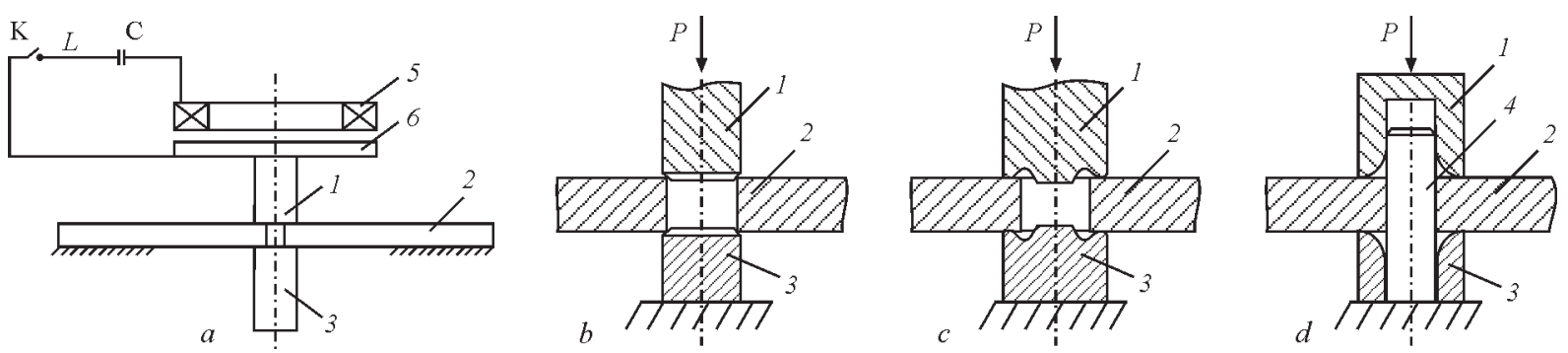

Figure 11. EDT of technological holes: $a$ - scheme of discharge circuit for EDT LDPD; $b$ - EDT-boring; $c$ - combined EDT-boring-compression; $d$ - EDT-compression; 1 - punch; 2 - stringer with hole; 3 - matrix; 4 - guiding bushing; 5 - inducer; 6 disc; K — contactor; C — capacitor; $P$ — electrodynamic effect

the area of compressive stresses in the hole area and the plastic deformation of its surface (Figure 11).

The scheme of discharge circuit for EDT LDPD is presented in Figure 11, $a$. The stringer supported against the rigid base was placed between the punch and the matrix. The punch is rigidly connected with the disc of a non-ferromagnetic material, which is the substrate for the plane inducer. During the start of discharge cycle of the capacitor with the contactor, the electrodynamic force is induced between the inducer and the disc tending to push them from each other, the vector of which is directed to the plane of the stringer along the normal. The effect of electrodynamic force on the punch and the matrix initiates their normal introduction into the treated material, at the same time providing LDPD in the hole area.

Considering the features of conventional schemes, described above $[4,7]$, the electrodynamic effect was used as a force factor providing dynamic introduction of the operating tool into the treated metal. Three schemes of EDT LDPD were proposed, such as EDT-boring (Figure 11, b), combined EDT-boring-compression (Figure 11, c) and EDT-compression (Figure 11, d).

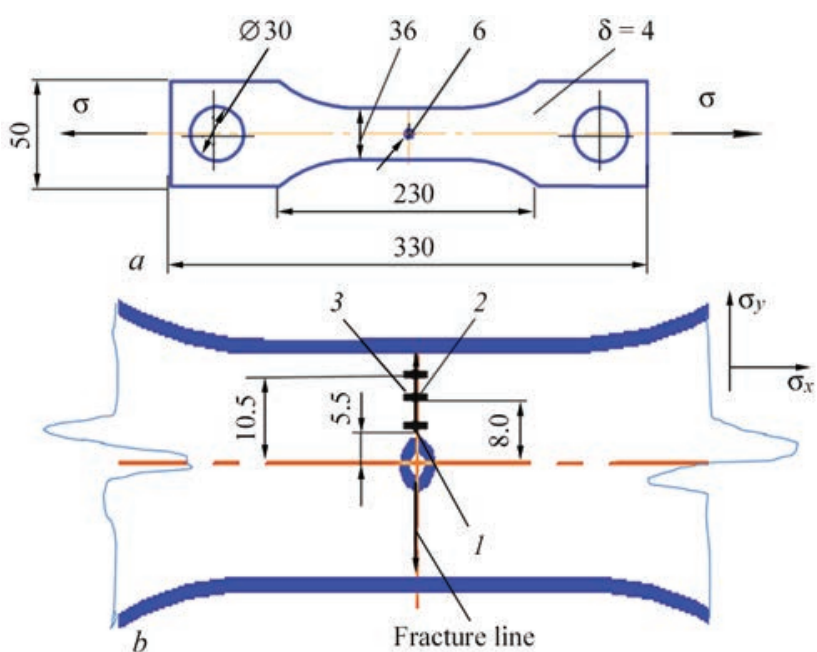

Figure 12. Specimen of alloy D16 stringer with technological hole of $6 \mathrm{~mm}$ diameter for test on fatigue resistance: $a-$ geometric characteristics; $b$ - testing areas of residual stresses in measured points $1-3$
The difference of EDT-boring from traditional EDT is the use of cylindrical punch and matrix, the working surfaces of which are in the form of the truncated cones instead of the mandrel extended through the hole. The electrodynamic effect of the tools on the treated metal provides LDPD of the hole surface of the stringer. The intensity of plastic deformation can be controlled by change in the level of stored energy and a number of PEC.

The combined EDT-boring-compression is the development of EDT-boring, where the profiled punch and the matrix except of LDPD of the hole itself provide the compression of the metal of the stringer surface behind the hole area. Moreover, the conical parts of the tool introduced into the treated surface in the LDPD process, provide alignment of the punch and matrix relatively to the hole edge.

During EDT-compression the alignment of the punch and the matrix with respect to the holes in the stringer is carried out by means of the cylindrical guiding bushing.

The investigations of efficiency of different schemes of EDT LDPD were carried out on the specimens of aluminum alloy D16 (Figure 12) used in the aircraft industry in the manufacture of stringer panels of aircraft wing.

The specimens were treated at three described schemes of EDT LDPD on the mode corresponding to the level of the stored energy of electrodynamic effect of not more than $800 \mathrm{~J}$ by the PEC series from 5 to 15 . The number of PEC in the cycle was determined by the type of the used tool. Thus, the minimum number of PEC, equal to 5, corresponded to EDT-boring (see Figure $11, b$ ), and that one equal to 15 - to EDT-boring-compression (see Figure 11, c).

After treatment of the hole area the level of residual compressive stresses $\sigma$ was registered in the area of the probable fatigue crack propagation (in points $1-3)$; in Figure 12, $b$ the direction of the $\sigma_{x}$ and $\sigma_{y}$ components is also shown. To evaluate the stressed state a non-destructive method of near-surface acoustic waves [8] was used, which allowed maintaining the integrity of specimens for the subsequent me- 
Table 2. Test results of specimens of D16 alloy with $6 \mathrm{~mm}$ hole after LDPD

\begin{tabular}{|c|c|c|c|c|c|}
\hline \multirow{2}{*}{ Scheme of EDT LDPD } & Number of specimen & $\sigma_{\text {max }}, \mathrm{MPa}$ & $N$ & $N_{\text {EDT }}$ & $N_{\text {EDT }} / N$ \\
\hline \multirow{2}{*}{ EDT-boring } & Free hole & 202 & 11000 & - & - \\
& 1 & 203 & - & 19000 & 1.72 \\
\cline { 2 - 6 } & $1^{*}$ & 202 & - & 16000 & 1.45 \\
\hline \multirow{2}{*}{ EDT-boring-compression } & $2^{*}$ & 203 & - & 17500 & 1.60 \\
\hline \multirow{2}{*}{ EDT-compression } & 3 & 201 & - & 27000 & 2.45 \\
\cline { 2 - 6 } & $3^{*}$ & 200 & - & 28000 & 2.54 \\
\hline
\end{tabular}

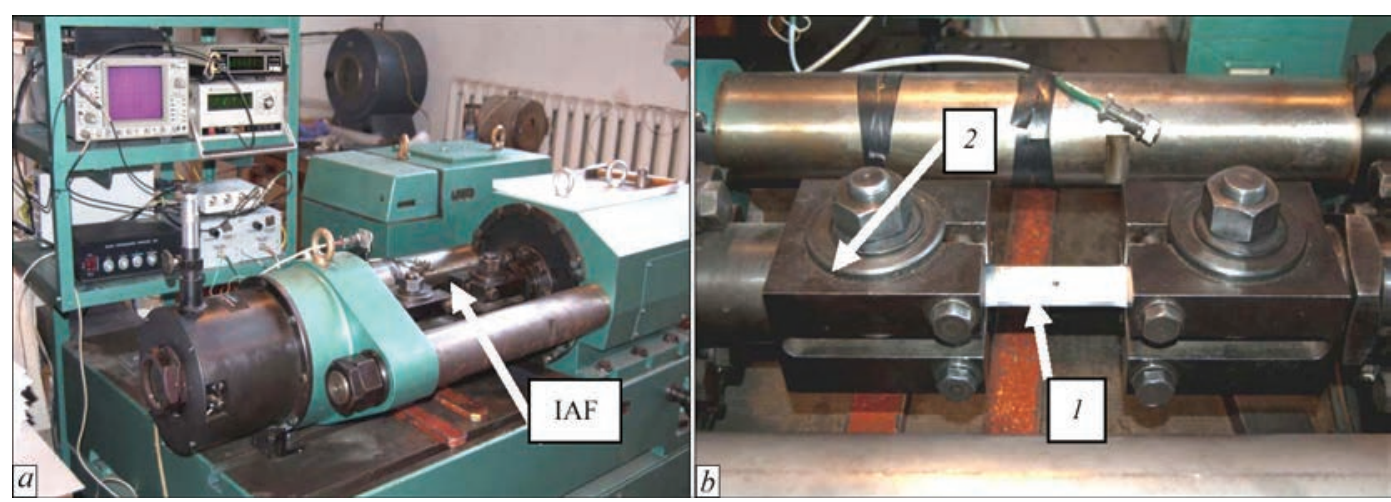

Figure 13. Installation for fatigue tests of specimens: $a$ - general view; $b$ - installation for applying force; 1 - specimen of stringer with hole; 2 - clamping unit

chanical tests on resistance to a delayed fracture. The maximum value of compressive $\sigma_{x}$ stress in point 1 reached -80 , in $2-40$ and in $3-105$, and $\sigma_{y}$ in points 1 and 2 was -95, in 3-120 MPa.

The tests of specimens were carried out at a gentle loading with the simultaneous registration of number of cycles $N$ before failure from zero cycle of loading by tension $\sigma_{\max }=200-203 \mathrm{MPa}$. The $N$ values were obtained for a free hole, and $N_{\mathrm{EDT}}$ - for treated ones. The tests, the results of which are shown in Table 2, were performed in the installation shown in Figure 13.

The dependence $\sigma_{\max }=f(N)$ in logarithmic coordinates for different schemes of EDT LDPD is presented in Figure 14.

Analyzing the data of Table 2 and Figure 14, it can be seen that EDT LDPD, realized on the basis of EDT-boring and EDT-boring-compression increase the resistance to delayed fracture of specimens in the hole area at $\sigma_{\max } \sim 200 \mathrm{MPa}$, determined by the $N_{\mathrm{EDT}} / N$ relation in 1.6 times, and EDT-compression - in 2.5 times.

On the basis of the presented data it can be concluded that the proposed schemes of EDT LDPD allow improving the resistance to fracture of technological hole, and taking into account possibilities of the method such as compactness and operating speed of the equipment, as well as the mobility of the operating tool positioning, they are promising for application in the production.

At the same time, there are opportunities to improve the efficiency of EDT LDPD, based on calculation-ex- perimental evaluations, for example [9]. Thus, the optimization of shape of working cones of the punch and the matrix for the proposed treatment schemes, taking into account the speed and the amount of dynamic loading at a normal introduction of the tool into the treated material, will provide the parameters of the stress-strain state of the metal in the hole area, necessary for the efficient fracture inhibition.

The results of the work were tested in the laboratory of aircrafts strength of the N.E. Zhukovsky National Aerospace University «KhAI».

On the basis of the carried out investigations on EDT of the repair welded joints of magnesium alloy ML10 and technological holes in aluminum alloy D16 it can be concluded that the electrodynamic effects allow regulating the stressed state of the thinsheet structural elements of light alloys in a wide

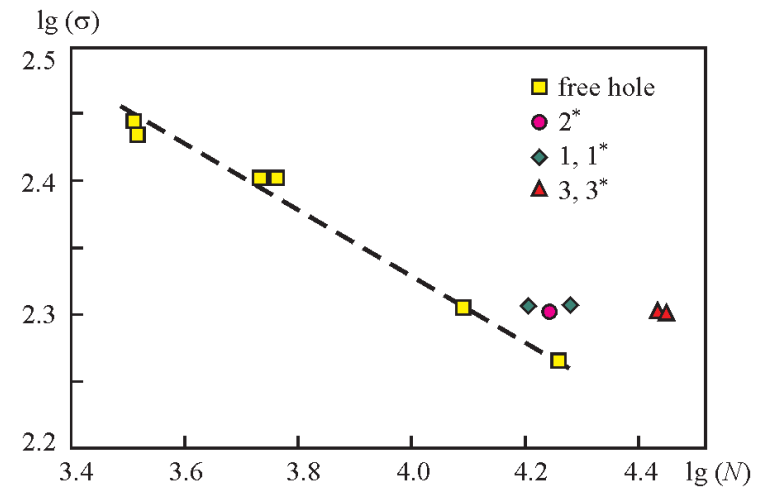

Figure 14. Tests results at from zero cycle of loading by $\sigma_{\text {max }}$ of D16 alloy specimens with $6 \mathrm{~mm}$ hole at different schemes of EDT LDPD acc. to Table 2: hatched line - resistance to fracture of hole without EDT LDPD 
range. Thus, EDT of welded joints of magnesium alloy provides transition of tensile residual stresses into the compressive ones, and the treatment of aluminum alloy initiates the field of compressive stresses in it, improving the resistance of metal against the delayed fracture under the cyclic loading.

The development of EDT method for its application in different technological processes will allow increasing the service life of metal structures of light alloys.

\section{Conclusions}

1. The pulsed electric current generator of the new generation with its controlled amplitude-frequency characteristics for electrodynamic treatment of thinsheet metal structures was designed and manufactured, which allows significant extension of capabilities of electrodynamic effects due to the controlled synchronization of the EDT dynamic and electric pulse components.

2. The effect of EDT on reducing of residual stresses in welded joints of magnesium alloy ML10 was investigated. It was established that using EDT it is possible to regulate the stressed state of ML10 welded joints, at the same time reaching compressive stresses.

3. It is shown that the local plastic deformation using EDT of specimens of aircraft wing stringer of aluminum alloy D16 in the area of technological holes 1.6-2.5 times increases the delayed fracture resistance.
1. Shalomeev, V.A., Tsivirko, E.I., Petrik, I.A. et al. (2009) Welding repair of surface defects in ML-10 alloy castings by using scandium-containing material. The Paton Welding J., 3, 23-27.

2. Lobanov, L.M., Pashchin, N.A., Cherkashin, A.V. et al. (2012) Repair welding of intermediate cases of aircraft engines from high-temperature magnesium alloy ML 10 with application of electrodynamic treatment. Ibid., 11, 28-33.

3. Lobanov, L.M., Pashchin, N.A., Savitsky, V.V. et al. (2014) Study of residual stresses in welded joints of high-temperature alloy ML10 with application of electrodynamic treatment. Problemy Prochnosti, 6, 33-41.

4. Zarutsky, A.V. (2014) Experimental study of service life of specimens with strengthened holes. Information 2: Software loading. In: Problems of design and manufacturing of aircraft structures: Transact. of KhAI, Issue 2(78), 57-65.

5. Lobanov, L.M., Pivtorak, V.A., Savitsky, V.V. (2006) Procedure for determination of residual stresses in welded joints and structural elements using electron speckle-interferometry. The Paton Welding J., 1, 24-29.

6. Lobanov, L.M., Pashchin, N.A., Loginov, V.P. et al. (2007) Change of the stress-strain state of welded joints of aluminium alloy AMg6 after electrodynamic treatment. Ibid., 6, 7-14.

7. Grebenikov, A.G., Krivov, G.A., Vasilevsky, E.T. (2009) Experimental study of influence of subsequent application of boring mandrelling and barrier compression on fatigue life of stringers in zone of fuel crossfeed hole. In: Open information and computer integrated technologies: Transact. of KhAI, Issue $43,54-64$.

8. Gushcha, O.I., Smilenko, V.N., Kot, V.N. (2009) Control of stresses on the base of application of subsurface acoustic waves. Tekhnich. Diagnostika i Nerazrush. Kontrol, 1, 11-13.

9. Fomichev, P.A., Zarutsky, A.V. (2014) Prediction of service life of structure elements with strengthened holes under regular loading. In: Open information and computer integrated technologies: Transact. of KhAI, Issue 64, 84-93. 


\title{
POSSIBILITIES OF REDUCTION OF GROWTH OF INTERMETALLIC INTERLAYER IN STEEL BRAZED USING BRAZING FILLER METALS OF COPPER-PHOSPHORUS SYSTEM
}

\author{
A.N. PISAREV, V.F. KHORUNOV, S.M. MAKSYMOVA and V.N. TOVMACHENKO \\ E.O. Paton Electric Welding Institute, NASU \\ 11 Kazimir Malevich Str., 03680, Kiev, Ukraine. E-mail: office@paton.kiev.ua
}

\begin{abstract}
Brazed joints are widely used in development of structures in the different branches of industry. Their service properties depend on safety of the brazed joints. One of the reasons of low properties of the brazed structures is formation of the solid continuous interlayers of brittle intermetallic compounds along seam-brazed metal interface. This work studies some dependencies of formation of iron phosphides in steel brazing using $\mathrm{Cu}-\mathrm{P}$ filler metals. Using the reference data and thermodynamic calculations it was an attempt to reduce their growth and rate of formation by means of manganese, titanium and nickel alloying. Interaction of metal being brazed with brazing filler metal can provoke two mutually antithetic processes at the interface, namely dissolving the solid metal in the liquid, and diffusion of atoms of the liquid metal in the solid one with formation of chemical compounds. Investigation of phase and chemical composition of interaction zone showed that it consists of a Cu-based solid solution and $\mathrm{Fe}_{2} \mathrm{P}$ and $\mathrm{FeP}$ phosphides, forming at the interface in form of continuous interlayer. Thermodynamic possibility of phosphide formation is verified by calculation of Gibbs thermodynamic potential of corresponding reactions. Study of phase equilibriums and mutual solubility of components and compounds of $\mathrm{Fe}_{2} \mathrm{P}-\mathrm{Cu}_{3} \mathrm{P}-\mathrm{Ni}$ section of tetradic system $\mathrm{Fe}-\mathrm{Ni}-\mathrm{Cu}-\mathrm{P}$ showed that nickel and its phosphides can form the continuous solid solutions with iron as well as copper. Similarity of the crystal lattices of copper solution and iron phosphide and their parameters indicate that introduction of nickel to $\mathrm{Cu}-\mathrm{P}$ brazing filler metal will provide their solving in a brazed seam. 11 Ref., 3 Figures.
\end{abstract}

Keywords : brazing, Cu-P brazing filler metal, intermetallics' solubility, thermodynamic calculations, diffusion, phosphides, $X$-ray pattern, phase

Brazing of the most structural materials and, in particular, of steels using $\mathrm{Cu}-\mathrm{P}$ BFMs does not provide sufficiently strong joint. However, taking into account that alloys of this system are cheap and domestically manufactured in a wide range, the industry is interested in development of the Cu-P BFM suitable for steel brazing [1, 2].

The main difficulty lies in the fact that these BFMs currently can not be used in brazing of Fe-based alloys, from which the most part of brazed components are made, due to formation of comparatively wide brittle interlayers of iron phosphides [1] at the seambrazed metal interface. Taking into account that presence of the intermetallic interlayer in a seam zone can be a reason of joint fracture, it was an attempt to set some dependencies of phosphides formation and possibility of reduction of their growth in steel brazing using $\mathrm{Cu}-\mathrm{P}$ BFMs.

30 alloys were melted for the experiments. The initial material for samples production were powders containing, wt.\%: Fe (0.9999), Ni (0.9998), Cu (0.9999) and red phosphorus (0.9999). $\mathrm{Fe}_{2} \mathrm{P}$ and $\mathrm{Cu}_{3} \mathrm{P}$ phosphides were preliminary produced by means of sintering a pressed charge in a quartz vessel at 1170 $1220 \mathrm{~K}$ during $24 \mathrm{~h}$. Then, produced phosphides and nickel were fused in an electric-arc furnace on copper water-cooled hearth using argon atmosphere; specimens' compositions were controlled by weighing (deviation of specimen mass from charge mass did not exceed $2 \%$ ). Homogenizing annealing was carried out at $870 \mathrm{~K}$ in the pumped quarts vessels during $1000 \mathrm{~h}$ and then they were quenched. The quartz vessels were gradually cooled from $870 \mathrm{~K}$ to room temperature during $200 \mathrm{~h}$ in order to study phase composition of the specimens at room temperature.

$\mathrm{X}$-ray phase analysis was carried out by means of comparison with known X-ray patterns of pure elements and compounds. The X-ray patterns were made in Debay cylindrical camera $(d=57.3 \mathrm{~mm})$ in chromium radiation with asymmetric film positioning.

Review of references [3, 4] and direct experiments, based on investigation of structure of the steel brazed joints, produced using $\mathrm{Cu}-\mathrm{P}$ BFMs, allowed determining that the solid intermetallic interlayer is formed in the seam in the case when solubility of elements of BFM and metal being brazed in each other is 


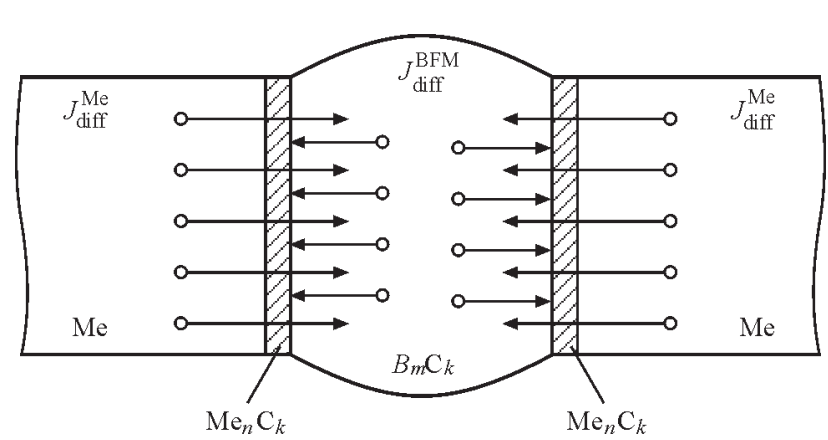

Figure 1. Scheme of mutual diffusion of solid brazed metal and liquid BFM: $J_{\text {diff }}^{\mathrm{Me}}$ - diffusion of solid brazed metal in liquid BFM; $J_{\text {diff }}^{\mathrm{BFM}}$ — diffusion of liquid BFM in solid brazed metal; $B_{m} C_{k}$ - seam; $\mathrm{Me}_{n} C_{k}$ - intermetallic interlayer

insignificant or completely absent, and level of their chemical affinity is high.

Interaction of brazed metal with liquid BFM (after wetting is finished) can promote at the interface two mutually opposite processes, namely dissolution of solid metal in liquid one, and diffusion of atoms of liquid metal in solid one (Figure 1).

Formation of the intermetallic interlayer at brazed metal-liquid BFM interface is possible:

- as a result of chemical reaction between brazed metal and liquid BFM under condition that the rate of intermetallic growth is higher than the rate of its dissolving in the seam; i.e. $v_{\mathrm{gr}}>v_{\text {dissol }}$;

- as a result of liquid BFM saturation with atoms of brazed metal along the interface.

As it is shown in work [5], growth of intermetallic in contact of solid, more refractory metal, and liquid, more fusible metal, in the first approximation obeys the law:

$$
\Delta^{2}=C\left(t-t_{0}\right)
$$

where $C$ is the concentration; $t, t_{0}$ are the time.

It follows from this that growth of the intermetallic is possible to the side of liquid phase, or to the side of solid metal. The rate of this process is determined by a rate of transfer of atom of solid metal in a near-boundary layer of liquid one, or by a rate of diffusion of dissolved atoms from a near-boundary layer in the seam. This dependence has parabolic nature typical for thermal-chemical processes. For the first time it was experimentally determined by G. Tamman. and then theoretically obtained by K. Wagner [6]. Formed continuous layer of solid product move away the reacting substances from each other, therefore rate of their diffusion delivery through the thickness of the intermetallic layer becomes the main factor, determining general rate of reaction [7].

Study of the process of intermetallic growth in liquid BFM-brazed metal system requires consideration of solubility of the reaction products. In liquid phase, if liquid is not saturated with a component of solid brazed metal, then its dissolving takes place simultaneously with intermetallic growth. Therefore, general change of layer thickness can be determined from a difference of dissolution and growth rates.

Rate of dissolution of layer of intermetallic is described by equation [8]

$$
\begin{gathered}
\frac{d x}{d t_{\text {dissol }}}=b \exp (-a t) ; \\
a=K(S / V) ; \quad C_{\mathrm{s}} K / \rho_{\mathrm{int}} \varphi,
\end{gathered}
$$

where $K$ is the constant of dissolution rate; $C_{\mathrm{s}}$ is the concentration of elements saturation in intermetallic; $\rho_{\text {int }}$ is the density; $\varphi$ is the content of elements in intermetallic; $t$ is the time of dissolution of brazed metal in BFM.

Due to the fact that brazing process is characterized by limited volume of the liquid BFM in a gap, the constant of dissolution rate can be found using Berthoud equation [6]:

$$
\left.\ln C_{\mathrm{s}}^{0} / C_{\mathrm{s}}^{0}-C^{0}\right)=K(S / V) t
$$

This equation describes the case of dissolution of semiinfinite solid, being in contact with area $S$ and volume $V$ of the liquid BFM in a brazing gap.

Growth rate is expressed as

$$
\frac{d x}{d t_{\mathrm{gr}}}=\frac{K_{0}}{1+\frac{K_{0} x}{K_{1}}},
$$

where $K_{0}$ is the chemical constant of diffusion; $K_{1}$ is the physical constant of diffusion.

In this connection one of the problems of current investigation was to study the ways for delaying the growth of intermetallic interlayer due to emission of elements promoting their dissolution in the seam.

Interface interaction of iron with liquid $\mathrm{Cu}-\mathrm{P}$ BFM usually provides for formation of the layers of higher phosphides, promoting embrittlement of the brazed joints.

Examination of phase and chemical composition of the interaction zone with the help of X-ray analysis showed that it consists of $\mathrm{Fe}_{2} \mathrm{P}$ and $\mathrm{FeP}$ phosphides (Figure 2), thermodynamic possibility of formation of which is verified by calculation of Gibbs potential of corresponding reactions [9], re-calculation of which on equilibrium constant showed that it is more than one in all cases:

$\mathrm{Cu}_{3} \mathrm{P}+2 \mathrm{Fe}=3 \mathrm{Cu}+\mathrm{Fe}_{2} \mathrm{P}, \quad \Delta \mathrm{G}_{298}=-40.74 \mathrm{~J} / \mathrm{mole} ;$

$\mathrm{Cu}_{3} \mathrm{P}+\mathrm{Fe}_{2} \mathrm{P}=2 \mathrm{FeP}+3 \mathrm{Cu}, \Delta \mathrm{G}_{298}=-11.3 \mathrm{~J} / \mathrm{mole}$.

It means that formation of reaction products in a form of iron phosphides is inevitable at presence in a reaction zone of the initial substances and at continuous removal of the reaction products from the zone. Their microhardness makes HV20-820-960 MPa, 
thickness of brittle interlayer depending on brazing mode and content of phosphorus in the BFM can reach $40 \mu \mathrm{m}$.

Constitutional diagram of $\mathrm{Fe}-\mathrm{Cu}-\mathrm{P}$ system, which is drawn based on results of thermal and microstructure investigations, show that formation of mixed crystals (solutions) were not observed at 2.5 wt.\% of $\mathrm{Fe}_{2} \mathrm{P}$, since even two alloys with 1 wt. $\%$ of $\mathrm{Fe}_{2} \mathrm{P}$ and 1 wt. $\%$ of $\mathrm{Cu}_{3} \mathrm{P}$ remained two-phase after twohour annealing below eutectic temperature (Figure 3 ). Wetting by $\mathrm{Cu}-\mathrm{P}$-based BFM and simultaneous elimination of possibility of iron phosphide formation at the fusion line requires selection of such an alloying element, which would promote for mutual dissolution between $\mathrm{Fe}_{2} \mathrm{P}$ and $\mathrm{Cu}_{3} \mathrm{P}$ and between iron and copper. In this connection, effect of alloying elements $\mathrm{Me}$ (where $\mathrm{Me}$ is $\mathrm{Zn}, \mathrm{Mn}, \mathrm{Cd}, \mathrm{Bi}, \mathrm{Pb}, \mathrm{Al}, \mathrm{Ni}, \mathrm{Sn}, \mathrm{Ti}, \mathrm{In}$ ) on phase composition of quasi-triple $\mathrm{Cu}_{3} \mathrm{P}-\mathrm{Fe}_{2} \mathrm{P}-\mathrm{Me}$ system is considered.

Thermal-dynamic evaluation showed the possibility of reaction of copper phosphide with titanium at titanium introduction in $\mathrm{Cu}-\mathrm{P}$ alloy:

$$
\mathrm{Cu}_{3} \mathrm{P}+3 \mathrm{Ti}=\mathrm{Ti}_{3} \mathrm{P}+3 \mathrm{Cu} \text {. }
$$

Formed titanium phosphide $\mathrm{Ti}_{3} \mathrm{P}$, having hexagonal lattice similar to copper phosphides $\mathrm{Cu}_{3} \mathrm{P}$, can form $(\mathrm{Cu}, \mathrm{Ti})_{3} \mathrm{P}$ solid solution. This solid solution prevents interaction of iron with phosphorus in brazing and eliminates formation of $\mathrm{Fe}_{2} \mathrm{P}$ interlayer.

Increase of titanium content to 0.9 atomic fractions revealed the copper lines on $\mathrm{X}$-ray pattern. This indicates $\mathrm{Cu}_{3} \mathrm{P}$ reduction to metallic copper with formation of titanium phosphides.

Introduction of manganese in $\mathrm{Cu}-7 \% \mathrm{P}$ alloy provides for a thermodynamic probability of formation of manganese phosphides $\mathrm{Mn}_{3} \mathrm{P}$ by reaction

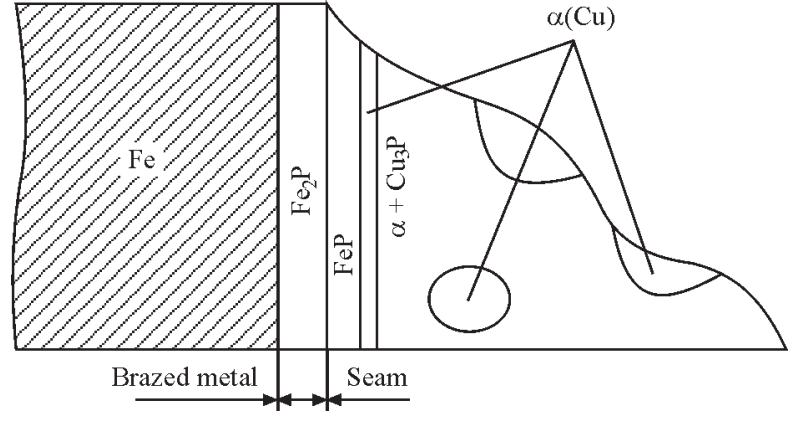

Figure 2. Scheme of formation of intermetallics in iron brazing using $\mathrm{Cu}-\mathrm{P}$ BFM

$$
\mathrm{Cu}_{3} \mathrm{P}+3 \mathrm{Mn}=\mathrm{Mn}_{3} \mathrm{P}+3 \mathrm{Cu} .
$$

According to reference data [8] the alloy forms a triple phase with hexagonal lattice similar to $\mathrm{Fe}_{2} \mathrm{P}$ at $0.25 \mathrm{~mol}$ \% Mn. Composition of the phase is not determined but, at the same time, phosphorus in these compounds is in bound state and eliminates its combination in brazing with iron with intermetallic formation.

The specimens of quasi-triple $\mathrm{Cu}_{3} \mathrm{P}-\mathrm{Fe}_{2} \mathrm{P}-\mathrm{Me}$ system contain the phases, which are present in quasi-binary sections $-\mathrm{Fe}_{2} \mathrm{P}-\mathrm{Mn}$ and $\mathrm{Cu}_{3} \mathrm{P}-\mathrm{Mn}$, limiting this system.

Nickel and its phosphides can form the continuous solid solutions with iron as well as copper [10]. Similarity of the crystalline lattices of copper solution and iron phosphides and their parameters indicate that introduction of nickel in the $\mathrm{Cu}-\mathrm{P}$ BFM in brazing will promote their dissolution in the seam.

Therefore, according to Kurnakov rule [11], a solid solution between the compounds is better on properties than the properties of the separate compounds.

30 alloys of a wide range of concentrations were examined in tetradic system $\mathrm{Fe}-\mathrm{Ni}-\mathrm{Cu}-\mathrm{P}$ on $\mathrm{Fe}_{2} \mathrm{P}-$ $\mathrm{Cu}_{3} \mathrm{P}-\mathrm{Ni}$ section.
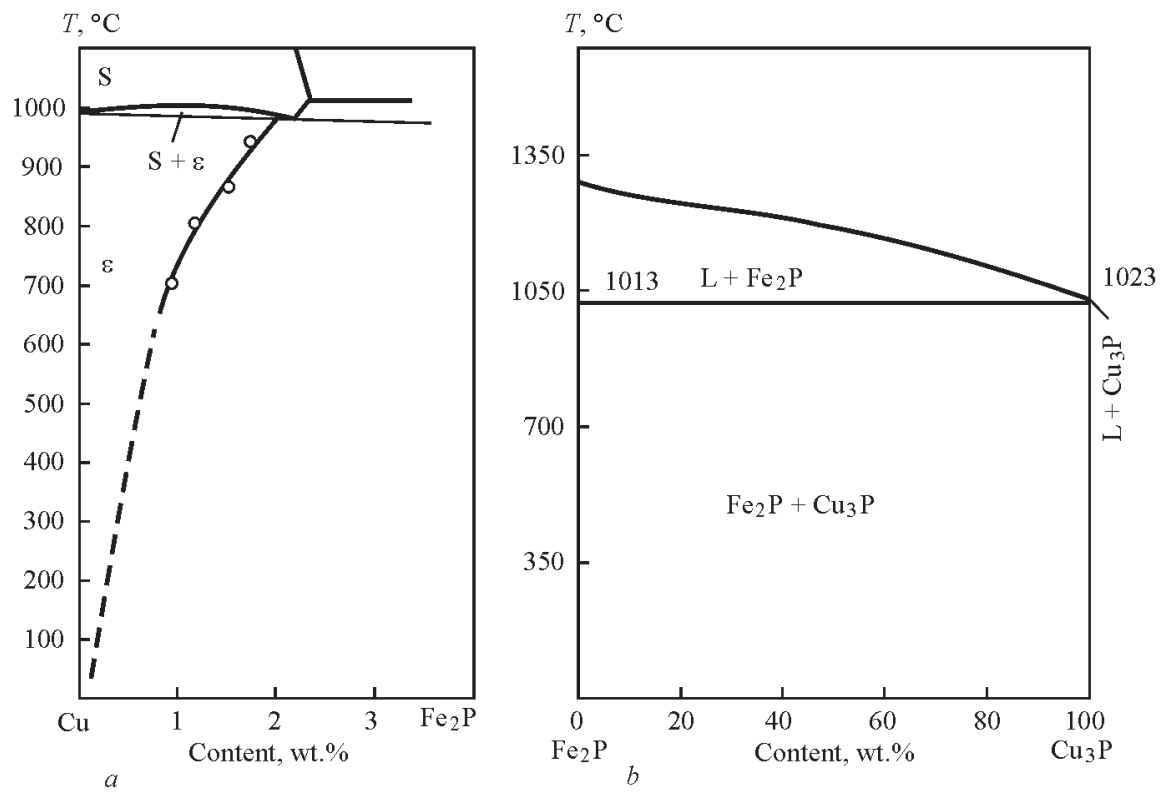

Figure 3. Quasi-binary section $\mathrm{Fe}_{2} \mathrm{P}-\mathrm{Cu}(a)$ and $\mathrm{Fe}_{2} \mathrm{P}-\mathrm{Cu}_{3} \mathrm{P}(b)$ of $\mathrm{Fe}-\mathrm{Cu}-\mathrm{P}$ system [8] 
In addition to earlier indicated phases of continuous series of solid solutions $(\mathrm{Cu}, \mathrm{Ni}),(\mathrm{Fe}, \mathrm{Ni})_{3} \mathrm{P}$, (Fe, $\mathrm{Ni})_{2} \mathrm{P}, \mathrm{FeP}$, a new phase (A) was discovered. It is received in the purest form at $\left(\mathrm{Fe}_{2} \mathrm{P}\right)_{0.6}\left(\mathrm{Cu}_{3} \mathrm{P}\right)_{0.2} \mathrm{Ni}_{0.2}$ composition, i.e. $\mathrm{Fe}_{1.2} \mathrm{Ni}_{0.2} \mathrm{Cu}_{0.6} \mathrm{P}_{0.8}$. Phase $\mathrm{A}$ is in equilibrium with continuous series of solid solutions $(\mathrm{Cu}$, $\mathrm{Ni}$ ) and $(\mathrm{Fe}, \mathrm{Ni})_{3} \mathrm{P}$, its $\mathrm{X}$-ray pattern is similar to the $\mathrm{X}$-ray pattern of $\mathrm{Co}_{2} \mathrm{P}$ phosphides having anti- $\mathrm{PbCl}_{2}$ structure type.

The specimen with phase A has less content of phosphorus than in phosphides with anti- $\mathrm{PbCl}_{2}$ structure. Therefore, 15 additional specimens of ( $\mathrm{Fe}, \mathrm{Ni}$, $\mathrm{Cu})_{2} \mathrm{P}$ composition with different ratio of atoms of metal and adjacent to them $\mathrm{Fe}_{4} \mathrm{Cu}_{2} \mathrm{P}_{3}$ specimen were manufactured. Manufacture of the latter was necessary in order to prove that phase A is a four-component compound and it is not a triple phosphide of $\mathrm{Fe}-\mathrm{Cu}-\mathrm{P}$ system. The phase analysis of all additional specimens verified that phase $\mathrm{A}$ is a tetradic phosphide of alternating composition $\mathrm{Fe}_{1.3-1.6} \mathrm{Ni}_{0.2} \mathrm{Cu}_{0.5-0.2} \mathrm{P}$ forming only after annealing at $870 \mathrm{~K}$.

Formation of the tetradic compound $(\mathrm{Fe}, \mathrm{Ni}, \mathrm{Cu})_{2} \mathrm{P}$ with anti- $\mathrm{PbCl}_{2}$ structure type indicate that its morphotropic transfer is related with change of electron concentration.

Carried analysis show that introduction of $\mathrm{Mn}, \mathrm{Ti}$ or $\mathrm{Ni}$ in the $\mathrm{Cu}-\mathrm{P}$ BFM improves the seam quality in brazing of Fe-based alloys. $\mathrm{Fe}_{1.3-1.6} \mathrm{Ni}_{0.2} \mathrm{Cu}_{0.5-0.2} \mathrm{P}$ phosphide, forming after annealing and having rhombic structure of anti- $\mathrm{PbCl}_{2}$ type, was found in the quasi-triple system $\mathrm{Cu}_{3} \mathrm{P}-\mathrm{Fe}_{2} \mathrm{P}-\mathrm{Ni}$.
From thermodynamic point of view, brazing process should be carried out at the lowest overheating and the minimum time of contact with the brazed metal. The brazing temperature should be lower and the rate of heating when reaching operating temperature the largest.

1. Mars, O., Srtoizcek, M., Persson, U. (2012) Erosion control of stainless steel brazing alloys. In: Proc. of $5^{\text {th }}$ Int. Brazing and Soldering Conf. (Las Vegas, USA, April 22-25, 2012), 169-173.

2. Lashko, N.F., Lashko, S.V. (1977) Contact and metallurgical processes in brazing. Moscow: Metallurgiya.

3. Duffey, M.J., Marchal, J.T., Loney, M.R. et al. (2015) Strength of brazed joints and metallurgical testing of $\mathrm{Cu}-4 \mathrm{Sn}-6 \mathrm{P}$ and $\mathrm{Cu}-40 \mathrm{Zn}-1 \mathrm{Sn}-0,3 \mathrm{Si}$ silver-free filler metals. In: Proc. of Int. Brazing and Soldering Conf. (Long Beach, USA, April 19-22, 2015).

4. Li Yajiang, Wang Juan, Liu Kun et al. (2015) Microstructure and fracture morphology of Mo/CuCr18-Ni18 brazing joint with Ni-Cr-P filler metal. In: Ibid.

5. Nikitin, V.I. (1967) Physical-chemical phenomena under the impact of liquid metals on hard metals. Moscow: Atomizdat.

6. Dybkov, V.I. (2002) Solid phase chemical kinetics and reactive diffusion. Kiev: NANU.

7. Shatinsky, V.F., Zbozhnaya, O.M. (1976) Producing diffusion coatings in fusible metals medium. Kiev: Naukova Dumka.

8. (1986) Constitutional diagrams of binary and multicomponent systems on iron base: Refer. Book. Ed. by O.A. Bannykh. Moscow: Metallurgiya.

9. Chase, M.W. (1980) JANAF Thermochemical Tables. 3rd ed., 1856. Midland: Thermal Group.

10. Matyushenko, N.N. (1969) Crystalline structures of binary compounds: Refer. Book. Moscow: Metallurgiya.

11. Kornilov, I.I. (1964) Metallides and their interaction. Moscow: Nauka. 


\title{
IRON-BASED ALLOY FOR PLASMA-POWDER SURFACING OF SCREW CONVEYORS OF EXTRUDERS AND INJECTION MOLDING MACHINES
}

\author{
A.I. SOM \\ Plasma-Master Ltd \\ 3 Krzhizhanovsky Str., 03680, Kiev, Ukraine. E-mail: info@plasma-master.com
}

\begin{abstract}
The structure and properties of wear- and corrosion-resistant alloy of $\mathrm{Fe}-\mathrm{Cr}-\mathrm{V}-\mathrm{Mo}-\mathrm{Ni}-\mathrm{C}$ system were investigated for plasma surfacing of screw conveyors of extruders and injection molding machines. It was shown that combination of high wear resistance and ductility of the alloy is achieved due to formation of a large amount of primary vanadium carbides VC and eutectics, located in the viscous austenitic-martensitic matrix in the form of single colonies. The alloy has an excellent formation and high resistance of the deposited bead to crack formation in surfacing, that allows surfacing rather massive parts without preheating. The service life of screw conveyors deposited using this alloy is $3-5$ times higher than that of nitrated screws. 10 Ref., 2 Tables, 10 Figures.
\end{abstract}

Ke ywords : plasma-powder surfacing, alloy structure, carbides, carbide eutectic, wear resistance, coefficient of linear expansion, bead formation

To increase the service life of screw conveyors of extruders and injection molding machines the plasma-powder surfacing of working surfaces using wear-resistant alloys is widely applied in the world [1-5]. Most often for these purposes the alloys are used based on nickel and cobalt. To avoid cracks in the deposited layer the parts are preheated to 400 $500{ }^{\circ} \mathrm{C}$, and sometimes the concurrent heating is used.

The experience shows that preheating of such parts not only complicates the process of surfacing, but also significantly raises its cost. In addition, the widespread use of nickel and cobalt alloys for surfacing of screw conveyors is rather traditional than it is caused by the necessity. Although such unique properties as heat resistance, hot hardness, corrosion resistance and others are important in the operation conditions of screw extruders, however they are not decisive. Therefore, according to the author opinion, they can be successfully replaced for the cheaper and more wear-resistant alloys based on iron.

Unfortunately, the known commercial alloys based on iron have the same serious technological disadvantage as nickel or cobalt alloys, namely increased tendency to crack formation during surfacing. There is an experience of application of high-speed steel 10R6M5 for the surfacing of screw conveyors, which under the certain thermal cycle due to the effect of martensite transformation can be deposited without cracking [6]. However, as was demonstrated by industrial tests, due to insufficient ductility of this steel during operation the cracks may be formed in the deposited layer and cause cleavages, that is unacceptable.

Specially for plasma-powder surfacing of screw conveyors, the author of this article together with (c) A.I. SOM, 2016 other authors developed a new wear-resistant alloy of system $\mathrm{Fe}-\mathrm{Cr}-\mathrm{V}-\mathrm{Mo}-\mathrm{C}$ resistant to cracks [7]. It belongs to the class of high-vanadium cast irons. During its development the maximum operating conditions of these components and their structural features were taken into account.

In the present work for the first time the properties of the alloy for surfacing of screw conveyors, and experience of its industrial operation are described in detail.

Structure and phase composition of the alloy after surfacing. The microstructure and phase composition of the deposited metal was investigated by optical and electron metallography, as well as using the methods of X-ray diffraction, X-ray spectral and chemical phase microanalyses (the investigations were carried out at PWI).

The structure of metal in the initial state after surfacing consists of a solid solution, based on iron, carbide eutectic and excessive vanadium carbides VC. The characteristic feature of the structure is a very fine grain $(10-15 \mu \mathrm{m})$ and eutectic of a fan shape, which are located in the form of separate colonies as if embedded into the matrix (Figure 1, $a$ ). The shape and structure of eutectic colonies are clearly visible in the SEM-photo (Figure 1,b), produced by microscope JSM-35, where thin plates of eutectic carbides are alternated with a solid solution filling the gaps between them. Such a structure of eutectic provides the alloy with a combination of high strength and ductility at the level of $\sigma_{\mathrm{t}}=1000 \mathrm{MPa}$ and $a_{\mathrm{n}}=25 \mathrm{~kg} / \mathrm{cm}^{2}$.

The vanadium carbides are fine (up to $5 \mu \mathrm{m}$ ), have a rounded shape, and are comparatively uniformly distributed throughout the whole volume of the alloy. The total amount of carbide phase, according to the data of chemical phase analysis, is about $16 \%$. As 


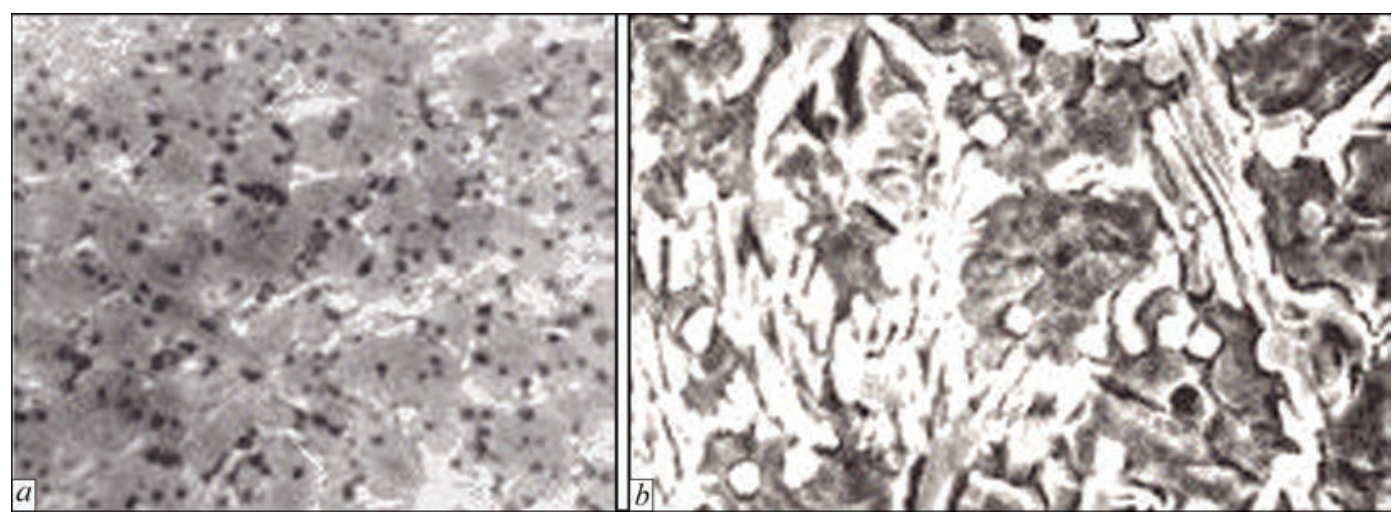

Figure 1. Microstructure of deposited metal: $a$ - optic microscope $(\times 500) ; b$ - electron microscope $(\times 3000)$

was shown by X-ray structural analysis of anode precipitation, except of vanadium carbides, the composition of carbide phase VC includes eutectic carbides, based on chromium of $\mathrm{Me}_{7} \mathrm{C}_{3}$ type, molybdenum of $\mathrm{Me}_{2} \mathrm{C}$ type and carbides of cementite type $\mathrm{Me}_{3} \mathrm{C}$, where a part of iron atoms is replaced by atoms of other elements. The matrix of the alloy represents $(\gamma+$ $\alpha$ )-solid solution with microhardness HV25-400-450. According to the data of X-ray microanalysis, the solid solution contains about, $\%: 15 \mathrm{Cr}, 3 \mathrm{~V}, 2 \mathrm{Mo}, 5 \mathrm{Ni}$.

A high degree of alloying of the solid solution with the given elements significantly delays $\gamma \rightarrow \alpha$ transformations. As is shown by investigations performed at a high-speed dilatometer under the continuous cooling from high temperatures (Figure 2), the starting point of martensitic transformation $\mathrm{M}_{\mathrm{s}}$, depending on the cooling rate, lies at the level of $110-130^{\circ} \mathrm{C}$.

Due to this fact, up to $60-80 \%$ of residual austenite is fixed in the alloy. It causes a beneficial effect to the ductility of the alloy and allows relaxing a significant part of stresses arising during rapid cooling at surfacing process.

Structure and phase composition of the alloy after heat treatment. In manufacture of screw conveyors the obligatory technological operation is high tempering, therefore, it is important to know its effect on the structure and properties of the deposited

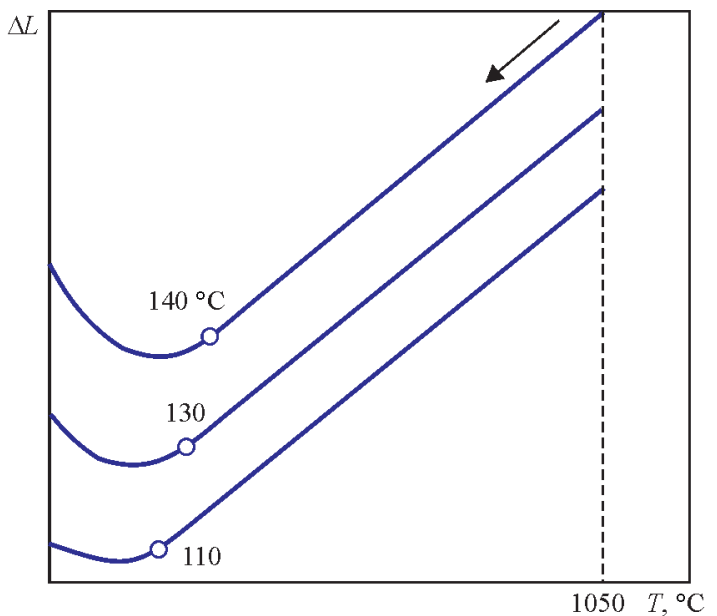

Figure 2. Dilatometric curves at continuous cooling of deposited metal from high temperatures metal. The investigations carried out in the vacuum differential Chevenar dilatometer, provide insight on the structural sensitivity of the alloy to the subsequent heating and cooling.

As is seen from the dilatometric curve (Figure 3) the phase $\gamma \leftrightarrow \alpha$ transformation occur in the deposited metal. The critical points are expressed quite clearly: $A_{c 1}$ lies at the level of $650{ }^{\circ} \mathrm{C}, A_{c 3}$ is at $850^{\circ} \mathrm{C}$.

During cooling the martensitic transformation with a significant volume effect occurs. It should be noted that structural transformations in the metal, characterized by reduction in volume (the curve is bent downwards), begin a little earlier, approximately at $550{ }^{\circ} \mathrm{C}$. At these temperatures the precipitation of fine-dispersed chromium, molybdenum and vanadium carbides from supersaturated austenite begins.

The abovementioned is confirmed by dilatograms of tempering at these temperatures (Figure 4), indicating a significant volume effect of additional martensite transformation, which occurs in the alloy due to depletion of austenite with the alloying elements and reduction of its resistance to decay. The HRC hardness of the deposited metal at the same time increases from 43-44 to 52-53 (Figure 5). Its maximum value is achieved at the tempering temperature of $650{ }^{\circ} \mathrm{C}$. Also at the same temperature the maximum decay of austenite is observed. The increase in duration of ex-

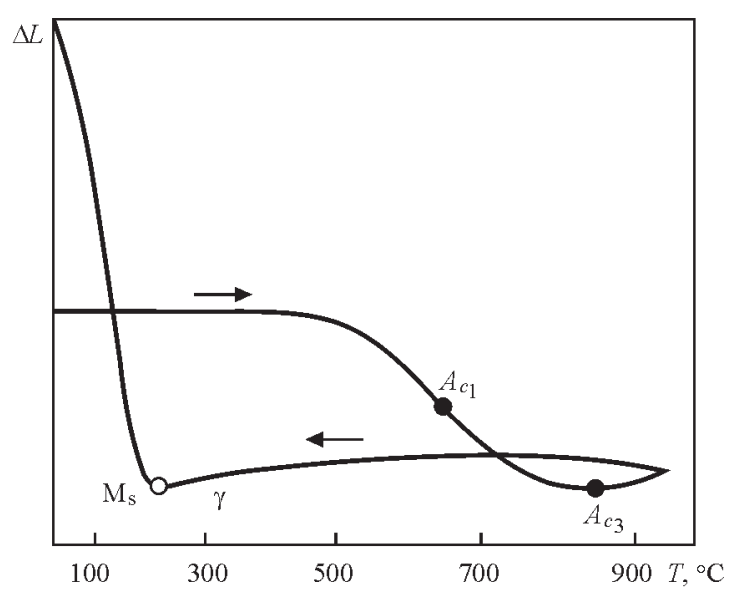

Figure 3. Dilatometric curve at continuous heating and cooling of deposited metal at $150-170{ }^{\circ} \mathrm{C}$ 


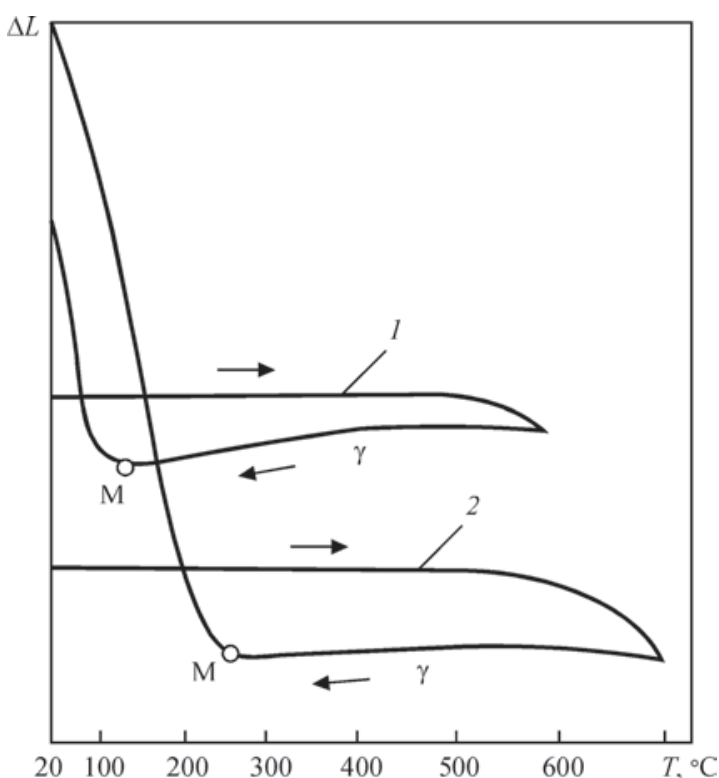

Figure 4. Dilatometric curves of tempering of deposited metal: $1-600^{\circ} \mathrm{C}, 1 \mathrm{~h} ; 2-700{ }^{\circ} \mathrm{C}, 1 \mathrm{~h}$

posure does not cause a noticeable increment in hardness since the most intensive precipitation of carbides is apparently occurs at the initial period.

After tempering at $700{ }^{\circ} \mathrm{C}$, due to a greater depletion of austenite, the volume effect of martensite transformation is expressed more clearly (see Figure 4 , curve 2), although the hardness of deposited metal the is somewhat lower (see Figure 5). Here the reduction in hardness, as compared to tempering at $650{ }^{\circ} \mathrm{C}$, occurs apparently due to decomposition of the initial martensite and carbides coagulation.

The precipitation of dispersed carbides at tempering of the alloy was managed to be revealed by SEM investigations. In Figure 6 the typical places of precipitation of these carbides are shown. They are originated both in the grains of solid solution, as well as in eutectic colonies, apparently in those places where the most favorable thermodynamic conditions for their formation exist, like dislocations in martensite, phase boundaries, etc.

Service properties of deposited metal. Taking into account structural sensitivity of deposited metal to heat treatment, let us consider the influence of tempering on its wear resistance and mechanical properties.

Wear resistance. The tests were carried out in laboratory installation NK-M [8]. A fine-dispersed quartz sand with grain size of $\leq 80 \mu \mathrm{m}$ served as abrasive. As a reference the specimens of annealed steel 45 were used.

As is seen from Figure 5, at first the wear resistance of deposited metal grows to $400{ }^{\circ} \mathrm{C}$ in the range of tempering temperatures and then slightly decreases. It is connected, first of all, with the influence of tempering on the amount and stability of residual austenite in the alloy, which plays a large role in wear processes $[9,10]$. The positive role of metastable austenite con-

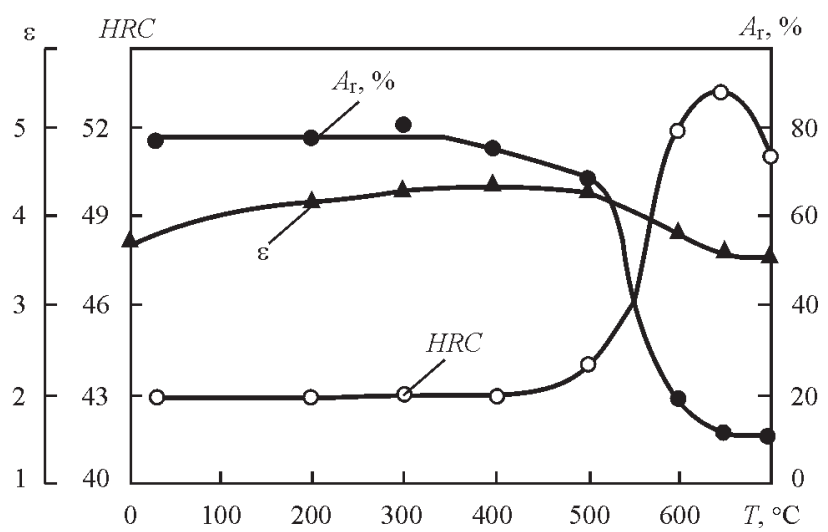

Figure 5. Influence of tempering temperature on hardness $H R C$, wear resistance $\varepsilon$ and amount of residual austenite $A_{\mathrm{r}}$ sists in the fact that not only properly itself is a good resistant to abrasive wear, but also firmly preserves the fine vanadium carbides against spalling during friction due to formation of martensite deformation in the surface layer. After low and medium tempering the total amount of residual austenite is still retained, but as a result of diffusion redistribution of carbon its stability decreases and more favorable conditions for formation of deformation martensite are created, by which the observed increase in wear resistance may be explained.

High tempering, especially at $650{ }^{\circ} \mathrm{C}$, causing decay of residual austenite, causes a somewhat reduction of wear resistance of the alloy as compared to medium tempering, though the hardness in this case is much higher.

The additional wear resistance of the deposited metal is given by nitration, which, as a rule, is applied to protect the rest part of the screw conveyor from wear in manufacture of new parts. Due to high alloying of the metal, a nitrated layer is produced not deep (up to $0.05 \mathrm{~mm}$ ), but very hard (HV25-1288 (Figure 7)). Due to this, the wear process of the deposited metal, especially at the initial stage, is significantly delayed.

Figure 8 shows the results of comparative tests in the same conditions of the considered alloy and some typical representatives of wear-resistant Ni-, Co-, Fe-

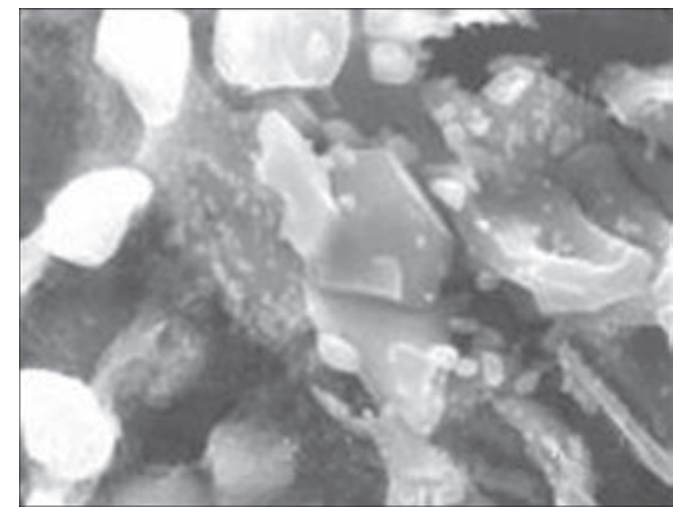

Figure 6. Precipitation of thin-dispersed carbides in the alloy after tempering at $650{ }^{\circ} \mathrm{C}$ for $1 \mathrm{~h}$ 


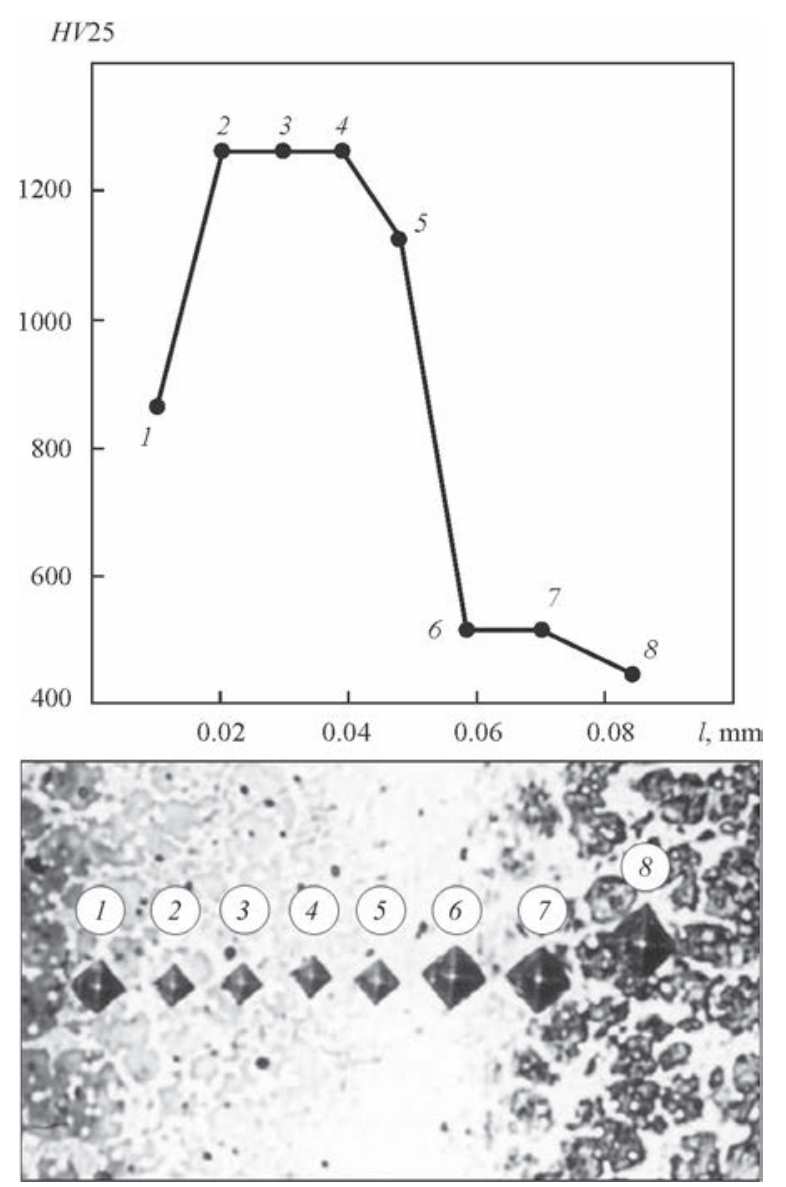

Figure 7. Distribution of hardness in nitrated layer of deposited metal

based alloys. The chemical composition of the tested alloys is given in Table 1 .

As is seen from Figure 8, the relative wear resistance of the new alloy both in the initial state as well as after tempering with nitration is considerably higher than that of nickel (PG-SR4) and cobalt (Stellite 6) alloys. After nitration, it also becomes higher than that of alloy Sormite 1.

Coefficient of linear expansion. CLE is an important characteristic for evaluation of operability of deposited product under the conditions of elevated temperatures. The closer are the CLE values of the deposited and base metals, the lower the level of residual stresses, the lower deformation of the deposited part and, finally, the better operating conditions of bimetallic part.

The results of measuring the CLE of the considered alloy at different temperatures are given in Table 2. For comparison, the data for steel $40 \mathrm{KhN}$ used

Table 1. Chemical composition and hardness of alloys tested

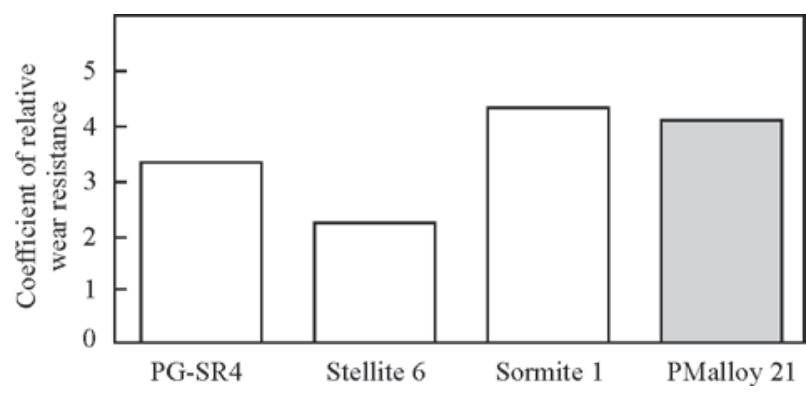

Figure 8. Relative wear resistance of tested commercial alloys as the base metal for manufacture of the screw conveyors were also given.

As can be seen from the Table, CLE of the alloy in as-surfaced state and after heat treatment are significantly different, which is connected with a large difference in the amount of residual austenite. Before heat treatment, it is significantly higher. After tempering at $600{ }^{\circ} \mathrm{C}$, due to the decay of residual austenite, the CLE becomes lower than that of steel $40 \mathrm{KhN}$. During heat treatment of deposited parts it should result in redistribution of residual stresses with the formation of compressive stresses in the deposited layer, which, as is known, favorably affects the operability of parts. From this point of view a high tempering is useful.

During restoration of worn-out parts a high tempering may result in unacceptable deformations caused both by difference in CLEs of the deposited and base metals, as well as volume effect of transformations occurring in the deposited metal during tempering. Therefore, in the given case, a medium tempering should be applied at the temperature of $400^{\circ} \mathrm{C}$, at which structural transformations in the deposited metal are absent.

Experience of industrial application of the alloy. The alloy developed as a powder is used in industry for surfacing screw conveyors by the company «Plasma-Master Ltd» predominantly in Ukraine. For more than 20-year period a wide experience was gained on surfacing and service of deposited parts both in processing of simple as well as filled polymers. At the present time the alloy is produced under trademark PMalloy 21.

In practice, the screw conveyors of casting and extrusion equipment of diameter from 32 to $250 \mathrm{~mm}$ and length from 600 to $5000 \mathrm{~mm}$ are surfaced. Powder PMalloy 21 provides a good formation of deposited metal (Figure 9) and a complete absence of cracks in it, even on very massive parts, at a correct selection of surfacing modes. This important technological advan-

\begin{tabular}{|c|c|c|c|c|c|c|c|c|c|c|c|c|}
\hline \multirow{2}{*}{ Grade of powder (alloy) } & \multicolumn{11}{|c|}{ Content of elements, wt. $\%$} & \multirow{2}{*}{$\begin{array}{c}\text { Hardness } \\
\text { HRC }\end{array}$} \\
\hline & $\mathrm{C}$ & $\mathrm{Si}$ & $\mathrm{Mn}$ & B & $\mathrm{Cr}$ & $\mathrm{V}$ & $\mathrm{W}$ & Mo & $\mathrm{Ni}$ & Co & $\mathrm{Fe}$ & \\
\hline PG-SR4 (Kh15N75S4R4) & 0.7 & 3.9 & - & 3.2 & 15.8 & - & - & - & Res. & - & $\leq 3$ & 58 \\
\hline PG-10K-02 (Stellite 6) & 1.1 & 2.1 & - & - & 28.1 & - & 4.4 & - & - & Res. & - & 42 \\
\hline PG-S1 (Sormite 1) & 2.7 & 2.9 & 2.7 & - & 28.6 & - & - & - & 4.3 & - & Res. & 46 \\
\hline PR-Kh18FNM (PMalloy 21) & 2.2 & 0.8 & 0.9 & - & 18.2 & 7.2 & - & 2.2 & 2.6 & - & Res. & 43 \\
\hline
\end{tabular}


Table 2. Comparison of coefficients of linear expansion depending on heating temperature

\begin{tabular}{|c|c|c|c|c|c|c|c|c|}
\hline \multirow{2}{*}{ Material } & \multirow{2}{*}{ State of alloy } & \multicolumn{7}{c|}{ CLE in the temperature range from $20^{\circ} \mathrm{C}$ to } \\
\cline { 3 - 9 } & After surfacing & 100 & 200 & 300 & 400 & 500 & 600 & 700 \\
\hline $\begin{array}{c}\text { Alloy PR-Kh18FNM } \\
\text { (PMalloy21) }\end{array}$ & After tempering $\left(600^{\circ} \mathrm{C}, 1 \mathrm{~h}\right)$ & 10.5 & 13.6 & 14.0 & 14.1 & 14.7 & 15.0 & - \\
\hline Steel $40 \mathrm{KhN}$ & Initial & 11.8 & 10.7 & 10.8 & 11.0 & 11.5 & 11.8 & 11.2 \\
\hline
\end{tabular}

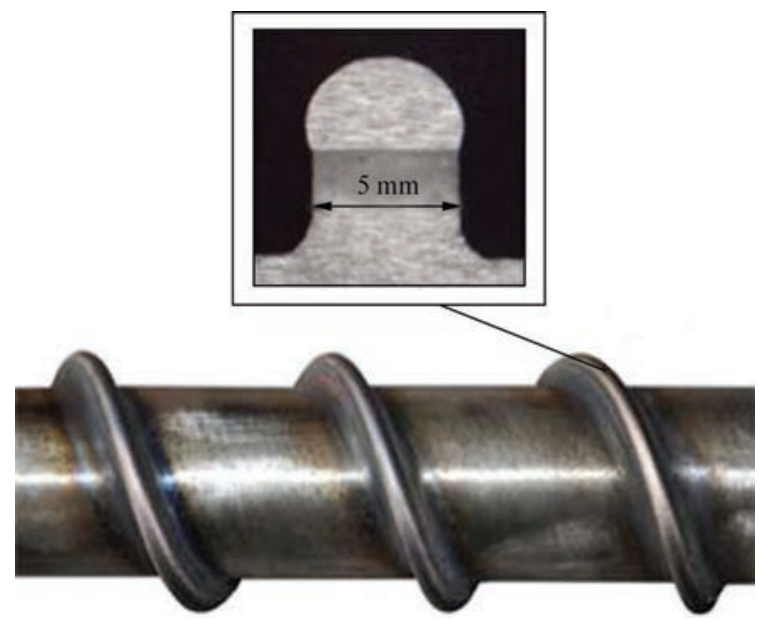

Figure 9. Appearance and macrosection of coil of deposited screw conveyor of $63 \mathrm{~mm}$ diameter

tage of the given alloy allows refusing from pre-heating of the workpiece and, thus, significant simplifying and cheapening the process of surfacing. The powder can be successfully applied both in manufacture of new screws as well as in restoration of worn-out parts. In the latter case, due to a good formation of deposited metal the machining is reduced only to the finish grinding of coil comb in the diameter.

As compared to the nitrated screws the resistance of the deposited ones grew in 3-5 times depending on the type of the processed materials. In Figure 10 the appearance of two screw conveyors of injection molding machine «Kuasy» is shown after service under the same conditions during processing of filled polyamide 6.6.

The photos convincingly prove the advantage of screws, deposited using alloy PMalloy 21. In the first case, the wear of coils is so great that almost nothing left from them, and in the second case they were preserved completely. Despite of some wear of the side surfaces of coils and dents, the screw remains suitable for the further operation and is able to provide a rated efficiency of processing polymers.

At the present time alloy PMalloy 21 is successfully used also for surfacing of other parts like blades of mills for processing of secondary polymers, plungers of hydraulic systems, axles, shafts, etc.

\section{Conclusion}

The complex investigations of structure and properties of developed alloy PMalloy 21 and a long experience of operation of deposited screw conveyors

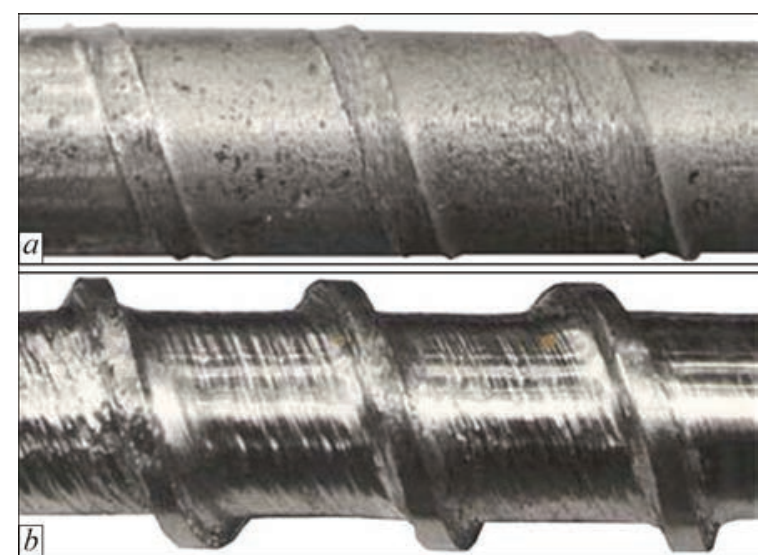

Figure 10. Appearance of screw conveyors of $45 \mathrm{~mm}$ diameter after service during processing of polyamide: $a$ - nitrated screw without surfacing; $b$ - screw deposited using alloy PMalloy 21 with subsequent nitration

convincingly show that the given alloy according to its operability can successfully replace the Ni- and Co-based alloys, traditionally used in industry for surfacing these parts. It is more wear resistant, more technological and considerably cheaper.

1. Maksimchuk, A.M., Mesyats, G.A., Nechiporenko, V.G. et al. (1973) Manufacturing of new and plasma surfacing repair of worn extruder worms. Khimich. i Neft. Mashinostroenie, 8, 22-23.

2. Luelsdorf, P. (1975) Verschleissprobleme mit Zylinder und Schnecke beim Extrudieren. Reilloy-Bericht., 4, 1-8.

3. (1977) Plasma arc weld surfacing - new route to hardfacing screws. Plastics Techn., 23(10), 17-19.

4. Gorka, J., Czuprynski, A., Kik, T. et al. (2011) Przemyslowe aplikacje napawania plazmowego proszkowego. Przeglad Spawalnictwa, 9, 87-94.

5. Gladky, P.V., Pereplyotchikov, E.F., Ryabtsev, I.A. (2007) Plasma surfacing. Kiev: Ekotekhnologiya.

6. Frumin, I.I., Som, A.I., Gladky, P.V. (1981) Plasma surfacing of extruder worms of polymer machines. In: Theoretical and technological principles of surfacing. Surfacing in machine-building and repair: Transact., 13-21. Kiev: PWI.

7. Som, A.I. (1983) New wear-resistant alloy for plasma surfacing. In: Theoretical and technological principles of surfacing. Surfacing consumables: Transact., 7-11. Kiev: PWI.

8. Yuzvenko, Yu.A., Gavrish, V.A., Marienko, V.Yu. (1979) Laboratory units for evaluation of wear resistance of deposited metal. In: Theoretical and technological principles of surfacing. Properties and tests of deposited metal: Transact., 23-27. Kiev: PWI.

9. Poznyak, L.A., Skripchenko, Yu.M., Timaev, S.I. (1980) Die steels. Moscow: Metallurgiya.

10. Popov, V.S., Titukh, Yu.I. (1975) X-ray structural examination of transformations in work surface of alloys under abrasive wear. MiTOM, 1, 24-27. 


\title{
TECHNOLOGICAL CAPABILITIES OF VIBRATION TREATMENT OF WELDED STRUCTURES (REVIEW)
}

\author{
G.I. LASHCHENKO \\ E.O. Paton Electric Welding Institute, NASU \\ 11 Kazimir Malevich Str., 03680, Kiev, Ukraine. E-mail: office@paton.kiev.ua
}

\begin{abstract}
Analysis of technological capabilities of postweld vibration treatment and vibration treatment during welding was performed on the basis of available publications. It is shown that the technology of postweld vibration treatment is an effective means of lowering residual stresses and increasing dimensional stability of beam, frame and casing structures (machine-tool construction, mechanical engineering, shipbuilding, etc.) made of steel, titanium and aluminium alloys. Compared to high tempering, power consumption is reduced tens of times and productivity is increased. Vibration treatment during welding and surfacing is an effective means of lowering residual stresses, increasing mechanical properties and performance of structures, and improving weldability of a number of steel grades. However, experience of industrial application of this technology is so far insufficient for formulating clear recommendations on specific fields of its application. 41 Ref., 3 Figures.
\end{abstract}

Keywords : welded structures, residual stresses, vibration treatment, dimensional instability, increased fatigue resistance, weldability

Residual welding stresses are an undesirable concomitant factor in welded joint formation. They, as a rule, have a negative influence on accuracy, corrosion resistance, endurance at dynamic loads and operational reliability of welded structures [1]. It is not always possible to sufficiently minimize their negative influence on the welded structure using pre-welding measures, as well as those performed during welding. Therefore, postweld heat treatment is used in a number of cases, which usually consists in thermal tempering of welded structures.

At the same time, known are a number of technologies, which allow reducing power consumption for postweld treatment of welded structures due to application of peening, ultrasonic impact treatment (high-frequency mechanical peening), shot peening, explosion treatment, static loading, vibration treatment, etc. [2]. All of them have their advantages, disadvantages and rational fields of application.

The objective of this work is analysis of technological capabilities of vibration treatment and substantiation of possible fields of its industrial application.

Postweld vibration treatment. Postweld vibration treatment is performed by excitation of low-frequency mechanical oscillations in the welded structure. Alternating stresses develop here, which are summed up with residual welding stresses. Microplastic and, under certain conditions, also macroplastic deformations proceed, which promote redistribution and lowering of residual stresses.

(c) G.I. LASHCHENKO, 2016
Vibration treatment is performed in the mode of non-resonant and resonant loading. Treatment at non-resonant frequencies has limited application, and is usually suitable for low rigidity structures.

In the case of resonant vibration loading, development of high amplitudes of dynamic stresses is ensured in the metal structure, that has a significant influence on redistribution of stresses in the entire volume of the material.

Starting from 1960 up to 1990, investigations of the process of vibration treatment and its industrial application have been intensively pursued in the USSR, USA, Great Britain, Poland, China and other countries. The main results of the performed work are summarized in a number of publications [3-10]. In 2000, the interest to postweld vibration treatment also remained quite noticeable [11-22].

Known are various technological schemes of postweld vibration treatment of metal structures $[8,10]$.

The most common scheme of vibration treatment envisages mounting the welded structure on anti-vibration supports and fastening a vibration exciter with adjustable frequency to it. Resonant frequencies of welded structure-fixture-exciter system are registered by a smooth variation of vibration frequency from minimal to maximal values. Then vibration treatment is performed on selected resonant frequencies.

Control of the mode of vibration treatment by this and similar schemes with unbalance exciter is performed by energy (by the value of energy, transmitted to the structure), amplitude (by resonance peak shift) 
and phase (by the change of phase shift between the driving force and forced vibrations) methods.

Composition of a modern technological complex for vibration treatment includes vibration exciter with AC motor accelerometer, measuring amplifier, rectifier, inverter, indicators of motor current frequency and amplitude of item vibrations, recorder or PC $[10,12,16]$.

Development of vibration treatment technology necessitates preliminary determination of natural frequency of structure vibrations.

For simple beam-type structures with constant longitudinal rigidity, natural frequency of vibrations $\omega$ can be determined with sufficient accuracy from the following formula [16]:

$$
\omega=\frac{\pi^{2} n^{2}}{l^{2}} \sqrt{\frac{E I_{x}}{m_{0}}},
$$

where $n$ is the number of natural vibration form; $l$ is the spacing of anti-vibration supports; $E I_{x}$ is the bending stiffness of the beam in the longitudinal direction; $m_{0}$ is the mass per a unit length of the beam.

It is known that the number of natural vibration form determines the number of half-waves of beam elastic axis at its vibrations.

At transition to a higher resonant frequency, the number of half-waves along beam length becomes greater, and sections developing maximum normal stresses, caused by vibration loading, are located closer to each other.

Simple analytical dependencies cannot be used at determination of resonant frequencies and natural vibration forms for complex structures of variable rigidity. It is recommended to perform such calculations by numerical methods, in particular, by finite element method. So, in [16], ANSYS software package was used for these purposes. It allows determination of natural frequencies of the model and studying its behaviour under the impact of harmonically alternating loads.

Magnetically anisotropic scanner-flaw detector «Kompleks-2» was used, when optimizing the technology of monitoring the change of residual stresses after vibration treatment. The instrument generates maps of the difference of principal mechanical stresses, concentrators of local mechanical stresses, as well as the coefficient of stress distribution non-uniformity [16].

So-called structural vibration is also used for stabilization of geometrical parameters of metal-cutting equipment. In this case, vibration loading of base parts of machine tools is performed through technological modes of plank cutting. In [22], a procedure was proposed for determination of dynamic load for vibration treatment of bed plates by this method.

To eliminate residual deformations of welded structures, it is proposed to apply a combined loading in the form of static tension or bending in combination with vibration treatment $[5,10]$. These technologies did not become extensively applied in industry. Many years of practical experience showed that postweld vibration treatment is an effective means of improving the dimensional stability of welded structures [3-12]. In practice, dimensional instability of items, in particular welded structures, is the result of relaxation processes and creep, running in the material and the welded joint under the impact of applied structural (operational) and residual inner stresses [6]. Relaxation processes develop particularly intensively in alloys with metastable phase and structural state (in steels this is transformation of residual austenite into martensite and tempering of quenching martensite).

Dimensional instability of welded structures is affected by a number of design-technological factors: base material, structural rigidity of the joint, thermodeformational cycle, applied welding consumables.

In production, instability of structural dimensions of welded structures can be manifested at the stage of machining, during maturing, at the change of temperature conditions, as well as in operation under the impact of service load. Therefore, stabilizing vibration treatment is usually performed prior to machining, or 2 times - before rough and before finish machining.

Vibration treatment of steel metal structures from carbon and low-alloyed steels allows reducing stresses of the first kind to $50-60 \%$ and those of the second kind - to $45 \%$.

In the case of treatment of structures from titanium alloys, stresses of the first kind decrease to $60-65 \%$, and in aluminium ones - to $70-75 \%[4,10,11]$.

Stabilizing vibration treatment is extensively used in machine-tool construction in production of welded and cast base parts (bases, bed frames, traverses, etc.), in shipbuilding (submarine hulls from titanium alloys. hull steel and aluminium parts of ships, etc.), in power, transportation and others engineering sectors, including manufacture of defense equipment [8-12].

Power consumption at postweld treatment of metal structures of up to $10 \mathrm{t}$ weight and more is approximately 50 times lower than that at general tempering, while productivity is 15-20 times higher [10].

As regards application of postweld vibration treatment to increase corrosion resistance of welded joints, we can refer to information given in [13, 14]. It is evidently insufficient for determination of rational fields of application of postweld treatment for these purposes. Additional research is required.

Speaking about applicability of vibration treatment to improve welded joint fatigue resistance, some studies have suggested that even a lowering of cyclic fatigue life can be anticipated as a result of accumu- 


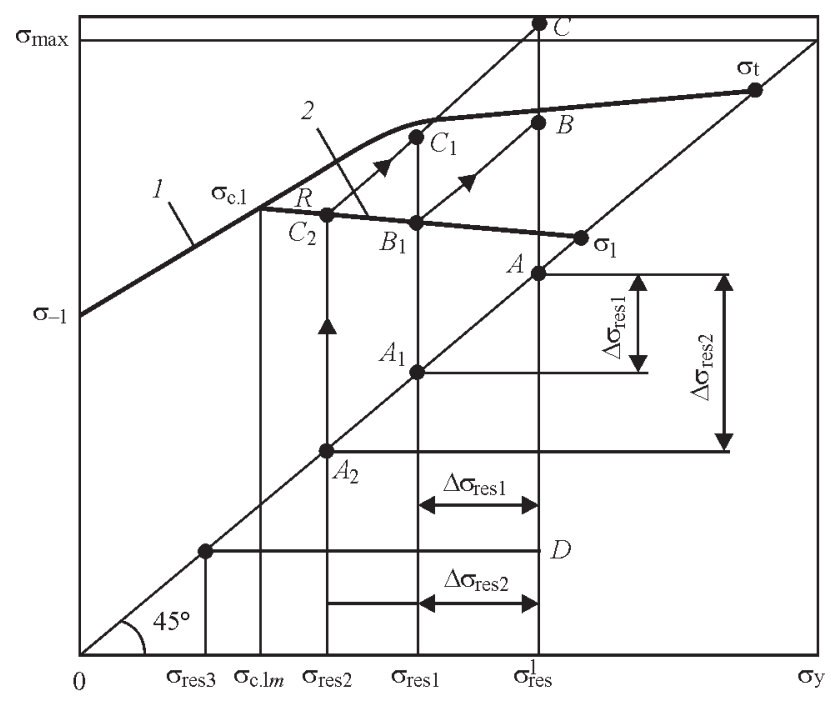

Figure 1. Assigning non-damaging modes of vibration treatment of metal structures to lower residual tensile stresses in them by a value not lower than the specified one [15] (for designations see the text)

lation of fatigue damage during treatment $[1,7]$. Obtained result largely depends on overloading stresses and treatment duration. Therefore, to avoid possible initiation of fatigue cracks at the technological stage, a procedure was developed for determination of non-damaging modes of vibration treatment of welded joints, providing lowering of residual stresses by the specified value [15].

This procedure is based on application of a complex program of limit cycle stresses, plotted in the coordinates of maximum stress $\sigma_{\max }$-mean stresses $\sigma_{y}$ (Figure 1). Line 1 corresponds to endurance limit $\sigma_{R}$ of welded joint (structure) and is limited by endurance limit at symmetrical loading $\sigma_{-1}$ and ultimate strength $\sigma_{t}$, and line 2 - by the cyclic creep limit of structure material $\sigma_{\text {c.c. } .}$. The latter is limited by creep limit under static loading $\sigma_{c}$ (yield limit $\sigma_{\mathrm{y}}$ is allowed), and endurance limit, called minimum cyclic creep limit $\sigma_{c c}$, at which the specified value of plastic deformation $\varepsilon_{\mathrm{pl}}$ is achieved. In development of vibration treatment technology the curve of residual stresses (RS) in a certain zone of welded structure is first determined experimentally, and maximum value of tensile RS $\sigma_{\text {res }}^{l}$ is plotted in the diagram (p·A). Value of stress $\sigma_{\text {res } 1}^{\text {res }}(\mathrm{p} \cdot \mathrm{A})$, to which $\sigma_{\text {res }}^{1}$ should be reduced, is assigned. For correct selection of the load, which would allow reducing RS by a value not less that $\Delta \sigma_{\text {resi }}$, it is necessary for line 2 to correspond to plastic deformation $\varepsilon_{\mathrm{pl}}$, determined from condition $\Delta \sigma_{\text {res } 1}=E \varepsilon_{\mathrm{pl}}$. Stress from external load $\sigma_{\text {ex.l. }}$, which should be applied to the structure, is determined from the following condition:

$$
\sigma_{\text {c.lR }}<\sigma_{\text {ex.l }}+\sigma_{\text {res }}^{1}<\sigma_{R},
$$

where $\sigma_{R}, \sigma_{c . l R}$ are the stresses, corresponding to the points of intersection of cyclic stress impact with lim- it stress lines 1 and 2, respectively. Thus, condition $\sigma_{\text {ex.l }}+\sigma_{\text {res }}^{1}<\sigma_{R}$ ensures absence of fatigue damage after vibration treatment, and $\sigma_{\text {c.lR }}<\sigma_{\text {ex.l }}+\sigma_{\text {res }}^{1}-$ an effective lowering of RS.

The diagram allows analyzing multistep application of vibration load to lower residual stresses by value $\Delta \sigma_{\text {res1 } 1}, \Delta \sigma_{\text {res2 } 2}, \Delta \sigma_{\text {res3 }}$ and the thus achieved lowering of residual stresses $\sigma_{\text {res1 } 1}, \sigma_{\text {res2 }}$ or $\sigma_{\text {res3 } 3}$. In the latter case, it is recommended to apply asymmetrical load: $\sigma_{m}=A D, \sigma_{\mathrm{a}}=A B$, for lowering initial residual stresses $\sigma_{\text {res3 }}$, which are lower than the mean stress of minimum cyclic creep limit $\sigma_{\text {c.lm }}$. If the condition of RS lowering by a value not smaller than the assigned one is not specified, loading modes can be selected arbitrarily, while following condition (2).

Proceeding from application of the above procedure in [15], we came to the conclusion that vibration treatment can be applied to extend the fatigue life of only non-critical structures.

Vibration loading during welding. Technologies using vibration loading during welding have attracted greater attention over the recent years [23-30]. Positive influence of low-frequency mechanical vibration of the item being welded on lowering of residual stresses and strains, increase of weld resistance to formation of solidification cracks and pores, improvement of mechanical properties is noted in a number of studies conducted already in 1980s [31]. Vibration treatment was regarded as one of the methods, designed to influence the processes running in the welding arc, in liquid and solidifying metal of the weld pool, and adjacent base metal region, with the purpose of integrated improvement of welded joint properties. In this period, respective practical results were obtained, which have found partial application in industry.

In recently published work [23], the influence of vibration during welding on cold resistance of welded joints $10 \mathrm{~mm}$ thick from low-alloyed steel 09G2S was studied. Two-sided submerged-arc welding was performed, and vibration loading was applied by a schematic, given in Figure 2, at the frequency of 50, 100, 150 and $200 \mathrm{~Hz}$ with 0.8-1.0 mm amplitude.

Excitation of low-frequency vibrations in molten metal of weld pool and in adjacent zones, leads to reduction of mean area of grains in different sections of welded joints. Here, maximum reduction of mean area of grains of HAZ and weld metal is achieved by concomitant vibration impact of $150 \mathrm{~Hz}$ and is equal to $32 \%$ for HAZ metal and $25 \%$ for welds, compared to untreated samples. Surface stresses were also decreased to a maximum at the same vibration frequency, which were determined by X-ray structural analysis (Figure 3). 
It is noted that with increase of frequency of concomitant vibration impact an increase of impact toughness $K C V$ of welded joint metal takes place. Here, maximum increase, compared to untreated samples, was achieved at the frequency of $150 \mathrm{~Hz}$ and was equal to $24 \%$ for samples, tested at $20{ }^{\circ} \mathrm{C}$, and $50 \%$ for samples tested at $-40{ }^{\circ} \mathrm{C}$.

The authors believe that the considered welding technology can be used in fabrication of metal structures with extended welds, operating under the conditions of considerable gradient of ambient temperatures.

Work [24] is a study of applicability of vibration treatment instead of preheating in welding of petroleum processing equipment parts from $12 \mathrm{MKh}$ steel. Samples were welded by manual arc welding with TsU-2MKh electrodes. It is found that in welding with vibration loading (50, 100 and $150 \mathrm{~Hz}$ frequency, 0.8 mm amplitude) weld metal structure has higher dispersion and uniformity. A bainitic structure forms in the HAZ metal. Level of residual welding stresses decreases by $16-19 \%$, compared to preheating. Mechanical properties of weld metal and near-weld zone are improved. For welding critical structures from $12 \mathrm{MKh}$ steel, it is recommended to use two vibration devices, operating in anti-phase [20, 21]. A process was patented of lowering RS in welded joints, according to which application of vibrations is performed during welding in the transverse direction in the vertical plane, normal to weld axis, from two exciters operating in anti-phase at frequencies from 50 up to $300 \mathrm{~Hz}$ with up to $0.8-1.0 \mathrm{~mm}$ amplitude and located symmetrically relative to weld axis on each of the edges being welded (see Figure 3) [26].

Another patent [27] describes the process of reducing RS in welded joints of pipelines, according to which application of low-frequency vibrations by vibration devices is performed during welding. Vibration frequency is equal to that of natural vibrations of pipeline section with welded joint between rigid fastening points.

Investigations were conducted to establish the impact of vibrations on the weld pool and the adjacent zone during welding cycle, in order to study their influence on strength properties of weld metal and susceptibility to intercrystalline corrosion (ICC) of joints from 12Kh18N10T steel [28]. Vibration loading was performed at the frequency of 50 and $100 \mathrm{~Hz}$ with 0.6-0.8 mm amplitude.

Test results showed that samples welded without vibration treatment turned out to be susceptible to ICC. Samples produced with application of vibration treatment, demonstrated resistance to ICC without cracking in bending. The authors attribute it to re-

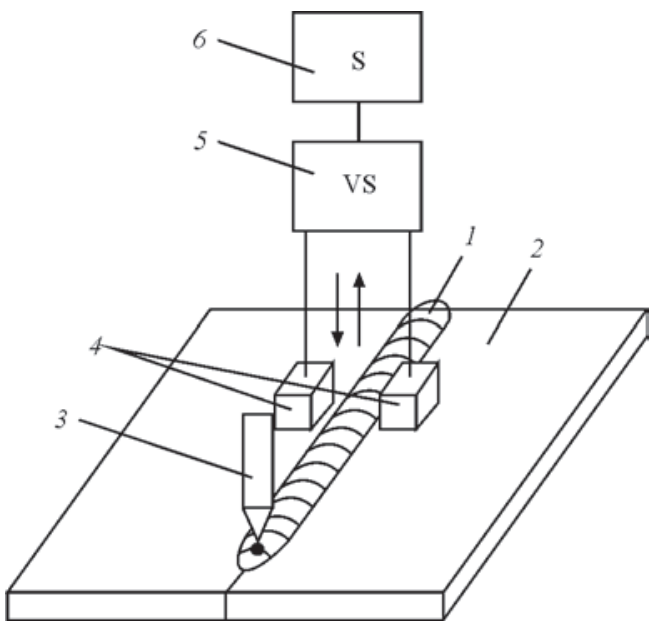

Figure 2. Schematic of vibration application during welding: 1 - weld; 2 - item being welded; 3 - electrode; 4 - vibration device; 5 - vibration synchronizer; 6 - vibration energy source [23]

finement of weld metal dendritic structure, leading to extension of grain boundaries that results in loading of continuous carbide network and reduction of the amount of carbides per a unit of grain boundary length.

Vibration treatment at $50 \mathrm{~Hz}$ frequency increases the value of weld metal impact toughness by $21 \%$, and treatment at $100 \mathrm{~Hz}$ - by $25 \%$.

Lowering of RS at vibration loading during welding (50 and $100 \mathrm{~Hz}$ ) results in increase of fatigue fracture resistance of welded joints from 12Kh18N10T steel by $18-22 \%$.

Results similar to those given above were derived by the authors in welding two-layer steel 09G2S + 12Kh18N10T with application of low-frequency vibration treatment [30].

Vibration has a positive influence on formation of structure and properties of castings metal [32]. Under the impact of vibration, the melt is intensively mixed, and growing crystals break off, new solidification centers are created in liquid metal volume, temperature gradient across the section decreases and bulk solidification is ensured. A more uniform crystalline structure of the ingots, which forms under the impact

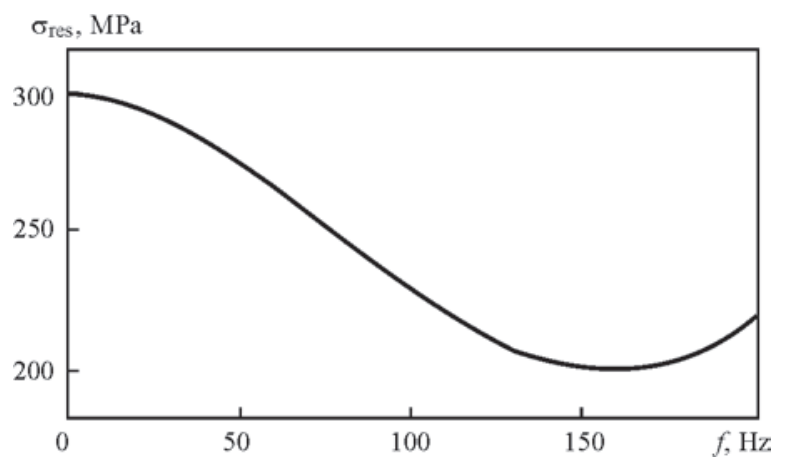

Figure 3. Residual stresses of the $3^{\text {rd }}$ kind versus frequency of concomitant vibration impact [23] 
of vibration, provides lower anisotropy of properties of structural components (individual crystals) and, consequently, smaller RS.

Conducted studies on determination by the method of laser interferometry - electron speckle-interferometry of RS in ingots of Kh18N9T steel showed that residual stresses decrease by $20-29 \%$ under the impact of vibration loading ( $0.5 \mathrm{~mm}$ amplitude, 60 $80 \mathrm{~Hz}$ frequency) [30]. In the same work the authors give experimental data on lowering of RS by up to 2.5 times under the impact of vibration in welding of samples from St.3 steel. It is emphasized that low-frequency vibration (up to $200 \mathrm{~Hz}$ frequency, up to $1 \mathrm{~mm}$ amplitude) leads to refinement of weld metal structure and to considerable reduction of the quantity of pores. More over, vibration has a positive influence on dispersion of nonmetallic inclusions, their quantity and nature of distribution in the weld.

The possibility of refining the structure and improving the deposited metal properties in induction surfacing is reported in several publications [33-36]. In this case the part is subjected to vertical or horizontal vibration at the moment, when powder-like charge is in the molten state. Direction of vibrations application, as well as their frequency and amplitude, are essential.

Experiments on induction surfacing with powders from high-carbon alloy PG-S (grade 1) with vibration amplitude of $0.2 \mathrm{~mm}$ and $50 \mathrm{~Hz}$ frequency showed that horizontal vibration leads to a noticeable refinement of the carbide component [33]. Carbides, having the form of a hexagon with average long side of 10-12 $\mu \mathrm{m}$ (in the case of surfacing without vibration), are refined to $7-10 \mu \mathrm{m}$ at vertical and to $3.5-7.0 \mu \mathrm{m}$ at horizontal vibration. Here, the highest hardness and wear resistance were demonstrated by samples, surfaced with horizontal vibration. The authors attribute it to favourable structure of deposited metal and formation of a greater quantity of carbides $(\mathrm{Fe}, \mathrm{Cr})_{7} \mathrm{C}_{3}$ that is confirmed by the results of microprobe analysis.

Works [37-39] report an improvement of weldability of 20KhGSFL, 15Kh5M and 12Kh17 steels under the impact of vibrations during arc welding. This is also confirmed by the data given in [31].

It is known that in welding steels with a high carbon equivalent, particularly high-strength steels, there arises the risk of cold cracking [40]. These cracks most often initiate in hear-weld zone. A mandatory condition for cold crack initiation and propagation is presence of quenching structures, a certain quantity of diffusible hydrogen and tensile stresses.

According to the above data of [23-25, 31, 37-39] vibration treatment in welding promotes a refinement of weld and HAZ metal structure, while tensile stresses decrease markedly. Moreover, intensive mixing of the weld pool should promote hydrogen desorption. This leads to a suggestion of the rationality of application of concomitant vibration treatment in high-strength steel welding. However, many points require verification. It is known that the thermodeformational cycle of welding leads to a significant inhomogeneity of hydrogen field concentration [41]. In case of concomitant vibration treatment, deformational component of the cycle changes noticeably, that certainly influences redistribution of dislocations and their interaction with hydrogen. Here, dislocations have the role of hydrogen traps and under certain conditions they can both increase and lower the risk of cold cracking.

\section{Conclusions}

Experience of industrial application of postweld vibration treatment gained over the last decades is indicative of this technology being an effective tool for improvement of dimensional stability of steel welded base parts of metal-working equipment (bed plates, pillar bases, etc.), frame and casing parts for power engineering, various parts for shipbuilding and defense engineering, including also those from titanium and aluminium alloys. Here, the extent of lowering of residual stresses of the first kind can reach 50-60\%, while power consumption will decrease by up to 50 times, compared to overall tempering.

Postweld vibration treatment in a specific mode range promotes certain increase of fatigue resistance, and can be used to increase fatigue life of non-critical welded structures. By this parameter it is inferior to other technologies, in particular, to peening.

Numerous publications are indicative of the fact that vibration treatment during welding and surfacing is an effective tool for lowering residual stresses, increasing mechanical and service properties, and improvement of weldability of a number of steel grades. However, experience of industrial application of vibration treatment during welding is so far insufficient to formulate clear recommendations on specific fields of its application.

1. (1993) Welded building structures. Vol. 1: Principles of structure design. Ed. by L.M. Lobanov. Kiev: Naukova Dumka.

2. Lashchenko, G.I., Demchenko, Yu.V. (2008) Energy-saving technologies of postweld treatment of metal structures. Kiev: Ekotekhnologiya.

3. Pisarenko, V.S., Verzhbinskaya, N.I. (1972) Decrease of residual stresses by vibration treatment (Review). Moscow: NII Informtyazhmash.

4. Gruzd, A.A. (1973) Examination of welded structure deformations in time and searching for methods for their accounting and stabilizing. Kiev: PWI.

5. Sagalevich, V.M. (1974) Methods of elimination of welding strains and stresses. Moscow: Mashinostroenie. 
6. Sagalevich, V.M., Saveliev, V.F. (1986) Stability of welded joints and structures. Moscow: Mashinostroenie.

7. Dawson, R., Moffat, D.G. (1980) Vibration stress relief. In: Proc. of ASM on Theor. Principles of Eng. Calculations, 2, $1-9$.

8. Ragulskis, K.M., Stupilnas, B.B., Tolutas, K.B. (1987) Vibration ageing. Leningrad: Mashinostroenie.

9. Sedek, P. (1990) Stabilisacja wibracyjna konstrukcji spawanych. Przeglad Spawalnictwa, 7, 16-18.

10. Lashchenko, G.I. (2001) Vibration treatment of welded structures. Kiev: Ekotekhnologiya.

11. Gorbach, V.D., Sokolov, O.G., Mikhajlov, V.S. (2003) Problems of welding and fatigue life of welded structures in shipbuilding. The Paton Welding J., 10/11, 158-163.

12. Dryga, A.I. (2004) Vibrostabilizing treatment of welded and cast parts in machine-building (theory, studies, technology). Kramatorsk: DGMA.

13. Xhou Wei, Chen Hui (2012) Study of possibility for decrease of stresses in joints from steel SWA490BW resistant to atmosphere corrosion using vibration treatment. Dian Hanji-Elec. Welding Mach., 9, 62-65.

14. Babichev, A.P., Butenko, V.I., Chukarin, A.N. et al. (2014) Improvement of resistance of welded joints. Uprochn. Tekhnologii i Pokrytiya, 6, 3-6.

15. Degtyaryov, V.A. (2013) Effect of strengthening treatment of welded joints on increase of their fatigue resistance. Problemy Prochnosti, 5, 85-103.

16. Grigoriants, A.G., Shiganov, I.N., Misyurov, A.I. et al. (2014) Technologies of low-frequency vibrotreatment of welded joints in machine-building. Svarochn. Proizvodstvo, 6, 19-23.

17. Rao, D., Wang, D., Chen, L. et al. (2007) The effectiveness evaluation of 314L stainless steel vibratory stress relief by dynamic stress. Int. J. Fatigue, 29.

18. Zhao, X.C., Zhang, Y.D., Zhang, H.W. et al. (2008) Simulation of vibration stress relief after welding based on FEM. Acta Metall. Sin., 21(21).

19. Sedek, P., Welzel, M., Kwiecinski, K. (2016) Stabilizazja wibrayjna - staly rozwoj dla praktyki przemyslowej. Biul. Inst. Spawalnictwa, 1, 29-35.

20. Yang, Y.P., Jung, C., Yancey, R. (2005) Finite element modeling of vibration stress relief after welding. In: Proc. of 7th Conf. on Trends in Welding Research (USA, May 16-20, 2005).

21. Klauba, B.B., Adams, C.M., Berry, J.T. (2005) Vibratory stress relief: Methods used to monitor and document effective treatment. A survey of users and directions for further research. Ibid.

22. Filippov, Yu.A., Amelchenko, N.A., Ruchkin, L.V. et al. (2002) Theoretical aspects of ageing vibrotechnologies of non-standard equipment welded bodies. Tekhnologiya Mashinostroeniya, 4, 33-35.

23. Karetnikov, V.D., Rizvanov, R.G., Fajrushin, A.I. et al. (2014) Increase in reliability of gas-oil equipment operating under conditions of abrupt thermal gradient. Ibid., 4, 33-37.

24. Abdullin, T.Z., Ibragimov, I.G., Fajrushin, A.M. (2013) Study of vibration treatment effect during welding on mechanical properties of welded joints. Svarka i Diagnostika, 1, 36-38.

25. Abdullin, T.Z. (2013) Improvement of technology for production of welding equipment from heat-resistant steel
12MKh: Syn. of Thesis for Cand. of Techn. Sci. Degree. Ufa: UfaGNTU.

26. Fajrushin, A.M., Karetnikov, D.V., Zaritov, M.Z. et al. Method of residual stress relaxation in welded joints of metals. Pat. 2424885 Russia. Publ. 27.07.2011.

27. Bolotov, V.I., Khafizov, O.F., Fajrushin, A.M. et al. Method of residual stress relaxation in welded joints of pipelines. Pat. 2492037 Russia. Publ. 10.09.2013.

28. Akhtyamov, R.M., Ibragimov, I.G., Zaripov, M.Z. et al. (2013) Increase in strength of $12 \mathrm{Kh} 18 \mathrm{~N} 10 \mathrm{~T}$ steel welded joints using low-frequency vibration treatment during welding. Uprochn. Tekhnologii i Pokrytiya, 1, 38-41.

29. Akhtyamov, R.M., Zaripov, M.Z., Fajrushin, A.M. (2012) Increase in strength of welded joints of two-layer 09G2S+12Kh18N10T steel using low-frequency vibration treatment during welding. In: Proc. of 5th Sci.-Pract. Conf. on Engineering and Tekhnology. New Prospects of Development (Moscow, 18 Apr. 2012), 8.

30. Nuradinov, A.S., Efimov, V.A., Taranov, E.D. et al. (2004) Effect of vibration on formation of macro- and microstructure of solidified steel ingots. Materialovedenie, 5, 24-26.

31. Lashchenko, G.I. (2006) Methods of consumable electrode arc welding. Kiev: Ekotekhnologiya.

32. Nuradinov, A.S., Eldarkhanov, A.S., Taranov, E.D. (2012) Effect of vibration on residual stresses in ingots and welds. Stal, 4, 19-20.

33. Pulka, Ch.V., Shably, O.N., Senchishin, V.S. et al. (2012) Influence of vibration of parts on structure and properties of metal in surfacing. The Paton Welding J., 1, 23-25.

34. Shably, O.N., Pulka, Ch.V., Senchishin, V.S. Method of surfacing of thin flat steel parts. Pat. on ut. mod. UA 54204. Int. Cl. B23K 13/00. Publ. 25.10.2010.

35. Pulka, Ch.V., Senchishin, V.S. Device for surfacing of thin shaped discs. Pat. on ut. mod. UA 59994. Int. Cl. B23K 13/00. Publ. 10.06.2011.

36. Pulka, Ch.V., Senchishin, V.S. Method of surfacing of parts. Pat. on ut. mod. UA 64371. Int. Cl. B23K 13/00. Publ. 10.11.2011.

37. Fajzulin, A.V., Madretdinov, A.I., Karetnikov, V.D. (2012) Repair welding of pump body made from medium-alloy steel 20KhGSFL. In: Proc. of 13th Int. Severgeoeko Junior Sci. Conf. (Ukhta, 21-23 March 2012), Pt 6, 70-72.

38. Rizvanov, R.G., Fajrushin, A.M., Karetnikov, D.V. (2013) Study of influence of vibration treatment on mechanical properties and crack resistance of pipe welded joints from heat-resistant steel 15Kh5M. Neftegaz. Delo, 1, 369-382.

39. Khalimov, D.N., Samigushin, V.V., Fajrushin, A.M. (2013) Study of influence of vibration treatment in welding on mechanical properties of steel $12 \mathrm{Kh} 17$ welded joint. In: Proc. of 64th Sci.-Techn. Conf. of Students, Post-Graduates, Young Scientists of UfaGNTU (Ufa, Russia, 2013), Book 1, 234.

40. Lobanov, L.M., Poznyakov, V.D., Makhnenko, O.V. (2013) Formation of cold cracks in welded joints from high-strength steels with 350-850 MPa yield strength. The Paton Welding J., 7, 7-12.

41. Pokhodnya, I.K., Ignatenko, A.V., Paltsevich, A.P. et al. (2013) Hydrogen-induced cold cracks in welded joints of high-strength low-alloyed steels (Review). Ibid., 5, 2-13. 


\title{
CONTROL OF MECHANICAL PROPERTIES OF HIGH-STRENGTH STEELS THROUGH OPTIMIZED WELDING PROCESSES
}

\author{
M. FIEDLER, A. PLOZNER, B. RUTZINGER and W. SCHERLEITNER \\ Fronius International GmbH \\ 1 Froniusplaz, A-4600, Wels, Austria. E-mail: Scherleitner.Wolfgang@fronius.com
}

\begin{abstract}
Time of cooling in the range from 800 to $500{ }^{\circ} \mathrm{C}$ is a crucial factor, which determines the properties of welded joints of high-strength steels significantly. In field welding the cooling time $t_{8 / 5}$ can be steered by the heat input even at different wall thickness of the base materials used. Modern arc processes with reduced heat input allow, at the same deposition rates, increasing the stability of strength level due to optimized equipment settings. This paper compares the influence of conventional GMAW processes, like short-arc, pulsed-arc ones and new launched processes, on properties of the weld. From this point of view practical conclusions and recommendations can be derived to optimize weld properties. 5 Ref., 5 Figures, 5 Tables.
\end{abstract}

Keywords: arc welding, high-strength steels, heat input, weld properties

High-strength steels are used in many areas of the industry to reduce weight and material costs. Typical applications for this kind of steels are mobile cranes, offshore platforms, concrete pumps and pressure pipelines.

The advantage of TMC-processed fine-grain steels is to reach an optimum of strength and toughness. In general high-strength steels are used to reduce the wall thickness, which leads to lower weight and the already mentioned cost savings. Due to the low carbon content the weldability of these steels is good, for sure the manufacturers recommendation on steel and welding consumable should be followed.

The temperature-time gradient during welding and the material chemistry are crucial for the mechanical properties of high-strength steels. The temperature-time gradient is also described as $t_{8 / 5}$ time, and it is the duration of the cooling between 800 and $500{ }^{\circ} \mathrm{C}$. This time is significant responsible for the structure formation in the weld and HAZ.

Parameters, like material thickness, weld shape, bead or layer sequence, preheating temperature and heat input, influence the $t_{8 / 5}$ time. The heat input can be specific controlled by the selection of the welding process. This paper compares GMAW single-wire processes and tandem GMAW processes and their influence on mechanical properties. In particular conventional GMAW processes like short-arc process, modified processes like pulsed GMAW, GMAW PMC (with pulse multi control), LSC (with low spatter control), and tandem GMAW like cold metal transfer processes (CMT Twin and Time-Twin) are surveyed.
Compared welding processes. Short-arc GMAW. The short-arc process has continues wire feeding. Process regulation parameters are arc voltage and welding current. The cycle sequence can be described as follows. The wire is melted by the arc and a drop is formed. At the beginning of the short circuit the drop is contacting the surface of the workpiece. To break up the short circuit and to reignite the arc, a high current is needed. The surface tension of the weld pool and the high current create the so called pinch-effect, which detaches a drop at the wire end. At the peak value of the current the arc is reignited. High short circuit current may create extensive spatter [1].

Pulsed GMAW. This process is proven and known in the industry for many years, electronic-regulated power sources made it possible. The drop detachment is controlled by a material and shielding gas depending on current pulse. A short-circuit-free material transfer allows almost no spatter formation. The function principle is explained like following. A liquid weld pool and a molten welding wire end is caused by the base line current level (ground current phase). Due to each rise of current (current peak), also the current density rises, the Lorentz force will increase and the droplet is moving to the workpiece [2].

GMAW LSC. As already mentioned the short-arc process enables the material transfer with a high current peak, which leads to a possibly higher amount of spatter. High measure and control rates in the welding power source allow the LSC process to lower the current before the short circuit brake up. This stabilizes 


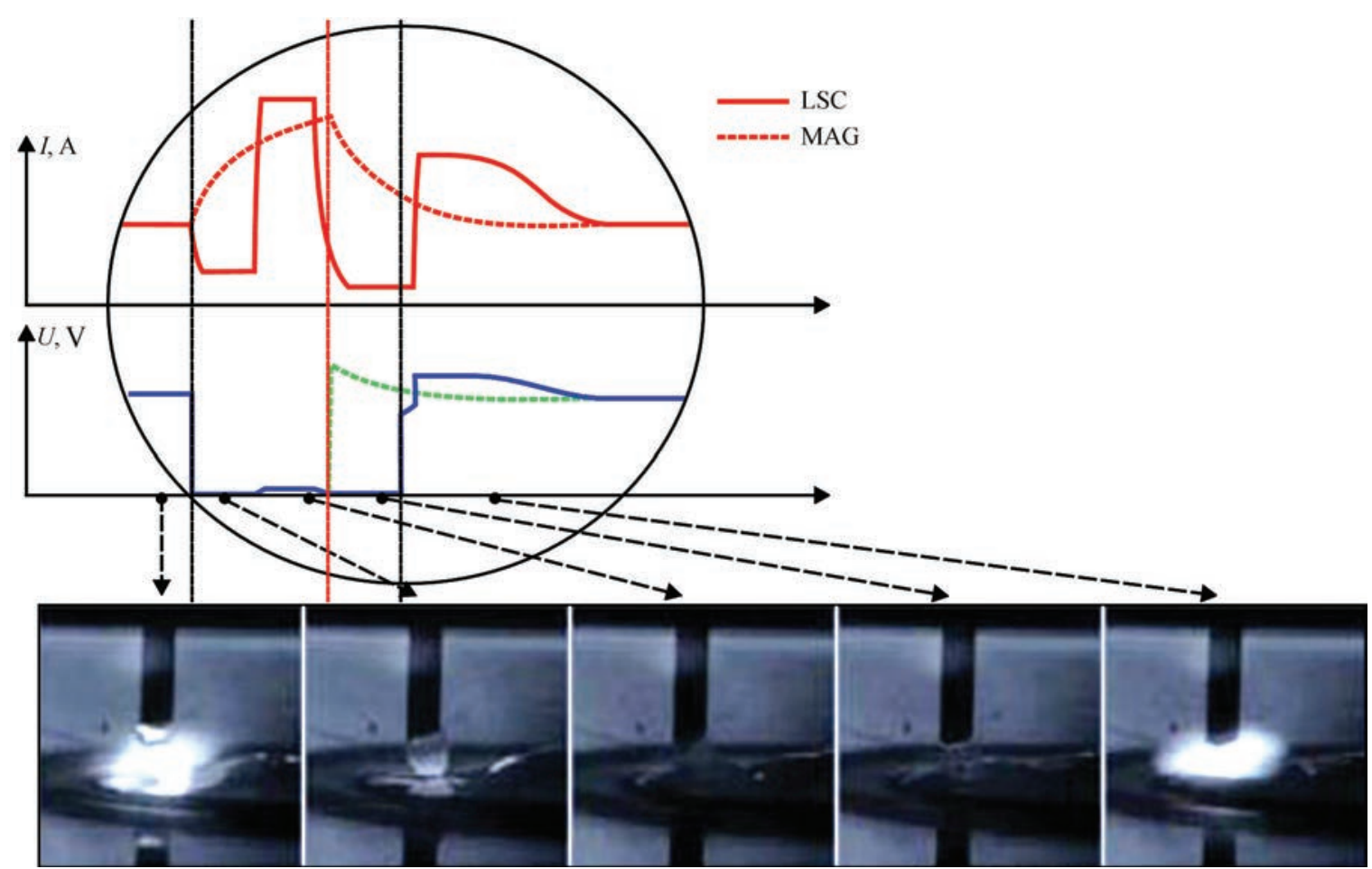

Figure 1. Current and voltage diagram for the LSC process

the welding performance and reduces the spatter to a minimum (Figure 1).

GMAW PMC. Pulse melt control is a further development of the pulsed GMAW process. New functions like penetration and arc length stabilizer, which have been realized by new algorithm, and higher calculation speed are integrated in the welding power source. TPS/i helps to control the arc in an efficient and easier way. Conventional welding machines use a constant wire feed rate. If the stickout of the welding wire is increased and the voltage is kept at the same level, the welding current will be decreased. This results in a reduction of the penetration, and a higher risk for lack of fusion may occurs. The «Penetration stabilizer» helps to detect variations in the stickout length and regulates according to the changes (with adjustment on the wire feed rate). The constant welding current helps to keep the penetration on a constant level over the whole length of the weld (Figure 2). Changes in the geometry of the bead or different welding speeds lead to variation in the arc length. The arc length stabilizer provides with a controlled short circuit during the drop detachment a constant arc length [3].

Tandem GMAW (Time-Twin). Tandem welding (Time-Twin) is performed using two separate welding electrodes, which are molten in one weld pool. Due to the separation of the electrical potentials, different arc combinations can be realized. This enables to regulate welding speed and deposition rate.

GMAW CMT Twin. CMT was basically developed as thin sheet metal joining process for the car indus- try. The main advantage of the CMT process is the low heat input due to the fact that the wire is pulled out of the liquid weld pool with an accordingly lower welding current. CMT Twin method is an upgrade of the tandem process. Similar to the tandem process, CMT Twin operates with two digital controlled power sources, which are completely independent from each other. The system makes a large spread of the wire feed rate possible and allows using two CMT arcs or the different arc combinations. The advantage of CMT Twin method is the arc stability and the reduced heat input.

Metallurgical aspects. New optimized welding processes are created by modified electrical parameters, especially the arc voltage and welding current have a main influence. This effect leads to variation in the heat input per unit length of weld (at constant welding speed) and therefore it influences the mechanical properties. The use of modern welding processes enables an easier handling of the weld pool and a higher arc stability, this results in higher welding speed. All these variation possibilities give a larger process window with regards to heat input and, for this reason, also for the cooling time $t_{8 / 5}$.

Using a modified arc process (at a comparable welding task) various mechanical properties can be expected. The LSC process, for example, reduces the welding current before the short circuit brake up, which leads to a lower heat input in comparison to conventional short-arc process. This effect gives lower heat input and leads to shorter cooling time. Ac- 


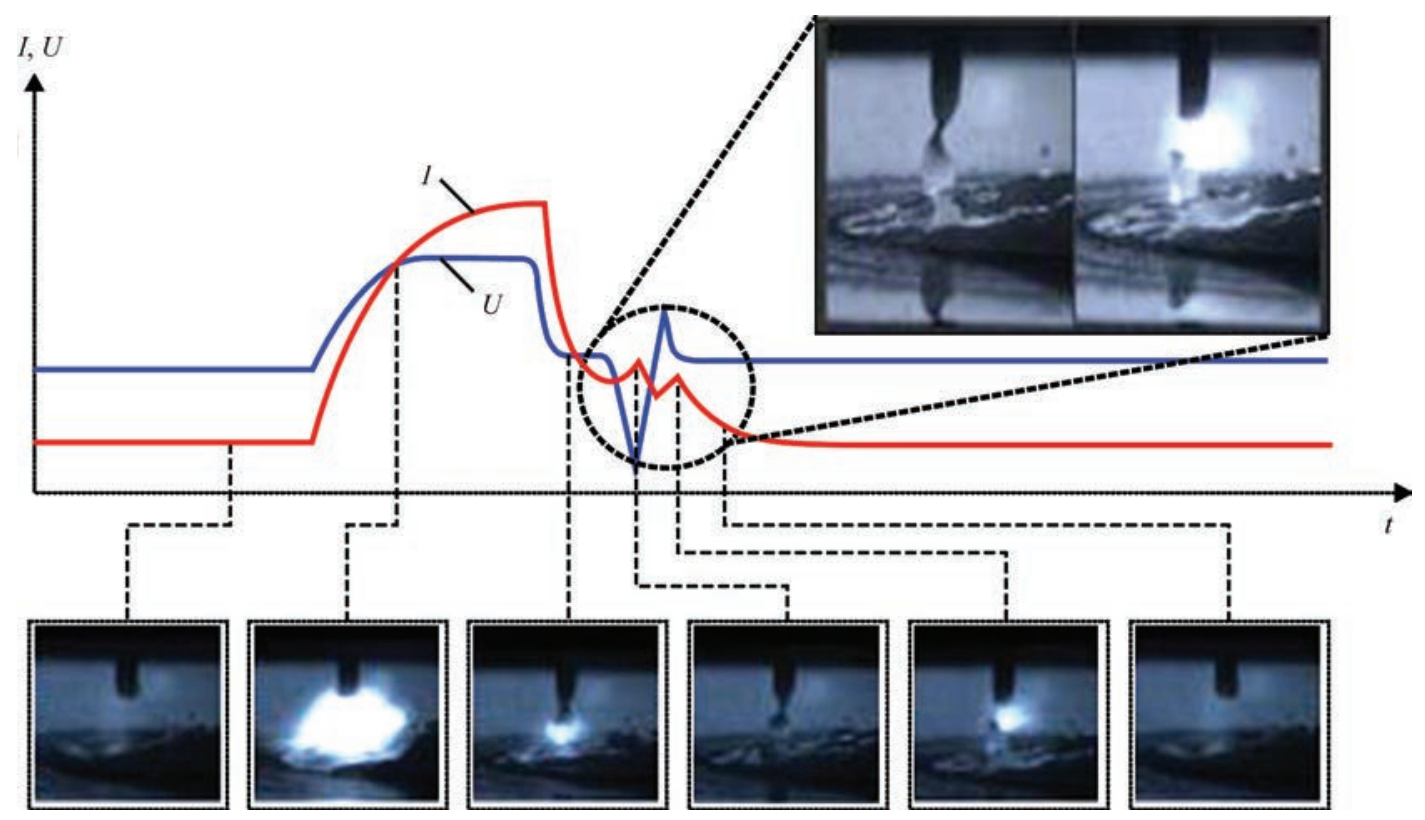

Figure 2. Current and voltage diagram for the PMC process

cordingly the strength is higher and the ductility is decreased due to a higher content of higher strength microstructure. Exists knowledge about these circumstances the welding engineer can take advantage out of that.

Experimental setup. To achieve comparable welding results, a standardized welding setup was chosen. Welding was performed with a robot in PA position in $\mathrm{M} 21$ shielding gas $\left(\mathrm{Ar}+18 \% \mathrm{CO}_{2}\right)$. Alform plate ${ }^{\circledR} 700$-M was used as the base material. Böhler Alform ${ }^{\circledR}$ 700-MC (metal-cored) and Böhler Alform $^{\circledR} 700$-IG (solid wire) with diameter of $1.2 \mathrm{~mm}$ were used as welding consumable. Weld and V-joints metal were surveyed, the interpass temperature for all tests was adjusted to $150^{\circ} \mathrm{C}$.

The test plates had dimension of $500 \times 150 \mathrm{~mm}$ and thickness of $20 \mathrm{~mm}$. Opening angle of $10^{\circ}$ was used with gap of $16 \mathrm{~mm}$ (all edges are buffered with similar material).

For the V-joints the dimensions were $700 \times 150 \times$ $\times 20 \mathrm{~mm}$; $60^{\circ}$ bevel angle was chosen, root gap was $2 \mathrm{~mm}$, and the ceramic backing was used. All test

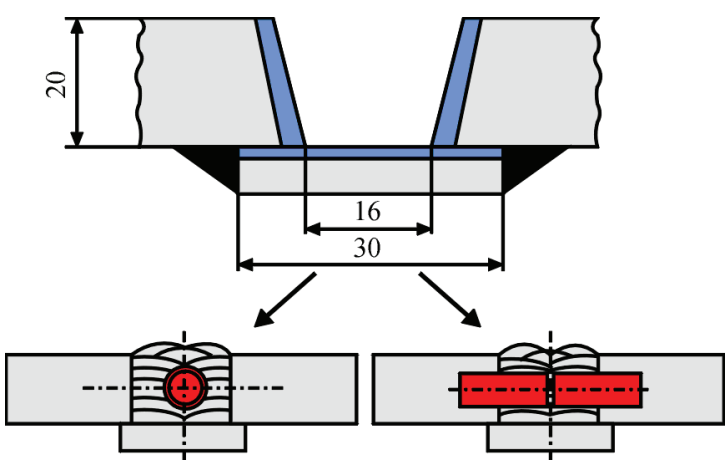

Figure 3. Edge preparation and sketches of weld metal specimens plates were welded in 6 layers, the V-joints — with 10 beads, the weld metal includes 12 beads.

Results. Weld metal. The setup and elaboration of the test samples was done according to standard EN ISO 18276 and EN ISO 16834 — in case of welding with adaption to robot method. Special emphasis was laid to use practical parameters also in regards to the repeatability of the joints. From weld metal longitudinal tensile specimen and impact specimen were taken. The impact specimens were tested from room temperature down to $-40^{\circ} \mathrm{C}$.

Figure 3 shows the bevel preparation and the sketches of weld metal specimens.

All specimens fulfilled the minimum requirement according to the standard. Due to chemical differences between solid and metal-cored wire, higher strength level is achieved with the usage of solid wires. The toughness values follow the common metallurgical correlation. This means that higher strength leads to lower toughness. Nevertheless tend the optimized single-wire GMAW processes for both products (solidand metal-cored wire) to result in higher toughness values in reference to the strength modification. Homogeneous welding parameter and homogenous solidification conditions (nucleation and precipitation) might have a beneficial influence on these circumstances.

Table 1 shows the results of the tensile test for weld metal. It also shows the connection between welding process and heat input. For practical reasons the technical term «heat input» was used without calculation of thermal efficiency. In this respect the documented parameters of the power source were used for calculation. Hence, a practical mode of operation was possible which is easy to follow by the user. 
Tabele 1. Yield strength, tensile strength and heat input for weld metal tested

\begin{tabular}{|c|c|c|c|c|}
\hline \multirow{2}{*}{ Process } & Welding wire & $\begin{array}{c}\sigma_{0.2}, \\
\text { MPa }\end{array}$ & $\begin{array}{c}\sigma_{\mathrm{t},} \\
\mathrm{MPa}\end{array}$ & $\begin{array}{c}\text { Q, } \\
\mathrm{kJ} / \mathrm{mm}\end{array}$ \\
\hline \multirow{2}{*}{ Standard } & Alform 700-IG & 763 & 814 & 1.44 \\
\cline { 2 - 5 } & Alform 700-MC & 736 & 787 & 1.27 \\
\hline \multirow{2}{*}{ PMC } & Alform 700-IG & 785 & 830 & 1.26 \\
\cline { 2 - 5 } & Alform 700-MC & 776 & 817 & 1.22 \\
\hline \multirow{2}{*}{ CMT-Twin } & Alform 700-IG & 877 & 926 & 1.11 \\
\cline { 2 - 5 } & Alform 700-MC & 786 & 828 & 1.05 \\
\hline \multirow{2}{*}{ Time-Twin } & Alform 700-IG & 814 & 857 & 1.26 \\
\cline { 2 - 5 } & Alform 700-MC & 778 & 814 & 1.19 \\
\hline \multirow{2}{*}{ Pulsed } & Alform 700-IG & 761 & 817 & 1.57 \\
\cline { 2 - 5 } & Alform 700-MC & 726 & 769 & 1.35 \\
\hline \multirow{2}{*}{ LSC } & Alform 700-IG & 767 & 814 & 1.51 \\
\cline { 2 - 5 } & Alform 700-MC & 727 & 772 & 1.37 \\
\hline
\end{tabular}

Due to controversial discussions about the investigation of the actual heat input, especially in regards to arc efficiency in tandem wire processes, it was relinquished as well.

The better wetting ability of the metal-cored wire allowed higher welding speeds which resulted in lower heat input. However, the batch caused lower strength values could not be compensated.

Due to its characteristic the CMT-Twin process provides low heat input which leads to higher strength levels.

Table 2 shows the results of impact test of weld metal. As already mentioned the higher strength (especially with the CMT-Twin process) gives lower toughness values. The optimized single-wire processes tend to have better toughness and strength performance.

Welded V-joints. The survey matrix for V-joints covers the investigation of strength values longitudinal and transverse to welding direction, the elaboration of longitudinal and transverse tensile samples and toughness analyses in the weld metal as well as a hardness profile over the entire weld.

Table 2. Impact force for weld metal tested

\begin{tabular}{|c|c|c|c|c|}
\hline \multirow{2}{*}{ Process } & \multirow{2}{*}{ Welding wire } & \multicolumn{3}{|c|}{ Impact force, J, at $T,{ }^{\circ} \mathrm{C}$} \\
\cline { 3 - 5 } & & 20 & 0 & -40 \\
\hline \multirow{2}{*}{ Standard } & Alform 700-IG & 118 & 113 & 64 \\
\cline { 2 - 5 } & Alform 700-MC & 137 & 126 & 97 \\
\hline \multirow{2}{*}{ PMC } & Alform 700-IG & 127 & 118 & 89 \\
\cline { 2 - 5 } & Alform 700-MC & 131 & 124 & 95 \\
\hline \multirow{2}{*}{ CMT-Twin } & Alform 700-IG & 82 & 77 & 69 \\
\cline { 2 - 5 } & Alform 700-MC & 103 & 96 & 79 \\
\hline \multirow{2}{*}{ Time-Twin } & Alform 700-IG & 130 & 123 & 98 \\
\cline { 2 - 5 } & Alform 700-MC & 108 & 104 & 86 \\
\hline \multirow{2}{*}{ Pulsed } & Alform 700-IG & 133 & 131 & 94 \\
\cline { 2 - 5 } & Alform 700-MC & 142 & 138 & 98 \\
\hline \multirow{2}{*}{ LSC } & Alform 700-IG & 128 & 116 & 77 \\
\cline { 2 - 5 } & Alform 700-MC & 152 & 141 & 108 \\
\hline
\end{tabular}

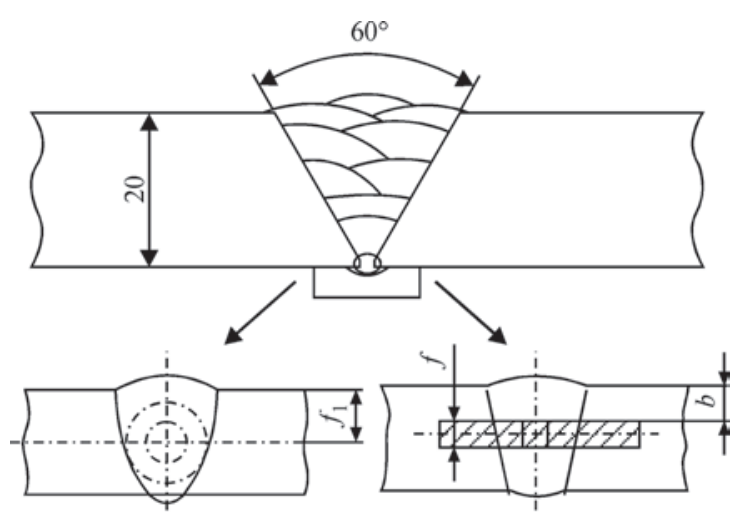

EN ISO 5178

EN ISO 9016

Figure 4. Layer sequence and sample preparation for welded V-joints test

Figure 4 shows the layer sequence and sample preparation.

The yield and tensile strength of the weld metal was investigated with longitudinal tensile samples according to the same procedure as described for the weld metal. For the welded joints similar parameters with practical adaption (on layer sequence) were used. Thereby no noteworthy discrepancy occurred.

Table 3 shows the results of tensile test for the V-joints. According to the already discussed difference in the layer sequence, the welding speed has been slightly increased, hence, the heat input was reduced. The dilution with the base material is the critical factor which influences the mechanical properties significantly [4]. Compared to weld metal test the heat input was lower, however the yield point was also reduced. The tensile strength followed the expected analogy according to the modified heat input. Therefore, a reduction of the yield point ratio $\left(\sigma_{0.2} / \sigma_{t}\right)$ in the weld can be realized.

By the use of a matched system between base material and welding consumable (Alform ${ }^{\circledR}$ welding system) optimized results can be achieved [5].

In particular, the toughness values in the joint (besides the dilution with the base material) were mainly

Table 3. Yield strength, tensile strength and heat input for welded V-joints tested

\begin{tabular}{|c|c|c|c|c|}
\hline Process & Welding wire & $\begin{array}{c}\sigma_{\mathrm{t}^{\prime}} \\
\mathrm{MPa}\end{array}$ & $\begin{array}{c}\sigma_{\mathrm{y}^{\prime}} \\
\mathrm{MPa}\end{array}$ & $\begin{array}{c}Q, \\
\mathrm{~kJ} / \mathrm{mm}\end{array}$ \\
\hline \multirow{2}{*}{ Standard } & Alform 700-IG & 714 & 872 & 1.32 \\
\cline { 2 - 5 } & Alform 700-MC & 712 & 806 & 1.25 \\
\hline \multirow{2}{*}{ PMC } & Alform 700-IG & 693 & 895 & 1.24 \\
\cline { 2 - 5 } & Alform 700-MC & 751 & 855 & 1.10 \\
\hline \multirow{2}{*}{ CMT-Twin } & Alform 700-IG & 833 & 888 & 0.97 \\
\cline { 2 - 5 } & Alform 700-MC & 824 & 902 & 0.79 \\
\hline \multirow{2}{*}{ Time-Twin } & Alform 700-IG & 798 & 873 & 1.13 \\
\cline { 2 - 5 } & Alform 700-MC & 757 & 837 & 1.14 \\
\hline \multirow{2}{*}{ Pulsed } & Alform 700-IG & 739 & 877 & 1.42 \\
\cline { 2 - 5 } & Alform 700-MC & 718 & 818 & 1.26 \\
\hline \multirow{2}{*}{ LSC } & Alform 700-IG & 715 & 854 & 1.38 \\
\cline { 2 - 5 } & Alform 700-MC & 701 & 810 & 1.27 \\
\hline
\end{tabular}




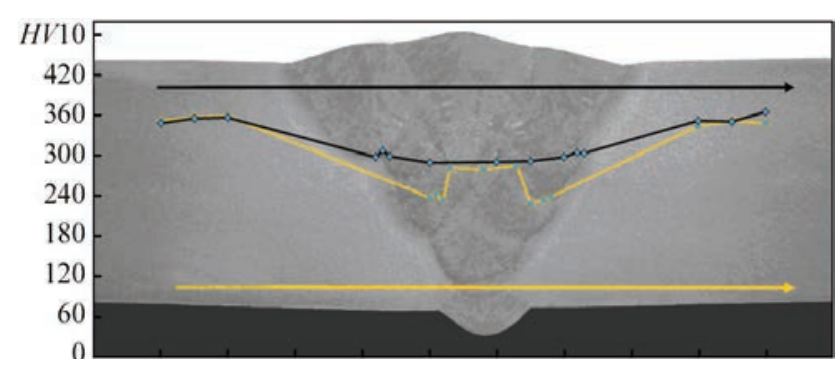

Figure 5. Hardness distribution over the weld weld-root-upper bead in PMC-welded joint with Böhler Alform ${ }^{\circledR} 700$-IG wire

influenced by the layer sequence. A comparison between weld and V-joints metal have been omitted due to the multidimensional parameter variations. Alike in the survey matrix (Table 4), an explicated correlation with the welding process is not possible. To get comparable results in this case a different testing setup with a similar layer sequence would be necessary. Essentially is that every process reached an impact force of $27 \mathrm{~J}$ at $-40{ }^{\circ} \mathrm{C}$.

Table 5 shows the evaluation of the transversal tensile strength as well of the fracture location. The fracture location depends on the lowest local stability in the weld or in the base material. In all cases the fracture strength is above $800 \mathrm{MPa}$.

Figure 5 shows the hardness profile over the weld. One hardness transverse was evaluated for the root, the other - for the upper layer. In any case, the hardness of the weld metal was always around $H V 10-280$ which is below the values of the base material.

\section{Summary and conclusions}

Modern arc processes do not only simplify the handling for the welder, they also enlarge the process window to control the mechanical properties for the welding engineer. The practical «modus operandi» (without additional measuring) was a particular focus in this paper. From a welder's point of view, higher welding speed with easier arc control could be achieved, which effects the heat input.

Especially the V-joints, which are in special focus for welding engineers, show in comparison to welds metal an improvement for the yield point ratio. This means that the lower yield point ratio value gives the higher reliability for the components.

Remarkable in this survey are the homogenous properties concerning strength and toughness by the use of modern arc processes. An improved toughness (at the same strength) can be recognized, this concludes of a homogenous solidification behaviour.
Table 4. Impact force values obtained

\begin{tabular}{|c|c|c|c|c|}
\hline \multirow{2}{*}{ Process } & \multirow{2}{*}{ Welding wire } & \multicolumn{3}{|c|}{ Impact force, J, at $T,{ }^{\circ} \mathrm{C}$} \\
\cline { 3 - 5 } & & 20 & 0 & -40 \\
\hline \multirow{2}{*}{ Standard } & Alform 700-IG & 170 & 156 & 101 \\
\cline { 2 - 5 } & Alform 700-MC & 134 & 123 & 79 \\
\hline \multirow{2}{*}{ PMC } & Alform 700-IG & 161 & 128 & 87 \\
\cline { 2 - 5 } & Alform 700-MC & 116 & 107 & 69 \\
\hline \multirow{2}{*}{ CMT-Twin } & Alform 700-IG & 128 & 113 & 90 \\
\cline { 2 - 5 } & Alform 700-MC & 98 & 95 & 72 \\
\hline \multirow{2}{*}{ Time-Twin } & Alform 700-IG & 127 & 113 & 74 \\
\cline { 2 - 5 } & Alform 700-MC & 113 & 104 & 78 \\
\hline \multirow{2}{*}{ Pulsed } & Alform 700-IG & 139 & 122 & 67 \\
\cline { 2 - 5 } & Alform 700-MC & 137 & 120 & 80 \\
\hline \multirow{2}{*}{ LSC } & Alform 700-IG & 160 & 141 & 83 \\
\cline { 2 - 5 } & Alform 700-MC & 146 & 137 & 82 \\
\hline
\end{tabular}

Table 5. Tensile strength and fracture location of transverse tensile samples of welded V-joints

\begin{tabular}{|c|c|c|c|}
\hline \multirow{2}{*}{ Process } & Welding wire & $\begin{array}{c}\sigma_{\mathrm{t}} \\
\text { MPa }\end{array}$ & $\begin{array}{c}\text { Fracture } \\
\text { location }\end{array}$ \\
\hline \multirow{2}{*}{ Standard } & Alform 700-IG & 832 & BM \\
\cline { 2 - 4 } & Alform 700-MC & 816 & WM \\
\hline \multirow{2}{*}{ PMC } & Alform 700-IG & 898 & WM \\
\cline { 2 - 4 } & Alform 700-MC & 870 & WM \\
\hline \multirow{2}{*}{ CMT-Twin } & Alform 700-IG & 858 & BM \\
\cline { 2 - 4 } & Alform 700-MC & 864 & BM \\
\hline \multirow{2}{*}{ Time-Twin } & Alform 700-IG & 870 & BM \\
\cline { 2 - 4 } & Alform 700-MC & 838 & BM \\
\hline \multirow{2}{*}{ Pulsed } & Alform 700-IG & 846 & WM \\
\cline { 2 - 4 } & Alform 700-MC & 818 & WM \\
\hline \multirow{2}{*}{ LSC } & Alform 700-IG & 818 & WM \\
\cline { 2 - 4 } & Alform 700-MC & 839 & WM \\
\hline
\end{tabular}

Hence modern arc processes do not only provide advantages for the welder (easier handling), they also influence in a positive way the formation of the weld metal microstructure.

The well tested and proven Alform ${ }^{\circledR}$ welding system can thus be used more flexible and with a high safety reliability. Modern welding power sources improve welding solutions.

1. Matthes, K.-J., Richter, E. (2008) Schweißtechnik Schweißen von metallischen Konstruktionswerkstoffen.

2. Artelsmair, J., Bruckner, J., Kazmaier, J. Der CMT-Prozess Ein neuer Prozess in der Fügetechnik.

3. Roßmann, F.-J. Neue Impulse für kontrolliertes und schnelles Schweißen.

4. Rutzinger, B. Influence of the welding process to the dilution rate, of weld overlays on unalloyed steel using the weld con-

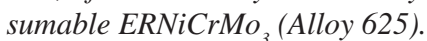

5. Fiedler, M., Rauch, R., Schnitzer, R. et al. Alform welding system - the world's first system for high-strength welded structures. In: Proc. of 68th IIW Ann. Assembly \& Int. Conf. (Helsinki). 


\title{
MODELING AND CALCULATION OF WELDED STIFFENERS IN FABRICATION OF LARGE-SIZED ITEMS FOR METALLURGICAL PRODUCTION
}

\author{
A.V. LOZA, V.V. CHIGAREV and A.N. SERENKO \\ Priazovsky State Technical University \\ 7 Respublika Lane, 87500, Mariupol, Ukraine. E-mail: loza_a_v@pstu.edu
}

\begin{abstract}
The main causes for formation of cracks and local sagging in cast large-sized case structures used in metallurgy are considered. Modeling of stress-strain state of the most loaded zones of slag carrier bowls in operation was performed. It is shown that to reduce residual deformations of cast bowls, it is necessary to apply additional stiffeners in the form of welded-on ribs. Calculation was used to determine the required parameters of stiffeners and welds. 7 Ref., 8 Figures.
\end{abstract}

\section{Ke y w o r d s : cast items, thermal loads, slag carrier bowl, deformation, stiffeners}

Case parts, metallurgical vessels and other complex-shaped components, operating at high temperatures, are used in metallurgy and mechanical engineering. Casting is usually applied for their manufacture as the least expensive method of production of complex-shaped parts. At the same time, cast steel products are characterized by presence of diverse, both internal and external defects, which weaken the structure strength, are sources of crack initiation, and may lead to a change of the specified profile and early failure of the equipment or may cause an emergency. Therefore, solving the problem of ensuring the reliability of cast items in operation is an important engineering task.

Application of additional stiffeners is a rational and technologically convenient technique of structure reinforcement. In large-sized items, however, for instance metallurgical slag carrier bowls (Figure 1), stiffeners produced by casting have inherent metallurgical defects [1], that is why they do not ensure an

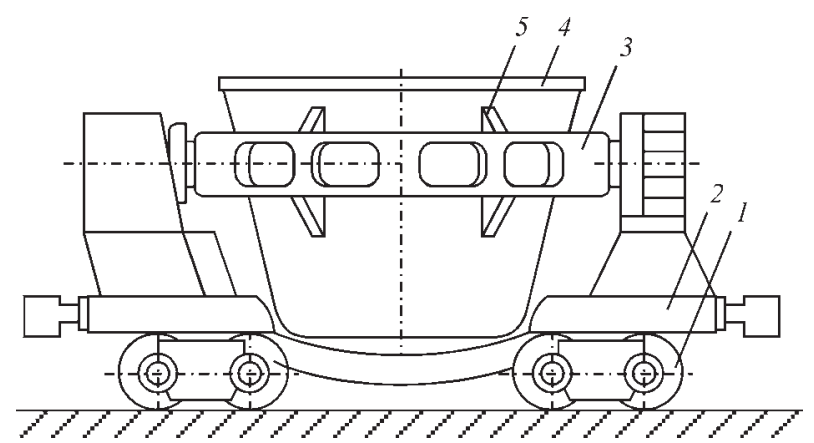

Figure 1. Slag carrier diagram: 1 - undercarriage; 2 - platform; 3 - support ring for bowl; 4 - bowl; 5 - support elements on the bowl increase of the part strength, particularly under the conditions of complex loading.

In-service cracks in the bowls very often form along the cast stiffeners, or defects associated with them, even in the case of local reinforcement of the structure (Figure 2).

Strengthening of large-sized items, due to application of expensive alloying elements, is not always rational. As it is difficult to predict the site of metallurgical defect location in cast components in practice, and impossible to prevent crack propagation, it is technologically convenient to enhance the item strength using additional structural elements, fastened by welding. They have the following main advantages:

- possibility to apply material with required properties;

- uniformity of properties over the section, that is achieved by application of rolled billets instead of cast ones.

Designing such elements to reinforce the structure, envisages fulfillment of two stages:

- designing the reinforcing element (stiffener);

- calculation of a welded joint for its fastening.

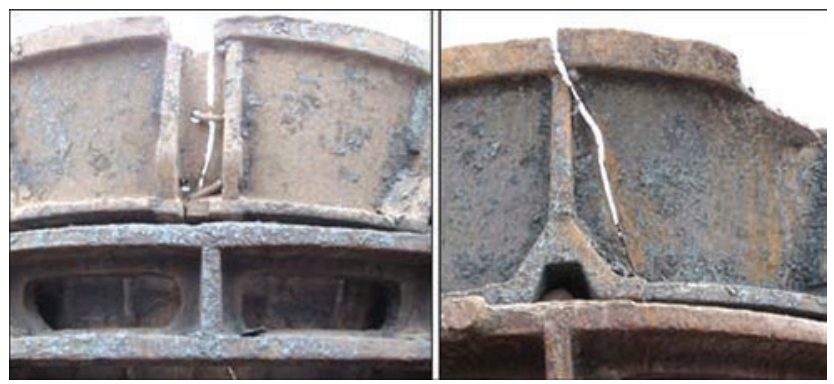

Figure 2. Cracks in slag bowls in the area of cast stiffeners 


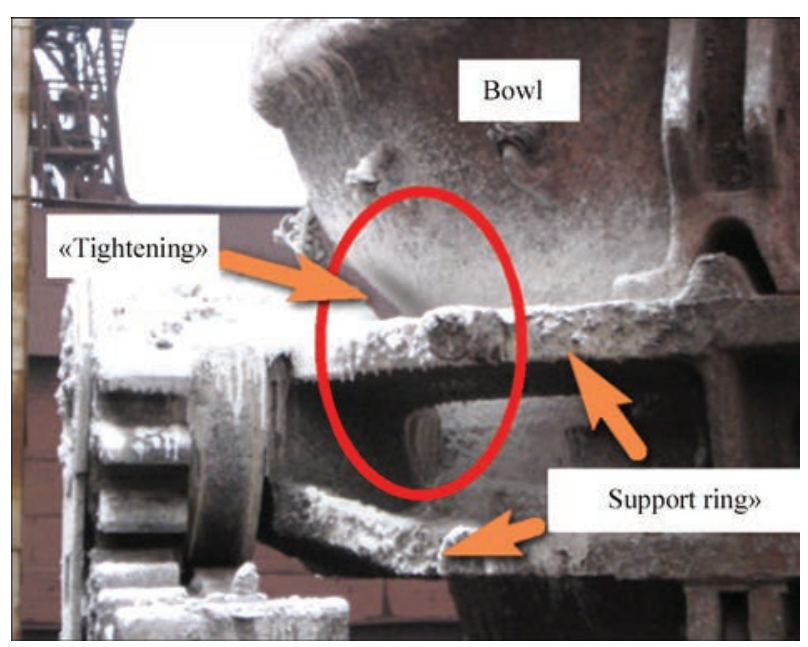

Figure 3. Formation of residual deformations of the bowl in the form of «tightening»

Practical operation of equipment shows that early failure of a part or development of residual deformations are associated with its use under critical conditions [2]. Therefore, design of a strengthening element, for instance, additional stiffener in case of the need to increase the structure rigidity, should be performed allowing for maximum loads, which can be applied to this equipment in non-standard modes. For instance, design temperature of bowl case outer wall is about $450{ }^{\circ} \mathrm{C}$. Under production conditions, however, such situations arise occasionally, when the slag carrier or a train of several slag carriers is forced to stay in one place for some time after loading (receiving molten slag of $1500-1600{ }^{\circ} \mathrm{C}$ ). In this case the slag bowl case is exposed to non-uniform heating of the walls up to temperatures higher than the design ones. In the vicinity of slag carrier support ring, the temperature of the bowl outer surface can be $620^{\circ} \mathrm{C}$. Mechanical properties of case material (usually, carbon steels) are temperature-dependent characteristics [3]. High-temperature operation of steel items leads to weakening of grain boundaries [4]. At heating of the case above $580-600{ }^{\circ} \mathrm{C}$, carbon steel yield point

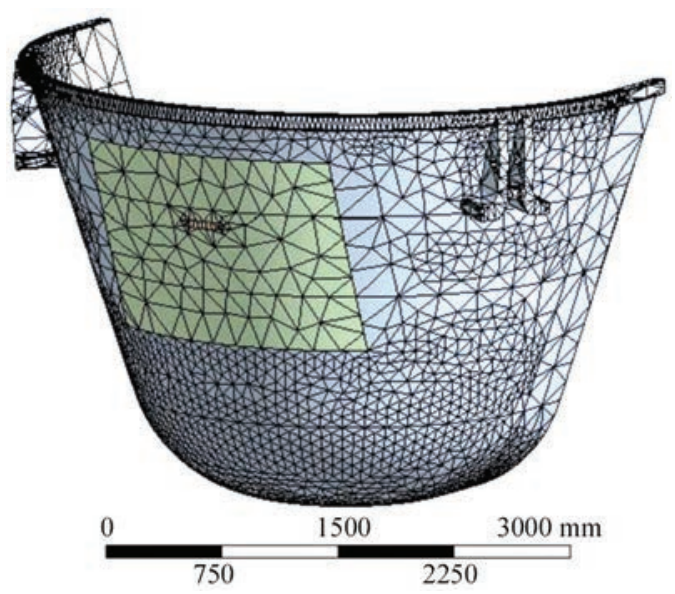

Figure 4. FEM-modeling of bowl case decreases considerably, that leads to development of residual deformations in the form of wall bending-in, its thinning and crack initiation.

In slag carrier operation, 3 to 4 months after the start of operating period, plastic deformations arise in the region of steering knuckle (so-called «tightening»), which develop with time (Figure 3).

Placing additional stiffeners is effective, if their welding point is maximum close to the zone of the highest deformations of bowl case. To assess development of the above defects, it is necessary to perform calculation of stress-strain state (SSS) of the slag carrier most loaded component - the bowl. Such a calculation can be performed, for instance, using the procedure of [5]. This allows determination of item regions, which need reinforcement to be able to operate at considerable thermal overloads.

Bowl state under the impact of process loads was modeled. Principles of frame design in a Cartesian system of coordinates were applied to develop a 3D geometrical model of slag carrier bowl (Figure 4).

Temperature distribution in the case of slag carrier bowl was determined when solving the thermal problem. During computation, the program compares the heat balance with the convergence criterion, specified in the problem. Checking results convergence was based on analysis of temperatures and heat flows. Results of solving the thermal problem are used to determine the strains.

During modeling it turned out that case deformations arise from non-equilibrium heating of wall material. Temperature of case outer surface is $420-620^{\circ} \mathrm{C}$, that of inner working surface is $800-900^{\circ} \mathrm{C}$. Thermal loads lead to bowl wall bending. Change of bowl case profile occurs in a certain zone of support ring steering knuckles that is critical in terms of preservation of the bowl working condition.

Calculation of temperature fields and arising deformations for the bowl with other (greater) case thicknesses show that increasing the bowl wall thickness at the same boundary conditions of the problem has virtually little impact on the values of wall bending-in. Therefore, improvement of bowl design by increasing its thickness is an unpromising and unprofitable direction.

It is established that in the case of local overheating of the wall above $600{ }^{\circ} \mathrm{C}$, case bending-in in this zone is inevitable (Figure 5) for bowls of currently available designs.

Cast stiffeners do not have the required ductility margin and cannot prevent residual deformations of the wall, and at cyclic variation of temperature they develop cracks, particularly in the presence of internal casting defects. Contrarily, stiffeners from rolled 


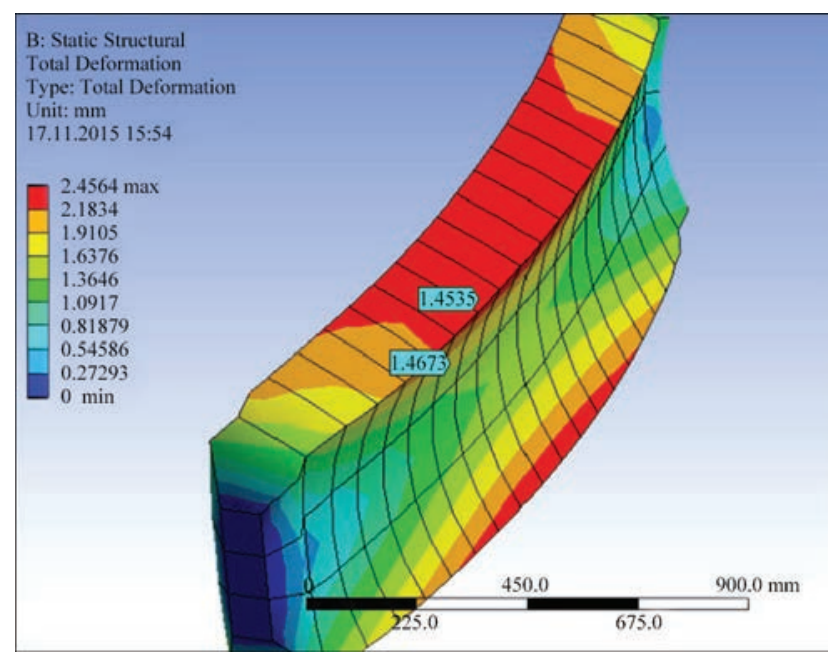

Figure 5. Modeling of behaviour of a section of slag carrier bowl wall in overheating zone in the area of support ring

metal with uniform properties, fastened by welding, have the required mechanical characteristics and are capable of solving the problem of ensuring the case rigidity at cyclic thermal and mechanical loads. The properties of such stiffeners can be variably assessed at the design stage, specifying in the calculation model the characteristics of the material of blanks from different steel grades.

To solve the problem of reinforcement of slag carrier bowl structure by welding stiffeners of required geometrical dimensions to it in specified zones, balancing load $F_{\text {bal }}$ was additionally determined first (Figure 6).

The problem is solved by finite element method (FEM). Here, balancing force $F_{\text {bal }}$ (estimated force) is determined, which can reduce the considered plate deformations to zero (or infinitely small values), i.e. to initial form of slag carrier bowl profile. Solving such a problem for the case of currently used bowl designs, yielded the value of design force $P_{1}=150 \mathrm{kN}$. Maximum force will be applied to welded stiffener in the horizontal plane at the level of stiffener lower edge.

Derived design force allowed determination of optimum shape and dimensions of additional reinforcing elements — stiffeners - with minimum material consumption. Several variants of geometrical dimensions were considered at analysis of stiffener design. Values of stiffener thickness of 10,16, 20, 30 and $40 \mathrm{~mm}$ were assigned. Stiffener loading was modeled in the case of application of balancing force along the horizontal (Figure 7, a). Stiffeners were separately tested for bending strength for the case of bowl resting on one stiffener (Figure 7, $b$ ) at load $P_{2}=120 \mathrm{kN}$ (half of bowl weight).

Modeling was performed with application of frame design technique. A section of bowl wall with greatest deformations was considered to solve the
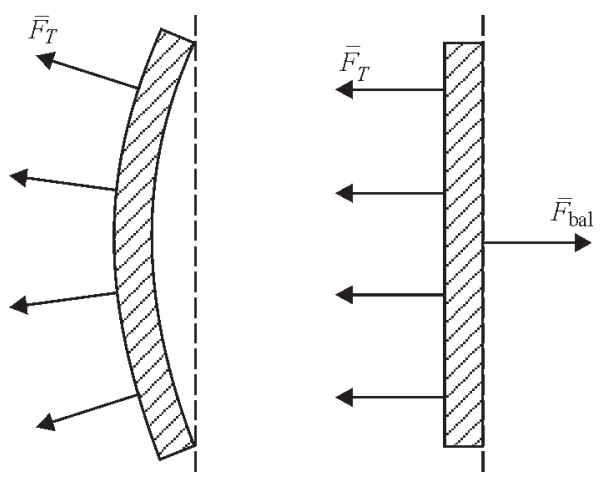

Figure 6. Diagram of load application to determine balancing force $F_{\text {bal }}$, leading to wall bending because of non-uniform heating system of equations. Stiffener fastening to the case by welding was modeled in the form of rigid connection along the line of stiffener and bowl contact. Analysis of SSS of several design variants allowed selecting such a variant, which has minimum values of stresses and possible strains under specified loads and boundary fastening conditions. Analysis showed that stiffener of $30 \mathrm{~mm}$ thickness corresponds to the strength condition.

Calculation of welds fastening the stiffener to slag carrier bowl (Figure 8) was performed for the case of application of fillet welds of tee-joints of T1 type by the procedure accepted in engineering practice [6, 7].

When selecting the scheme of force impact on welds of both the first and the second variant acc. to Figure 7 (Figure 8, $a, b$ ), it is necessary to take into account the fact that forces $P_{1}$ and $P_{2}$ are located at a distance from the welds, so that their stressed state will be determined by simultaneous action of the torque and the force directed at an angle to weld longitudinal axis. If we reduce all the forces to center $C$ and decompose $P_{1}$ and $P_{2}$ into normal $N$ and tangential $Q$ components (Figure $8, c, d$ ), we will obtain a plane system of forces applied to the weld:
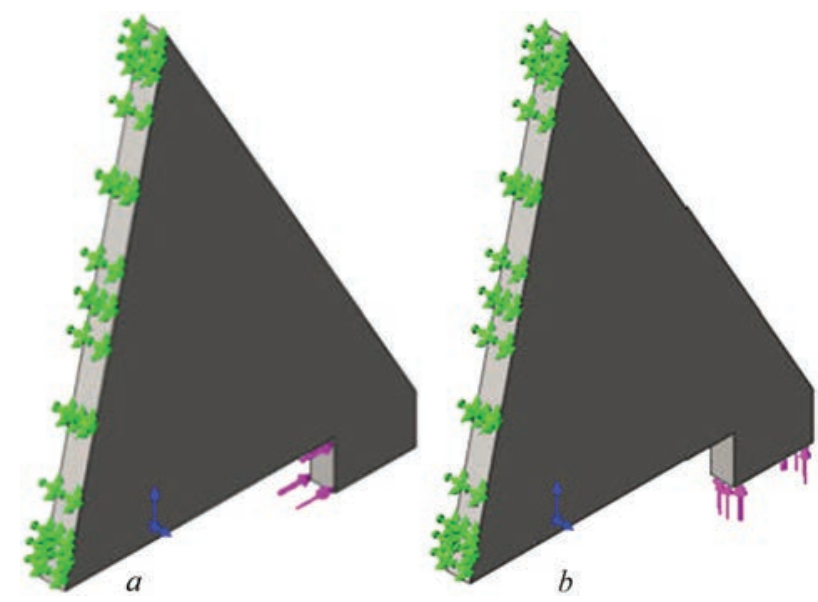

Figure 7. Scheme of calculation of bowl stiffener for first $(a)$ and second $(b)$ loading variants 

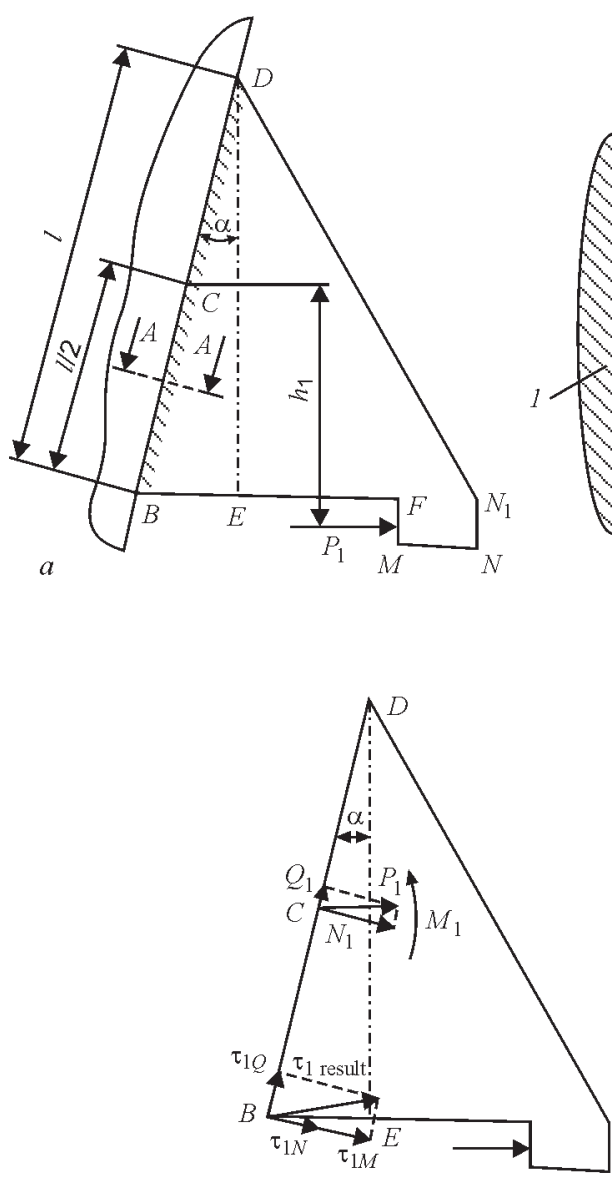

$c$
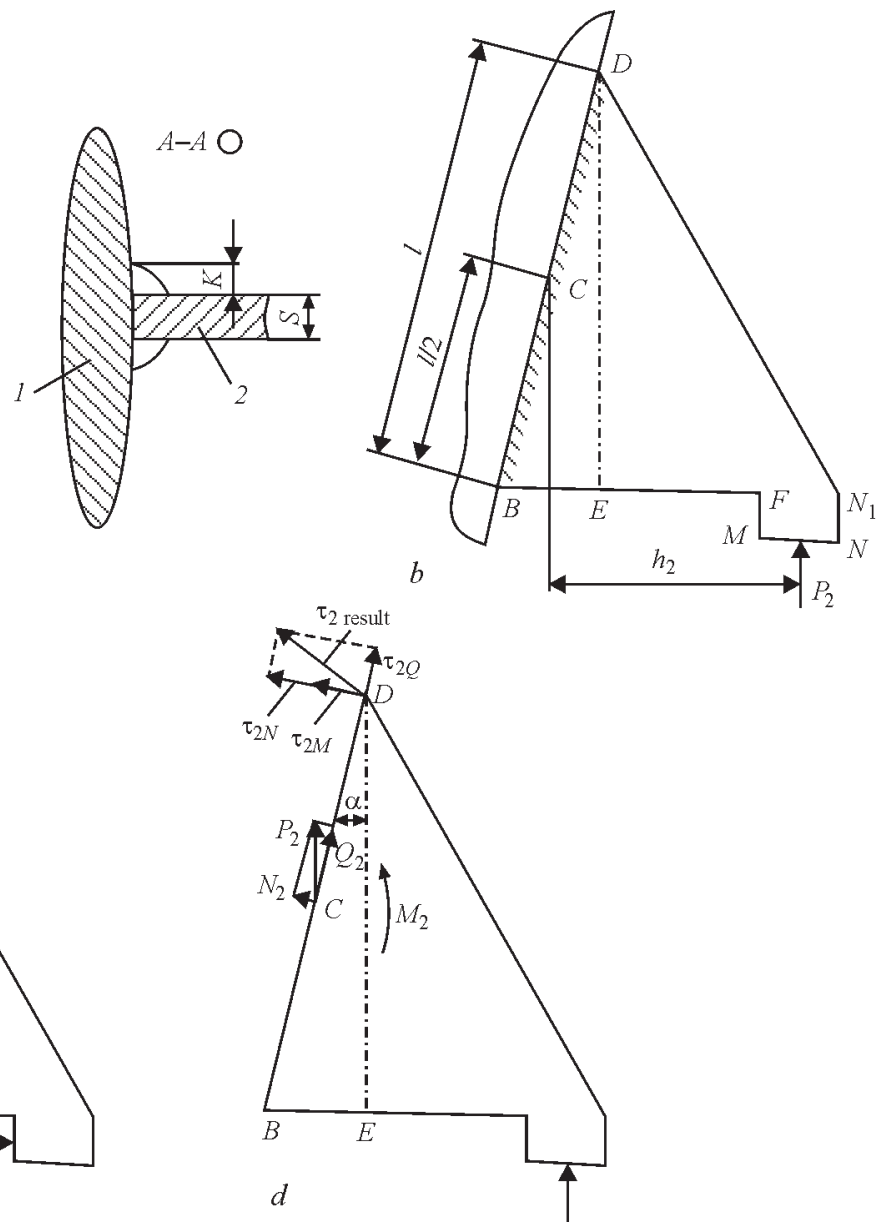

d

Figure 8. Scheme of welding stiffener to bowl and force impact on it: 1 - bowl wall; 2 - stiffener

$$
\begin{array}{ll}
M_{1}=P_{1} h_{1}, & M_{2}=P_{2} h_{2}, \\
N_{1}=P_{1} \cos \alpha, & N_{2}=P_{2} \sin \alpha, \\
Q_{1}=P_{1} \sin \alpha, & Q_{2}=P_{2} \cos \alpha,
\end{array}
$$

where $h_{1}, h_{2}$ are the arms of forces $P_{1}$ and $P_{2}$, respectively; $\alpha=\arcsin (B E / B D)$ is the angle of weld deflection from the vertical.

Highest stresses from the torque arise at weld ends (points $B$ and $D$ in Figure 8) and are given by the following formulas:

$$
\tau_{1 M}=\frac{M_{1}}{W_{1}}=\frac{P_{1} h_{1}}{W_{1}} ; \quad \tau_{2 M}=\frac{M_{2}}{W_{2}}=\frac{P_{2} h_{2}}{W_{2}},
$$

where $W_{1}, W_{2}$ are the moments of resistance of calculated sections of fillet welds for the first and second loading variants.

Shear area of fillet welds is determined by calculated thickness of fillet weld $h_{\text {calc }}$ and its length. Calculated thickness of the weld depends on the method of making the weld, its kind and is connected with weld leg by the following dependence:

$$
h_{\text {calc }}=\beta K \text {, }
$$

where $\beta$ is the coefficient for determination of calculated thickness of fillet weld, taken to be equal to: 1.1 for single-pass automatic welding; 0.9 for two- and three-pass automatic welding; and 0.7 for manual welding.

Moments of resistance of calculated sections of welds in T-joint are given by the following dependencies:

$$
W_{1}=\frac{2 h_{1 \mathrm{calc}} l^{2}}{6}=\frac{\beta K_{1} l^{2}}{3} ; \quad W_{2}=\frac{2 h_{2 \mathrm{calc}} l^{2}}{6}=\frac{\beta K_{2} l^{2}}{3},
$$

where $K_{1}, K_{2}$ are the weld legs calculated at the first and second loading variants; $l$ is the length of welds in the joint.

Taking into account all the above formulas, it is possible to find the components of tangential stresses from all the force factors for point $B$ and $D$ (Figure 8, $c, d)$ :

$$
\begin{gathered}
\tau_{1 M}=\frac{3 P_{1} h_{1}}{\beta K_{1} l^{2}}, \quad \tau_{1 N}=\frac{P_{1} \cos \alpha}{2 \beta K_{1} l}, \\
\tau_{1 Q}=\frac{P_{1} \sin \alpha}{2 \beta K_{1} l}, \quad \tau_{2 M}=\frac{3 P_{2} h_{2}}{\beta K_{2} l^{2}}, \\
\tau_{2 N}=\frac{P_{2} \sin \alpha}{2 \beta K_{2} l}, \quad \tau_{2 Q}=\frac{P_{2} \cos \alpha}{2 \beta K_{2} l} .
\end{gathered}
$$

Then, the resulting tangential stresses in the most stressed points of the weld, i.e. $B$ for the first loading 
variant and $D$ for the second loading variant, will be determined from the following formulas:

$$
\begin{gathered}
\tau_{\text {1result }}=\sqrt{\left(\tau_{1 M}+\tau_{1 N}\right)^{2}+\tau_{1 Q}^{2}}= \\
=\frac{P_{1}}{\beta K_{1} l} \sqrt{\left(\frac{3 h_{1}}{l}+\frac{\cos \alpha}{2}\right)^{2}+\frac{\sin ^{2} \alpha}{4}} ; \\
\tau_{2 \text { result }}=\sqrt{\left(\tau_{2 M}+\tau_{2 N}\right)^{2}+\tau_{2 Q}^{2}}= \\
=\frac{P_{2}}{\beta K_{2} l} \sqrt{\left(\frac{3 h_{2}}{l}+\frac{\sin \alpha}{2}\right)^{2}+\frac{\cos ^{2} \alpha}{4} .}
\end{gathered}
$$

Considering that the resultant stress vector is not normal to weld longitudinal axis, its calculated thickness and, therefore, weld leg should be increased $\gamma$ times, i.e. $\gamma_{1} K_{1}$ and $\gamma_{2} K_{2}$ instead of $K_{1}$ and $K_{2}$ should be assumed in (6) and (7), where

$$
\begin{aligned}
& \gamma_{1}=\frac{\sqrt{\left(\tau_{1 M}+\tau_{1 N}\right)^{2}+\tau_{1 Q}^{2}}}{\left(\tau_{1 M}+\tau_{1 N}\right)}= \\
& =\frac{\sqrt{\left(\frac{3 h_{1}}{l}+\frac{\cos \alpha}{2}\right)^{2}+\frac{\sin ^{2} \alpha}{4}}}{\frac{3 h_{1}}{l}+\frac{\cos \alpha}{2}} ; \\
& \gamma_{2}=\frac{\sqrt{\left(\tau_{2 M}+\tau_{2 N}\right)^{2}+\tau_{2 Q}^{2}}}{\tau_{2 M}+\tau_{2 N}}= \\
& =\frac{\sqrt{\left(\frac{3 h_{2}}{l}+\frac{\sin \alpha}{2}\right)^{2}+\frac{\cos ^{2} \alpha}{4}}}{\frac{3 h_{2}}{l}+\frac{\sin \alpha}{2}} .
\end{aligned}
$$

Substituting (8) and (9) into (6) and (7), after transformations we can write the strength condition for both the loading variants in the following form:

$$
\begin{aligned}
& \tau_{\text {1result }}=\frac{P_{1}}{\beta K_{1} l} \sqrt{\left(\frac{3 h_{1}}{l}+\frac{\cos \alpha}{2}\right)^{2}} \leq\left[\tau^{\prime}\right] ; \\
& \tau_{\text {2result }}=\frac{P_{2}}{\beta K_{2} l} \sqrt{\left(\frac{3 h_{2}}{l}+\frac{\sin \alpha}{2}\right)^{2}} \leq\left[\tau^{\prime}\right],
\end{aligned}
$$

where $\left[\tau^{\prime}\right]$ are the admissible stresses in the weld in shear.
We will obtain from expressions (10) and (11) the following formulas for weld leg determination:

$$
\begin{aligned}
& K_{1} \geq \frac{P_{1}}{\beta\left[\tau^{\prime}\right] l} \sqrt{\left(\frac{3 h_{1}}{l}+\frac{\cos \alpha}{2}\right)^{2}} ; \\
& K_{2} \geq \frac{P_{2}}{\beta\left[\tau^{\prime}\right] l} \sqrt{\left(\frac{3 h_{2}}{l}+\frac{\sin \alpha}{2}\right)^{2}} .
\end{aligned}
$$

Proceeding from design considerations, stiffener dimensions (in $\mathrm{mm}$ ) are taken to be as follows (see Figure 8): $B D=550, D E=534, B E=125, B F=330$, $M N=100, F M=60, h_{1}=0.5(D E \pm F M), h_{2}=B F-$ $0.5 B E+0.5 M N$. Weld length is $l=B D$. Stiffener material is St3 steel. Welds are made with E42 electrodes for manual arc welding; $\beta=0.7 ;\left[\tau^{\prime}\right]=0.6[\sigma]=$ $=96 \mathrm{MPa}$.

Substituting into formulas (12) and (13) the required magnitudes of values included into them, we obtain the following dimensions of weld leg: for the first loading variant (see Figure 7,a) $K_{1} \geq 8.55 \mathrm{~mm}$; for the second loading variant (see Figure $7, b$ ) $K_{2} \geq 5.62 \mathrm{~mm}$.

At simultaneous impact of both the forces, that is theoretically possible at hot bowl returning to initial position after tilting at the moment of slag unloading, $K \geq 14.17 \mathrm{~mm}$.

Allowing for possible scatter of real weld leg dimensions, technological dimension $K=15 \mathrm{~mm}$ is recommended.

Industrial trials of bowls with welded stiffeners confirmed the rationality of the proposed method for lowering thermal deformations of large-sized cast items.

1. Zhegur, A.A., Repyakh, S.I. (2010) On supply of T-shaped thermal centers in investment casting. Lit. Proizvodstvo, 12, 15-19.

2. Artyukh, V.G. (2008) Loads and overloads in metallurgical machines: Monography. Mariupol: PGTU.

3. (1989) Reference book on grades of steels and alloys. Ed. by V.G. Sorokin. Moscow: Mashinostroenie.

4. Goritsky, V.M. (1987) On causes of crack formation in bodies of oxygen-blow vessels. Metallurg. i Gornor. Promyshlennost, 1, 57-60.

5. Loza, A.V., Chigarev, V.V., Rassokhnin, D.A. et al. (2015) Study of deformation in final slabs during continuous steel casting. Izvestiya Vuzov. Chyorn. Metallurgiya, 58(3), 197202.

6. Nikolaev, G.A., Vinokurov, V.A. (1990) Welded structures. Calculation and design: Manual. Moscow: Vysshaya Shkola.

7. Serenko, A.N., Krumboldt, M.N., Bagryansky, K.V. (1977) Calculation of welded joints and structures. Examples and problems. Kiev: Vyshcha Shkola. 


\title{
APPLICATION OF ROBOTIC AND MECHANIZED WELDING UNDER DISTURBING FACTOR CONDITIONS
}

\author{
E.V. SHAPOVALOV, V.V. DOLINENKO, V.A. KOLYADA, T.G. SKUBA and F.S. KLISHCHAR \\ E.O. Paton Electric Welding Institute, NASU \\ 11 Kazimir Malevich Str., 03680, Kiev, Ukraine. E-mail: office@paton.kiev.ua
}

\begin{abstract}
The work studies the main problems of automation of processes of multi-pass MIG/MAG welding of large-dimension parts in all spatial positions under conditions of low repeatability of assembly operations. Necessity is shown and, at the same time, insufficiency of application of only laser-television sensor for adapting purpose. A procedure was proposed for equipping a robot-technical (mechanized) welding complex with the computer vision means such as a system of laser-television and video-pyrometric sensors. The results of development of technical means, algorithmic and software support of adaptive welding complex are presented. Proposed control algorithms use the results of on-line measurement of geometry parameters of preparation of butt joint groove as well as position of molten pool. It is shown that the adaptive robotic system performes all the basic functions, typical for it, namely adjustment of electrode position and parameters of welding mode under disturbing factor conditions, and is capable to provide necessary geometry and mechanical characteristics of the weld. As an example, this work uses a robotic complex of ABB company, including welding robot ABB IRB-1600, equipped with laser-television and video-pyrometric sensors, and arc power source ESAB Aristo MIG 5000I. The welding experiments showed that the developed software and hardware allow adapting robotic technical complex for application in welding of butt joints under effect of disturbing factors such as gap size change, distortion of electrode wire, ambient temperature change etc. 8 Ref., 6 Figures.
\end{abstract}

Ke ywords : welding robot, manipulator, geometry and technical adapting, automatic control system, operator interface

Application of the robotic technical complexes (RTC) in the automatic control systems of arc welding of large-dimension thick-wall parts allows increasing efficiency and ensuring necessary level of quality of welded joint formation. Therefore, the developments aimed at determination of the possibilities of application of series mechanical multilink manipulators of welding torch and part are relevant for realizing a concept of unmanned welding technologies. A constricting factor of RTC application is insufficient accuracy of repeatability of assembly operation in butt joint welding. It results in alternation of value of butt edges gap and varying geometry of the whole butt joint. Thus, welding process promotes additional displacements in the part caused by thermal deformations and structural transformations in the weld, that as a result complicates production of the quality welded joint.

One of the methods to remove the difficulties in the process of wide application of series RTC is their equipping with computer vision systems, i.e. laser-television and video-pyrometric sensors.

The main task of the laser-television sensors is a contact-free measurement of the geometry parameters of butt joint and transmission of their values to RTC control system. The received results are used not only for adjustment of movement trajectory of the welding torch relatively to the butt axis, but also for adaptive control of welding parameters such as arc voltage, wire feed rate and amplitude of welding torch oscillations. RTC is equipped with a laser-television sensor, capable to provide necessary geometry parameters of the weld and its mechanical properties. The main advantage of the optical sensors in comparison with the touch probes is acquiring more complete information on butt geometry that allows developing more accurate algorithms of edge fill in multi-pass welding.

However, equipping the robots with only laser-television sensors is insufficient under conditions of disturbances such as change of ambient temperature, magnetization of parts, distortion of electrode wire, thermal deformation of butt etc. The indicated factors result in change of penetration depth or displacement of welding arc (weld pool) to one of the edges of butt joint which can be a reason of insufficient penetration of the other one.

In order to minimize the effect of indicated disturbances it is necessary to equip the robot with additional sensor for direct tracking a weld pool for the purpose of on-line evaluation of weld size and its spatial position relatively to butt axis without transportation lag. For this, a special video-pyrometric sensor was developed and integrated in the adaptive RTC.

At present time, a significant attention is paid abroad to a problem of development of the systems 


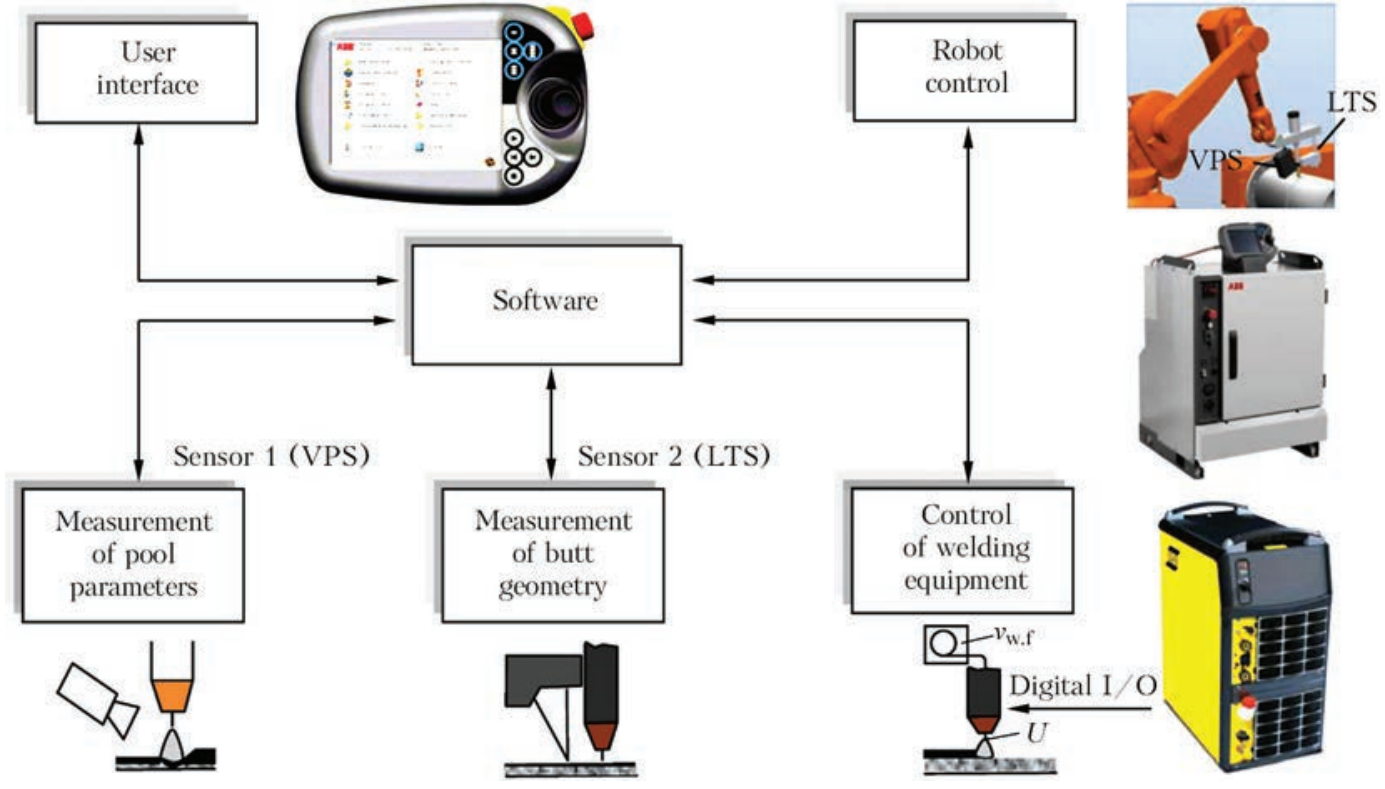

Figure 1. Flow chart of parallel double sensor system

for adaptive control of MIG/MAG welding [1-4]. However, the task has not being solved to full extent.

This work is dedicated to development of a procedure for creation of algorithmic and software support for ABB IRC5 controller of ABB IRB-1600 welding robot equipped with laser-television (LTS) and video-pyrometric sensor (VPS). LTS is used for measurement of geometry parameters of butt joints with groove preparation, and VPS is applied for evaluation of size and position of weld pool (Figure 1).

The main functions of software support of the system for automatic control of welding process parameters based on information from LTS are the following:

- regulation of welding torch movement along butt center based on actual spatial position of current butt section which is calculated on-line by LTS;

- control of shape and amplitude of torch oscillations based on current geometry parameters of the butt and, in particular, size of the gap before torch;

- control of welding mode parameters (value of electrode wire feed rate, arc voltage, welding speed), based on current geometry parameters of the butt before torch relatively to welding direction. An algorithm of calculation of values of these parameters is similar to one proposed in work [5].

Software has two levels of welding process control. Software of the upper level is realized using C\# programming language in MS Visual Studio programming environment. A program code in form of dll library files is downloaded in operator panel $\mathrm{ABB}$ FlexPendant [6] (Figure 2). Software of the lower level is developed using Rapid (ABB) language in ABB RobotStudio programming environment.

The developed software is designed for operation under control of real-time OS Windows CE.
The software is realized in form of several flows which are executed in parallel using program interrupts mechanism:

- control of robot movement (movement of sensors, mounted to last robot link) on preplanned trajectory taking into account on-line correction;

- robot controller inquiry for determination of coordinates of tool central point (TCP) current position. A value of coordinate $X$ corresponds to the position of LTS laser plane in welding direction along the butt;

- LTS on-line inquiry and receiving form it $Y$ and $Z$ coordinates of points of intercept of sectional laser plane with butt edges;

- VPS on-line inquiry for determination of coordinates of weld pool center and its geometry;

- calculation of current values of welding mode parameters and values for correction of torch position (in transverse direction and on height relatively to butt axis) and transmission of these values to robot controller.

After the dll library files, created in MS Visual Studio, are downloaded in the robot controller, the main menu of the panel in addition to the basic items starts

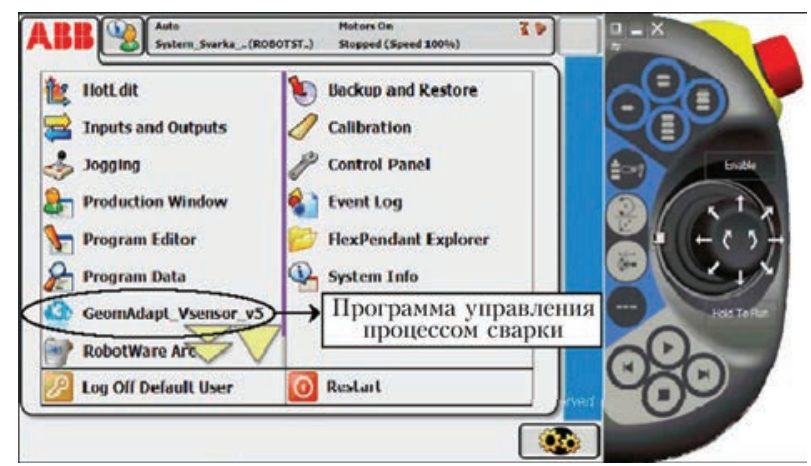

Figure 2. Main menu of operator panel ABB FlexPendant 


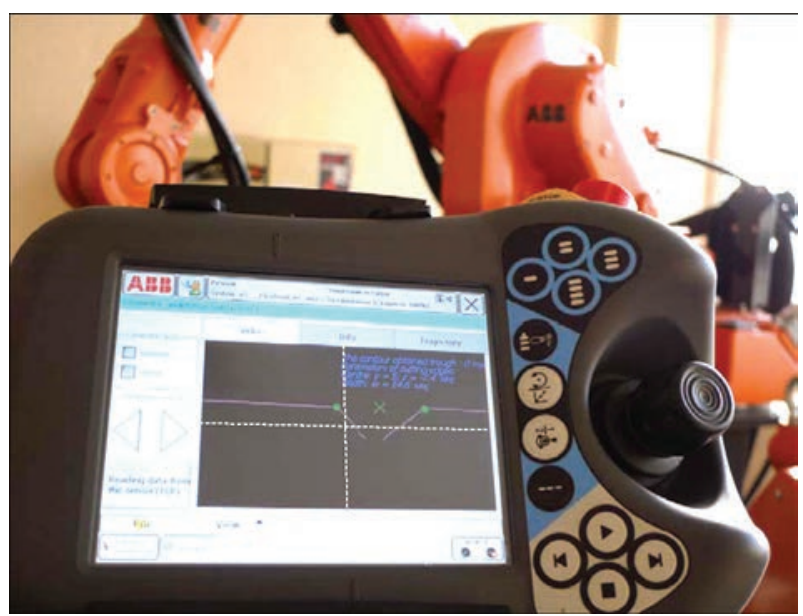

Figure 3. Main dialogue box of operator interface on screen of ABB FLexPendant panel

displaying an item, including title of a program for welding process control, for example, «GeomAdaptVsensor_v5» (see Figure 2).

This menu item launches the program of welding process control (Figure 3). A significant part of interface of dialogue box is taken by an image of laser band contour, which is dynamically changed in a process of scanning of the butt before and during welding.

In the upper part of the screen there are «Video» and «Info» inlays which contain information on butt geometry, weld pool and calculated values of torch trajectory correction, and «Trajectory» inlay is designed for displaying the butt and trajectory of torch movement. In the left part of the window there are control elements (buttons) for selection of manual («Correction manual») or automatic («Correction auto») correction mode of welding torch. Menu items «File» and «View» are located in the lower part.

Menu item «File» allows saving a real (with correction) trajectory of torch movement in a file after welding of each weld. As a result, part passport can be received, which shows all necessary information on trajectory and welding modes in all sections of root and fill welds of part being welded.

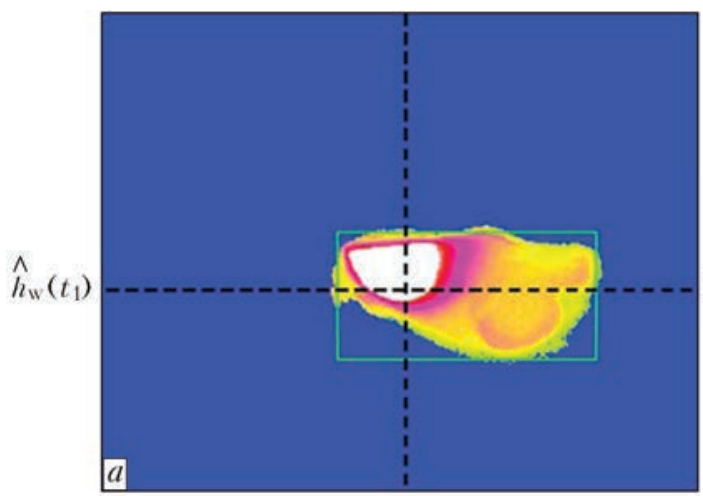

Menu item «View» provides for a possibility to display on the operator panel screen a mesh with selected step and central axes which intersect in a point with $y=0, z=0$ coordinates. Thus, the operator has a possibility of visual evaluation of butt displacement and change of its geometry in process of welding.

In addition to measurement of the butt geometry and its spatial position, a corresponding information on weld pool is also evaluated in process of welding. The latter can be displayed on the operator panel screen. Registration of the image of weld pool thermal field and estimation of height of weld pool relatively to low surface of butt groove is carried out with the help of double channel pyrometric sensor. Based on given information the RTC control system forms a correction of electrode position in process of welding and correction of welding mode parameters. Figure 4 shows an image of a thermal field of weld pool in two extreme positions of the torch, which makes transverse oscillations.

Position of a zone of maximum heating (arc burning area) is kept in the middle part of the frame, while less heated zone of the weld pool is periodically moved, that is caused by torch transverse oscillations. Stationary position of the zone of maximum heating is explained by the fact that a pyrometer sensor is mounted directly to the torch and, therefore, the arc is stable on the image, and weld pool contours are moved.

Interaction between welding robot controller, LTS and VPS is realized with the help of Ethernet technology of batch data transmission on software upper level. Figure 5 shows a structure of software for realizing the interaction between the system components. C\# MS Visual Studio programming language was used in software development.

The main functions used in software realizing are the following:

- development of end points on socket and port addresses, which correspond to IP-addresses of sensors;

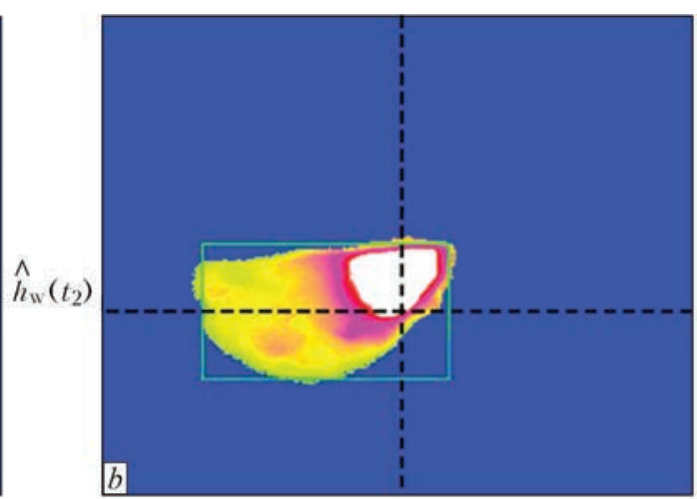

Figure 4. Image of thermal field of weld pool in welding of root weld with transverse oscillations in extreme left $(a)$ and right $(b)$ postion relatively to butt axis 


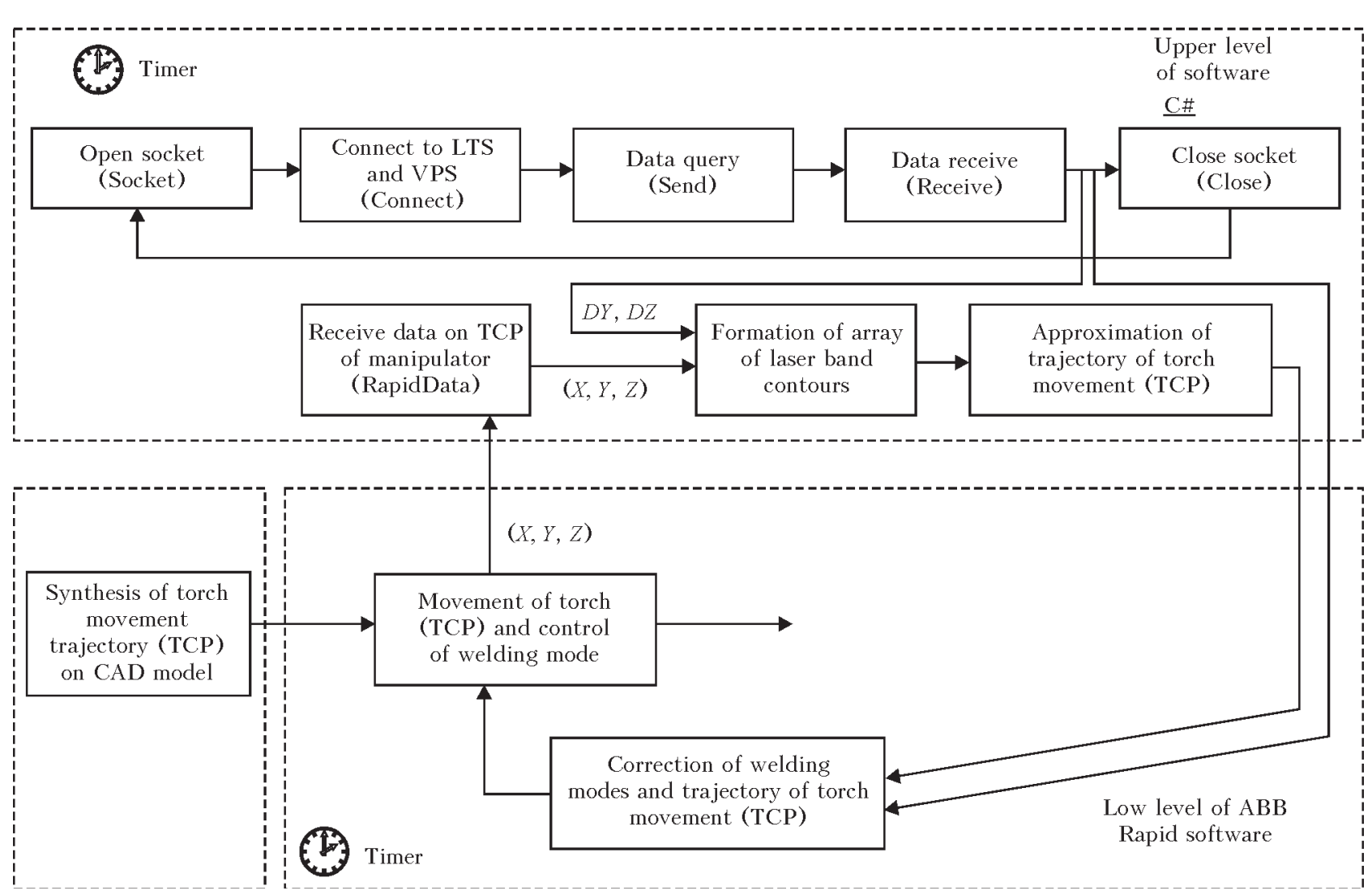

Figure 5. Flow chat of software for information transmission between system components

- development of socket TCP/IP (Transmission Control Protocol/Internet Protocol);

- tie the point to the developed socket - myscoket.Connect(ipep);

- send data via open socket - mysocket.Send$\operatorname{To}(0)$;

- wait for an answer from the sensors - Listen() procedure forms a list of coordinates of characteristic points of the laser band contour received from the sensor, which are used for determination of geometry of edge preparation and gap.

Connect working space (namespace) RapidDomain [6] in order to get access to robot data in a format of Rapid programming language from $\mathrm{C \#}$ program. This document describes PC SDK classes with different types of Rapid data. RapidData-object, which is linked to corresponding data, is created for reading and recoding of RapidData.

The following steps of algorithm are performed in order to transmit the values of the corrected coordinates of welding torch to the low level program (Rapid):

- on-line read out of current coordinates;

- correction of coordinates in accordance with LTS and VPS readings;

- transmission of corrected coordinated to the welding robot controller.

The software of low level (ABB Rapid), designed for realizing adaptive correction of torch vertically and horizontally in process of welding, has the fol- lowing main structural components, namely main procedure «main()», procedure of pre-formed trajectory «Path_10» in accordance with ideally assembled welding object, and procedure «TRAP Path_10_correct», which takes into account the errors of groove preparation and assembly operations. Before procedure fetching the variables are declared, for example «hori_id» and «veri_id», which are connected to «correction generator» for performance of horizontal and vertical correction.

Receiving the data from software of upper level was carried out with the help of timer interruption mechanism. Firstly, a «timeint» variable with «intnum» data type is declared [7]. After that, the «timeint» variable with the help of CONNECT function is connected with TRAP type procedure, which in this project is titled «Path_10_correct». Besides this procedure turn on ITimer interruption timer, parameters of which indicate value of time interval between sensor sampling (for example, $0.2 \mathrm{~s}$ that equals $5 \mathrm{~Hz}$ period). «Path_10_correct» procedure performs correction of values of coordinates of goal point, to which torch is moved in process of welding of root weld, and correction of welding mode parameters.

CorrWrite function is used for displacement record (in coordinate system it is a trajectory). It results in immediate correction of coordinates of the goal point of trajectory (TorchPos) and, respectively, torch movement trajectory to corrected point. ArcRe- 


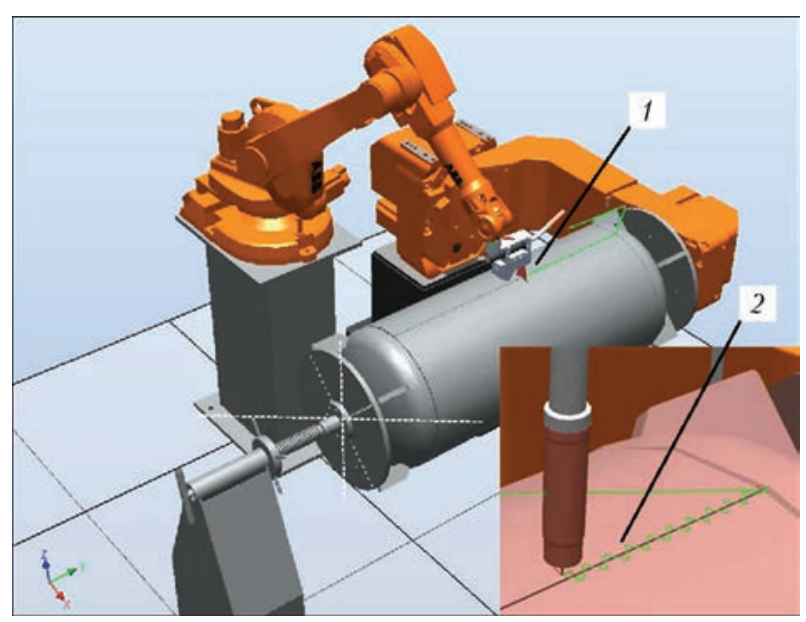

Figure 6. Simulation model of adaptive RTC: 1 - butt scanning trajectory before welding; 2 - corrected trajectory of torch movement (with oscillations)

fresh function is used for updating the welding mode parameters (adaptWd) in process of program performance [8]. Updated values of the welding parameters are transmitted to welding instructions «ArcX» that in accordance with program structure is refer to «Path_10» procedure. ArcL function [8] is used for realizing welding along linear trajectory instruction. Its first parameter is a goal point, value of coordinate of which is continuously corrected using interruption timer. Besides, rate of movement, values of welding start parameters adaptSm, values of welding mode parameters, accuracy of positioning fine, parameters of working tool MyNewToll_Torch_Esab and working objects Workobject_truba are indicated. The latter parameter indicates that the goal point is not constant.

RTC simulation model was constructed for checking the correctness of operation of algorithmic and software support (Figure 6). The model allows reconstructing the main structural peculiarities of the complex, i.e. kinematics of robot, part positioner and their mutual location, geometry of part being welded with butt groove preparation, design of welding torch, LTS and VPS. Also, the model allows recreating all the steps of technological process, starting from launch of control program performance with the help operator virtual panel and ending with a step of on-time torch movement on the corrected trajectory along the butt (see Figure 6). The next possibilities are realized for this, namely butt scanning with the help of LTS, formation of a list of typical points of laser plane projection on the butt and calculation of welding torch movement trajectory taking into account correction.

\section{Conclusions}

1. The procedure was developed for creation of algorithmic and software support of a subsystem for stabilizing geometry of weld pool based on information from laser-television and video-pyrometric sensors. This procedure can be used for development of software of adaptive mechanisms and robotic welding complexes.

2. The approach was proposed on development of simulation 3D model, that allows reconstructing all the steps of technological process, namely scanning of butt joint, planning the trajectory of welding torch movement and direct torch movement taking into account correction on data from LTS and VPS. The developed model can be used for evaluation of work of separate system components as well as operation of complex in whole.

1. Gladkov, E.A., Brodyagin, V.N., Perkovsky, R.A. (2014) Automation of welding processes. Moscow: N.E. Bauman MGTU.

2. Fernando de Aguiar Faria, Abraao Marques Tavares, Marina Spyer Las Casas (2010) Machine vision and artificial neural networks for seam tracking and weld inspection. $A B C M$ Symp. Series in Mechatronics, Vol. 4, 768-775.

3. Xiao, Z.W., Tarn, T.-J. et al. (2010) Research on a trilines laser vision sensor for seam tracking in welding: Robotic welding, intelligence and automation. LNEE, Vol. 88, 139-144.

4. Moon, H.S., Beattie, R.J. (2002) Development of adaptive fill control for multitorch multipass submerged arc welding. Int. J. Adv. Manuf. Technol., Vol. 19, 867-872.

5. Skuba, T.G., Dolinenko, V.V., Kolyada, V.A. et al. (2013) Algorithm of technological adaptation for automated multipass MIG/MAG welding of items with a variable width of edge preparation. The Paton Welding J., 1, 14-20.

6. (2013) Robotics application manual. FlexPendant SDK RobotWare: Doc. ID 3HAC036958-001, Rev. B.

7. (2013) Robotics technical reference manual. RAPID instructions, functions and data types RobotWare: Doc. ID 3HAC16581-1, Rev. P.

8. (2013) Robotics application manual. Arc and arc sensor RobotWare: Doc. ID 3HAC16591-1, Rev. Q.

Received 26.01.2016 


\title{
OXYGEN INFLUENCE ON THE PROCESS OF NITROGEN-INDUCED PORE FORMATION IN CONSUMABLE ELECTRODE ARC WELDING*
}

\author{
V.A. PISAREV and S.N. ZHIZNYAKOV \\ Belarussian National Technical University \\ 65 Nezavisimost Ave., 220013, Minsk, Belarus Republic. E-mail: niil_svarka@bntu.by
}

\begin{abstract}
Nitrogen-induced porosity is one of the most common defects in welded joints produced by consumable electrode arc welding, particularly, in open sites. It is believed that in order to produce sound welds in low-carbon and low-alloyed steels, their nitrogen content should not exceed $0.01-0.03 \%$. At the same time, cases of producing tight welds at up to $0.18 \%$ nitrogen content are found in practice. This is indicative of the fact that alongside nitrogen concentration and temperature, other factors also have a determinant influence on the process of nitrogen-induced pore formation. One of such factors, as shown by the conducted analytical and experimental investigations, is oxygen present in weld pool metal. It is capable of slowing down penetration of nitrogen atoms from the melt into the gas cavity of developing nucleus or bubble (effect of oxygen adsorption inhibition). The newly established regularity was used in development of the technology of $\mathrm{CO}_{2}$ welding of steel structures in open sites under the impact of wind with the speed of up to $8-10$ m/s. 11 Ref., 1 Table, 1 Figure.
\end{abstract}

Keywords : arc welding, pores, nitrogen, adsorption inhibition, tight weld, technology

Standard technology of $\mathrm{CO}_{2}$ welding does not allow producing sound welded joints in open sites at wind speed above $2-3 \mathrm{~m} / \mathrm{s}$, as this leads to violation of gas shielding of the welding zone, into which atmospheric air penetrates in inadmissible quantities. This leads to formation of excess porosity, caused by nitrogen from the air.

Currently available $\mathrm{CO}_{2}$ welding methods, which allow the process to be conducted at wind speeds higher than $3 \mathrm{~m} / \mathrm{s}$, involve application of various wind-protection devices; special welding torches, improving gas-dynamic stability of shielding gas jet; with application of respective welding modes; welding wires alloyed with strong nitride-forming elements (Al, Ti, Zr, etc.).

For a number of reasons, however, the above welding methods and technologies did not become widely accepted in construction or in erection sites.

A rational way to solve the problem of increasing the scope of $\mathrm{CO}_{2}$ welding and, hence, raising the level of mechanization of welding operations in open areas, is searching for and development of a welding process, which would provide a real possibility of direct impact on nitrogen-induced pore formation mechanism proper, and, by controlling it, of slowing down pore formation.

\footnotetext{
${ }^{*}$ As a matter for discussion.

(C) V.A. PISAREV and S.N. ZHIZNYAKOV, 2016
}

For this purpose, it was, first of all, necessary to find an explanation of some of the known and contradictory facts, associated with nitrogen-induced pore formation:

- in arc welding in open air, porosity (by pore quantity and size) in welds, produced with wire of grade $\mathrm{Sv}-08$, is much smaller than that of welds made with wire of grade Sv-08G2S;

- in arc welding (surfacing) in an air jet with wire of grade Sv-08A with air flow rate of $301 / \mathrm{min}$, no pores form in welds. At the same time, at application of wire Sv-08G2S no tight welds are produced;

- in welding in a mixture of $\mathrm{CO}_{2}+4 \% \mathrm{~N}_{2}$ pores are absent. At the same time, in welding in a mixture of $\left(\mathrm{Ar}+20 \% \mathrm{CO}_{2}\right)+4 \% \mathrm{~N}_{2}$ welds have abundant porosity;

- in manual arc welding at increased arc length with rutile electrodes no pores form in welds, in welding with basic electrodes, providing better gas shielding of welding zone, considerable porosity is found in welds;

- in manual arc welding with chalk-coated electrodes, not providing sufficiently complete gas shielding of the welding zone from air, welds have no pores.

The above facts, given in the Table and in the Figure, complemented by information on nitrogen and oxygen content in weld metal, suggest the existence of the determinant influence of oxygen present in the melt on the process of formation of nitrogen-induced pores. 
Gas content and evaluation of pore formation in the metal of welds produced with different variants of welding zone protection from air

\begin{tabular}{|c|c|c|c|c|c|}
\hline \multirow{2}{*}{ \# } & \multirow{2}{*}{ Welding process and conditions } & \multicolumn{2}{|c|}{ Gas content, $\%$} & \multirow{2}{*}{ Porosity } & \multirow{2}{*}{$\begin{array}{c}\text { Information } \\
\text { source }\end{array}$} \\
\hline & & {$[\mathrm{N}]$} & {$[\mathrm{O}]$} & & \\
\hline 1 & $\mathrm{CO}_{2}$ welding, Sv-08G2S wire & 0.015 & 0.06 & No pores & Authors' data \\
\hline 2 & Welding in air, Sv-08G2S wire & 0.13 & 0.06 & Pores (coarse) & [1] \\
\hline 3 & Same, Sv-08 wire & 0.15 & 0.08 & Pores (fine) & [1] \\
\hline 4 & Welding in air jet (flow rate of $30 \mathrm{1} / \mathrm{min}$ ), Sv-08A wire & 0.18 & 0.13 & No pores & [1] \\
\hline 5 & Welding in mixture of $\mathrm{CO}_{2}+4 \% \mathrm{~N}_{2}$, Sv-08G2S wire & 0.03 & 0.07 & Same & Authors' data \\
\hline 6 & Welding in mixture of $\left(\mathrm{Ar}+20 \% \mathrm{CO}_{2}\right)+4 \% \mathrm{~N}_{2}$, Sv-08G2S wire & 0.04 & 0.03 & Pores & Same \\
\hline 7 & Manual short-arc welding, MR-3 electrodes & 0.02 & 0.08 & No pores & $»$ \\
\hline 8 & Same, with elongated arc & 0.04 & 0.08 & Same & $»$ \\
\hline 9 & Manual short-arc welding, UONII-13/55 electrodes & 0.02 & 0.02 & $»$ & $»$ \\
\hline 10 & Same, with elongated arc & 0.03 & 0.02 & Pores & $»$ \\
\hline 11 & Manual arc welding, electrodes with chalk coating & 0.14 & 0.13 & No pores & [2] \\
\hline
\end{tabular}

Note. It is believed [1] that in welding of low-carbon and low-alloyed steels, pores in weld metal in the general case form at nitrogen content above $0.01-0.03 \%$ in it.

Detailed analysis of the derived data clearly demonstrates that with increase of dissolved oxygen concentration nitrogen-induced pore formation threshold rises abruptly.

Evolution of gases dissolved in the metal into an independent phase primarily requires availability of nucleation centers (nuclei) of gas bubbles in the melt. Probable sites of nucleus formation are present in the weld pool various kinds of microvoids, solid non-metallic inclusions poorly wetted by the metal and other suspensions contained in the melt. Some researchers $[1,3]$, and also the authors of this paper, believe that pore nuclei in arc welding of low-carbon and low-al-

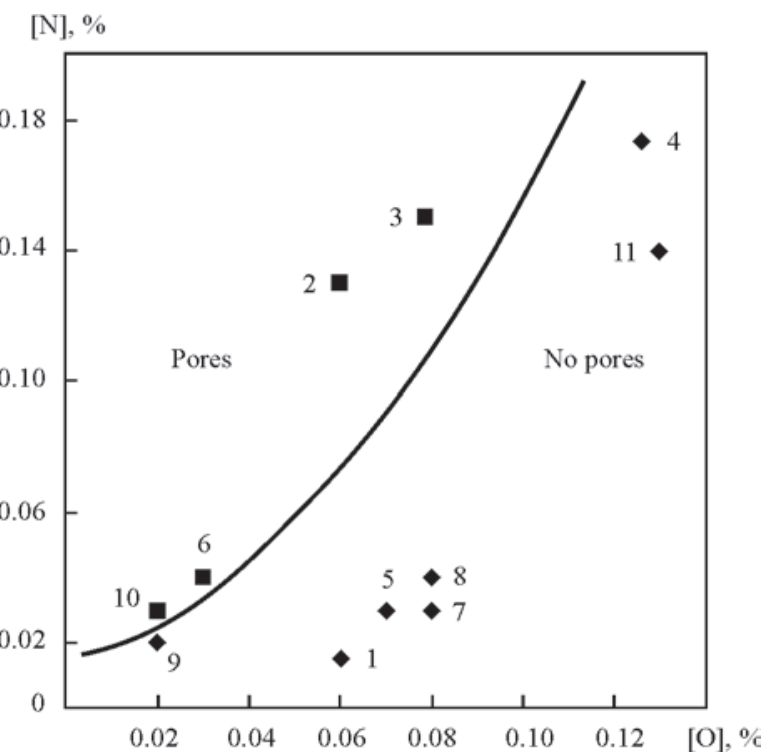

Influence of oxygen content on formation of nitrogen-induced pores in welds produced in consumable electrode arc welding of low-carbon and low-alloyed steels (1-11 - acc. to the Table) loyed steels are caused predominantly by the reaction of carbon oxide formation.

Subsequent development of a nucleus and its transformation into a gas bubble, after achievement of critical radius, as well as further bubble growth up to visible dimensions, and its transition into a pore at weld pool metal solidification, can occur under the impact of both continuing formation of carbon oxide and evolving from the surrounding volume of liquid metal hydrogen and nitrogen - gases present in oversaturated state in the melt.

There is an opinion $[1,4]$ that weld metal proneness to pore formation can be theoretically assessed by the total latent partial pressure of gases capable of evolving from the metal as a result of reactions running under equilibrium conditions. Here, pores (more correctly, bubbles) are capable of appearing, when the latent total pressure of gases $\Sigma P_{1}$ (carbon, hydrogen and nitrogen oxides) will be noticeably higher than external pressure $P_{\mathrm{ex}}$, which can be conditionally taken equal to $0.1 \mathrm{MPa}$.

However, the data given in the Table and practical experience of welding operations performance, point to the fact that such an approach to evaluation of the role of all or one of the gases in pore formation needs to be precisely refined. So, actual participation of nitrogen in pore formation, in particular, in welding in oxidizing medium, cannot be determined unambiguously by calculation through determination of latent partial pressure of gases present in the weld pool. The latter is due to the fact that in this case behaviour of nitrogen dissolved in liquid steel does not follow the Sieverts square root law, establishing the dependence 
between gas concentration in liquid metal and its partial pressure.

According to this law, at nitrogen content in the metal equal to 0.14 and $0.18 \%$, its calculated partial pressures in gas cavity of the bubbles should approach 12 and $20 \mathrm{MPa}$, respectively, that, as a consequence, should cause extremely large porosity, according to the above opinion. However, in reality, even at such high nitrogen contents porosity in weld metal is absent (see the Table), and, therefore, partial pressures of nitrogen in the bubbles (or developing nuclei) do not exceed $0.1 \mathrm{MPa}$. The cause for this phenomenon, as was established by experimental and analytical investigations, is the high content of oxygen of $0.13 \%$ in the weld pool. Thus, qualitative assessment of appearance of gas bubbles, which are the precursors of pores induced by nitrogen, requires not only knowledge of concentrational and temperature parameters of nitrogen dissolved in the metal, but also understanding of the specifics of the influence of oxygen contained in the melt, as one of strong surfactants, on pore formation process.

Analysis of published data on the issues of gases absorption and evolution from the weld pool and pore formation in weld metal made by arc welding, familiarization with diffusion of gases in metal melts and with the processes of liquid metal degassing in steel production [1-10] suggested the following path of nitrogen penetration into the developing nucleus or growing bubble (furtheron - bubble), consisting of the following four stages.

First stage. Transfer by means of convective diffusion (convective and diffusion processes are involved in transfer) of atoms of nitrogen dissolved in weld pool metal to metal-bubble gas phase interface.

Owing to high temperature of molten metal and presence in the weld pool in consumable electrode arc welding, of convective metal flows, moving continuously at the speed, which is by 10 to 20 times higher than welding speed [6], and continuously washing the surface of the growing and floating bubble, nitrogen atoms approach the interface with a high intensity.

Second stage. Adsorption of nitrogen atoms by surface layer of liquid metal on metal-bubble gas phase interface.

Simultaneously with nitrogen, other gases dissolved in weld pool metal are brought to the interface (surface layer), including (and this is particularly important) oxygen, which is characterized by high diffusion mobility and is always present in the metal melt. Here, atoms of oxygen, which is a strong surfactant, according to Gibbs (adsorption) law are adsorbed by the surface layer, taking up in it, on a priority basis, the part of free adsorption sites (centers), correspond- ing to their concentration, and partially also the sites occupied by nitrogen atoms, driving the latter away from the interface. This reduces the fraction of sites, potentially capable of adsorbing the atoms of nitrogen, also having surface-active properties, even though to a much smaller degree.

Reduction of adsorption sites vacant for nitrogen, reduces adsorption rate and, hence, the coefficient of mass transfer of nitrogen atoms across metal-bubble gas phase interface that may be assessed by the following expression: $v_{\text {ads }}=K C(1-\alpha)$, where $K$ is the coefficient of proportionality; $C$ is the nitrogen concentration in the weld pool; $\alpha$ is the fraction of adsorption sites taken up by oxygen on the interface, determined by its content in the metal melt.

At low content of oxygen in weld pool metal of not more than $0.01-0.03 \%$, when the fraction of adsorption sites $\alpha$ taken up by oxygen is extremely small, a high proneness of weld metal to formation of nitrogen-induced pores (argon-arc welding, welding in a mixture of $\mathrm{CO}_{2}+\mathrm{Ar}$, manual basic-electrode arc welding) is in place. A noticeable increase of resistance to pore formation is observed at oxygen content in the weld pool of the order of $0.07-0.11 \%$. In this case, oxygen atoms take up a considerable part of the interface, that reduces the rate of nitrogen atom adsorption and facilitates producing tight welds in manual arc welding with rutile or acid electrodes by an elongated arc and in open air at high wind speed, as well as in $\mathrm{CO}_{2}$ welding with bleeding up to $4 \%$ nitrogen or up to $6 \%$ air into the welding zone.

At higher concentration of oxygen in the melt (above $0.11-0.13 \%$ ) its atoms are, apparently, capable of taking up the entire interface $(\alpha=1)$, and even forming in the surface layer chemical groups of composition close to that of iron oxide. Such a layer practically stops atom transition across the interface, and bubble development does not proceed even at very high content (high degree of oversaturation) of nitrogen in the weld pool $(0.14-0.18 \%)$. This exactly can be the explanation for absence of visible porosity in welding in an air jet with $\mathrm{Sv}-08 \mathrm{~A}$ wire at air flow rate of $30 \mathrm{l} / \mathrm{min}$ (weld pool metal is further oxidized due to participation of oxygen from the air in the metallurgical process), as well as in welding with chalk-coated electrodes.

An event takes place, which can be defined as the effect of oxygen adsorption inhibition of the process of nitrogen-induced pore formation.

Third stage - molization of adsorbed nitrogen atoms. Physically adsorbed nitrogen atoms, present in the surface layer, enter into chemical interaction with formation of molecules with highly stable three covalent bonds: $2 \mathrm{~N}_{\mathrm{ads}}=\mathrm{N}_{2}$. Here, a large amount $(945 \mathrm{~kJ} /$ 
mol) of thermal energy evolves (energy of molization activation is just $0.4 \mathrm{~kJ} / \mathrm{mol}$ ).

Fourth stage - desorption of formed nitrogen molecules into the bubble gas cavity. Under the conditions of high temperature of molten metal and low partial pressure of nitrogen in the gas cavity, desorption of nitrogen molecules is limited, mainly, by the intensity of nitrogen atom mass transfer across the interface, determined by nitrogen concentration and oxygen content in weld pool metal.

Thus, and this very clearly follows from the above material, one of the main factors, determining the process of formation of nitrogen-induced pores in consumable electrode arc welding of low-carbon and low-alloyed steels, also is the specific impact of oxygen contained in weld pool metal, that may be used as an effective regulator of pore formation mechanism.

The postulate and its consequence - the effect of oxygen adsorption inhibition - were taken as the metallurgical basis in development of $\mathrm{CO}_{2}$ welding technology, providing sound welded joints in open construction and assembly sites at wind speed of up to $8-10 \mathrm{~m} / \mathrm{s}$, when the welding zone is «enriched» by atmospheric air. In order to increase oxygen content in the melt up to a moderate rational level of $0.07-$ $0.09 \%$, application of wire with minimum admissible content of deoxidizer elements and of gas mixture of carbon dioxide gas with oxygen having a higher oxidizing ability, compared to pure carbon dioxide gas, was successfully tried out [11]. The influence of gases contained in weld metal on mechanical properties of welded joints was taken into account.

\section{Conclusions}

1. Oxygen contained in weld pool metal has a significant influence on the process of formation of nitro- gen-induced pores in consumable electrode arc welding of low-carbon and low-alloyed steels. It directly influences the mechanism of nitrogen atoms (molecules) penetration into the gas cavity of the developing nucleus and growing bubble, blocking the process of pore formation (effect of oxygen adsorption inhibition).

2. Increase of oxygen concentration in the melt is capable of greatly reducing the proneness of weld metal to formation of nitrogen-induced porosity. This phenomenon was successfully used in development of the technology of $\mathrm{CO}_{2}$ welding of steel structures in open air at wind speed of 8-10 m/s.

1. Novozhilov, N.M. (1979) Principles of metallurgy of gas-shielded arc welding. Moscow: Mashinostroenie.

2. Alov, A.A. (1947) Electrodes for arc welding and surfacing. Moscow: Mashgiz.

3. Alov, A.A. (1969) Principles of theory of welding and brazing processes. Moscow: Mashinostroenie.

4. Pokhodnya, I.K. (2004) Metallurgy of arc welding. Interaction of metals with gases. Moscow: Mashinostroenie.

5. Ershov, G.S., Majboroda, V.P. (1990) Diffusion in metallurgical melts. Kiev: Naukova Dumka.

6. Erokhin, A.A. (1973) Principles of fusion welding. Moscow: Mashinostroenie.

7. Konishchev, B.P., Kurlamov, S.A., Potapov, N.N. et al. (1989) Welding consumables for arc welding. Shielding gases and welding fluxes, Vol. 1. Moscow: Mashinostroenie.

8. (1993) Welding consumables for arc welding. Welding wire and electrodes, Vol. 2. Moscow: Mashinostroenie.

9. Kudrin, V.A. (2003) Theory and technology of steel making: Manual. Moscow: Mir.

10. Rimsky, S.T. (2008) Methods for increase of weld metal resistance to crack formation in shielded-gas arc welding. Svarshchik v Belorussii, 4, 15-18.

11. Zhiznyakov, S.N., Timalev, L.N. (1977) Influence of oxygen on welding process in $\mathrm{CO}_{2}+\mathrm{O}_{2}$ mixture. Svarochn. Proizvodstvo, 2, 25-27. 